Andrews University

Digital Commons @ Andrews University

\title{
Intergovernmental Mediation : a Technique for Successful Local Government Partnerships
}

W Thomas Wiseman

Andrews University

Follow this and additional works at: https://digitalcommons.andrews.edu/dissertations

Part of the Industrial and Organizational Psychology Commons, Law Commons, and the Public Affairs, Public Policy and Public Administration Commons

\section{Recommended Citation}

Wiseman, W Thomas, "Intergovernmental Mediation : a Technique for Successful Local Government Partnerships" (2001). Dissertations. 1552.

https://digitalcommons.andrews.edu/dissertations/1552

This Dissertation is brought to you for free and open access by the Graduate Research at Digital Commons @ Andrews University. It has been accepted for inclusion in Dissertations by an authorized administrator of Digital Commons@ Andrews University. For more information, please contact repository@andrews.edu. 


\section{Andrews \$university}

Seek Knowledge. Affirm Faith. Change the World.

Thank you for your interest in the

\section{Andrews University Digital Library of Dissertations and Theses.}

Please honor the copyright of this document by not duplicating or distributing additional copies in any form without the author's express written permission. Thanks for your cooperation. 


\section{INFORMATION TO USERS}

This manuscript has been reproduced from the microfilm master. UMI films the text directly from the original or copy submitted. Thus, some thesis and dissertation copies are in typewriter face, while others may be from any type of computer printer.

The quality of this reproduction is dependent upon the quality of the copy submitted. Broken or indistinct print, colored or poor quality illustrations and photographs, print bleedthrough, substandard margins, and improper alignment can adversely affect reproduction.

In the unlikely event that the author did not send UMI a complete manuscript and there are missing pages, these will be noted. Also, if unauthorized copyright material had to be removed, a note will indicate the deletion.

Oversize materials (e.g., maps, drawings, charts) are reproduced by sectioning the original, beginning at the upper left-hand comer and continuing from left to right in equal sections with small overlaps.

Photographs included in the original manuscript have been reproduced xerographically in this copy. Higher quality $6^{n} \times 9^{n}$ black and white photographic prints are available for any photographs or illustrations appearing in this copy for an additional charge. Contact UMI directly to order.

ProQuest Information and Learning 300 North Zeeb Road, Ann Arbor, MI 48106-1346 USA 800-521-0600

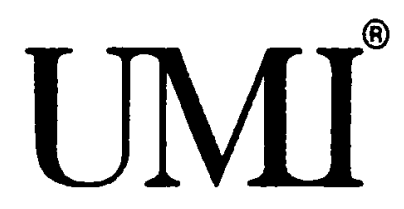


Reproduced with permission of the copyright owner. Further reproduction prohibited without permission. 
Andrews University

School of Education

INTERGOVERNMENTAL MEDIATION: A TECHNIQUE FOR SUCCESSFUL LOCAL GOVERNMENT PARTNERSHIPS

\author{
A Dissertation \\ Presented in Partial Fulfillment \\ of the Requirements for the Degree \\ Doctor of Philosophy
}

by

W. Thomas Wiseman

July 2001 
UMI Number: 3019340

Copyright 2001 by

Wiseman, $W$. Thomas

All rights reserved.

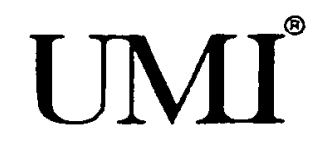

UMI Microform 3019340

Copyright 2001 by Bell \& Howell Information and Learning Company.

All rights reserved. This microform edition is protected against unauthorized copying under Title 17, United States Code.

Bell \& Howell Information and Learning Company

300 North Zeeb Road

P.O. Box 1346

Ann Arbor, Ml 48106-1346 
Copyright by W. Thomas Wiseman 2001

All Rights Reserved

Reproduced with permission of the copyright owner. Further reproduction prohibited without permission. 


\title{
INTERGOVERNMENTAL MEDIATION: A TECHNIQUE FOR SUCCESSFUL LOCAL GOVERNMENT PARTNERSHIPS
}

\author{
A dissertation \\ Presented in partial fulfillment \\ Of the requirements for the degree of \\ Doctor of Philosophy
}

By

W. Thomas Wiseman

APPROVAL BY THE COMMITTEE:

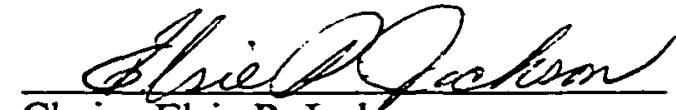

Chair: Elsie P. Jackson
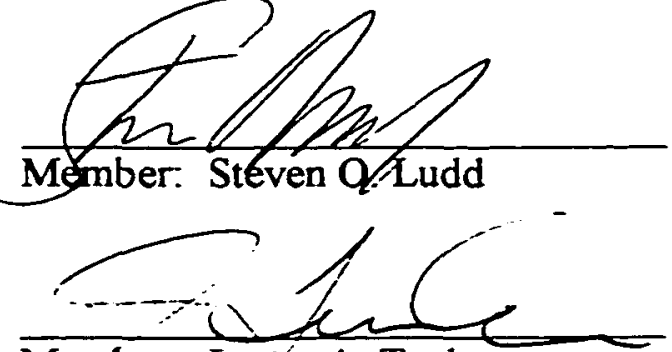

Member: Jamés A. Tucker

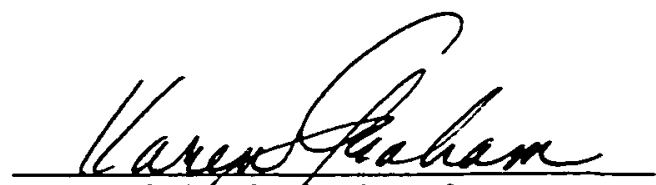

Dean: Sch6ol of Education

Karen Grahtan

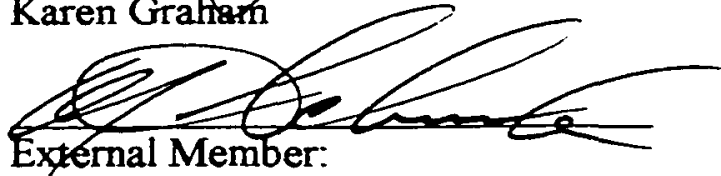

Judge Joesph Schmenk

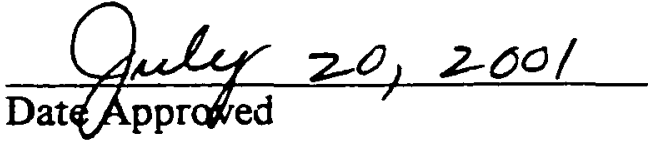




\begin{abstract}
INTERGOVERNMENTAL MEDIATION: A TECHNIQUE FOR SUCCESSFUL LOCAL GOVERNMENT PARTNERSHIPS
\end{abstract}

by

W. Thomas Wiseman

Chair: Elsie P. Jackson 


\title{
ABSTRACT OF GRADUATE STUDENT RESEARCH \\ Dissertation
}

\author{
Andrews University \\ School of Education
}

Title: INTERGOVERNMENTAL MEDIATION: A TECHNIQUE FOR SUCCESSFUL LOCAL GOVERNMENT PARTNERSHIPS

Name of researcher: W. Thomas Wiseman

Name and degree of faculty chair: Elsie P. Jackson, Ph.D.

Date completed: July 2001

\section{Problem Statement}

Local government officials are faced with ever-increasing citizens' demands and unfunded Federal and State mandates while competing with neighboring governments for dwindling federal and state monies. Both of these tend to fuel intergovernmental conflicts. Research is necessary, therefore, to determine the most effective ways of addressing the alarming rate at which intergovernmental conflict is occurring in order to meet the needs of local government officials. 


\section{Methodology}

This study examined the relationship between local government organizations in terms of intergovernmental mediation, conflict resolution, and the sharing of revenues and resources. Data were collected from county commissioners in Ohio, township trustees, appointed local government officials, and citizens at large.

\section{Conclusion}

Too few local governments employ intergovernmental mediation as a method to address conflict and intergovernmental disputes. Only $32 \%$ of those surveyed had any experience with intergovernmental mediation. In addition, many of the local government officials who employed mediation were not using a neutral third party.

In examining Defiance County government's intergovernmental mediation practices, it was discovered that intergovernmental mediation does help to reduce the potential of intergovernmental conflict. In addition, there was a positive relationship between intergovernmental conflict mediation and timely solutions at a relatively low cost. 
The dedication of my academic career and this dissertation is to my deceased sister, Peggy Lee Lulfs, who taught us, through her valiant but unsuccessful effort to defeat cancer, the love of our Lord Jesus Christ.

This dissertation is also dedicated to my mother, Mary Lee Wiseman, deceased father, Jack G. Wiseman, to my children Chad and Aimee Wiseman, and my beautiful granddaughter Tayloure Michelle Wiseman as well as to my entire family. Special dedication is given to Sharon J. Waidron who truly is very special to me and has given much assistance in the course of this research and writing. Thank you for your encouragement and support. Most of all, thank you for believing in me. I love you all. 


\section{TABLE OF CONTENTS}

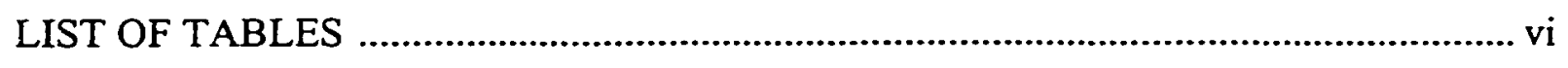

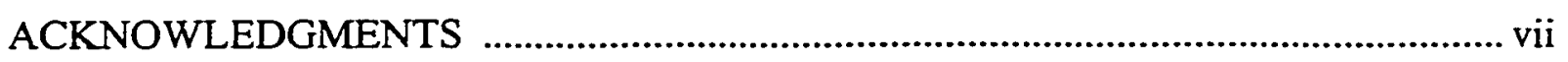

Chapter

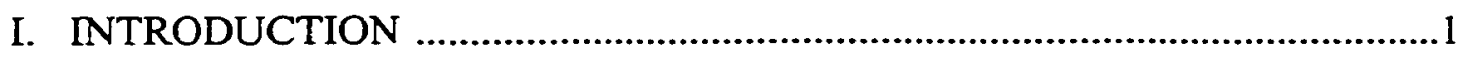

Statement of Problem ...................................................................................

Purpose of the Study .....................................................................................

Research Questions ..................................................................................6

Significance of the Study ...............................................................................6

Limitations of the Study ..............................................................................

Delimitations of the Study .......................................................................

Setting ..........................................................................................................

Definition of Terms ...............................................................................

Organization of the Study ..........................................................................15

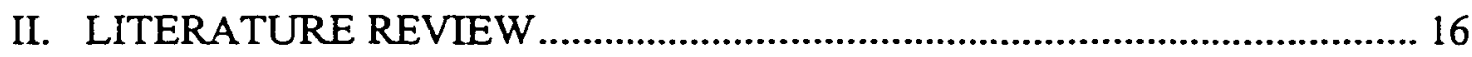

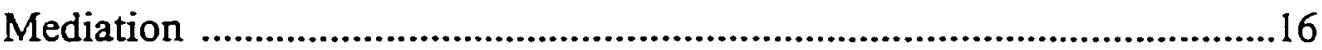

What Types of Issues Can Be Mediated .................................................. 19

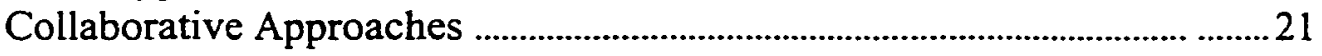

Collaborative Approach Example …………………………………….......22

Evaluating Collaborative Approaches .................................................... 23

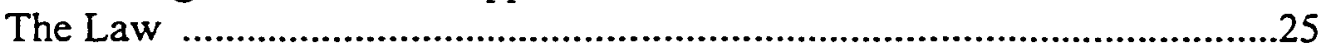

Ohio State Law ................................................................................28

Ohio Commission on Dispute Resolution and Conflict Management ......29

Mission Statement ................................................................................29

Educational/School Settings ....................................................................31

Mediation Rules ................................................................................

Private Sector .......................................................................................

Arbitration and Grievance Mediation Services ..........................................35

Choosing a "Best Method" ......................................................................36

Private Versus Public Sector/Multisector Collaboration ............................ 37

Why Mediate............................................................................................ 40 


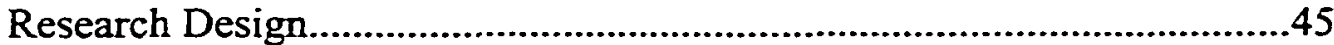

Sample Population ...............................................................................46

The Rationale for Using Interviews ...........................................................47

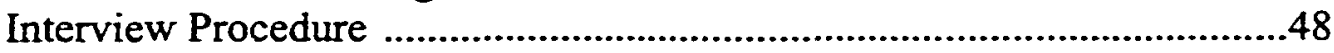

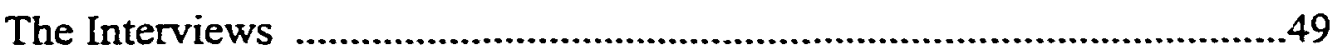

Interview Questions ..................................................................................49

Document Review ………..........................................................................52

Procedure and Disclaimer ........................................................................53

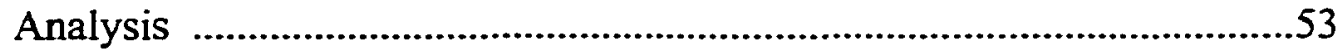

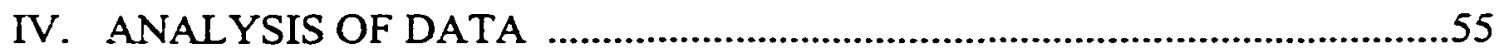

General Characteristics of the Sample ...................................................5

Defiance County Case Study ...........................................................72

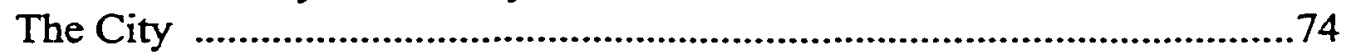

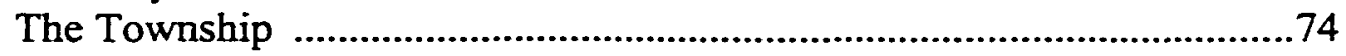

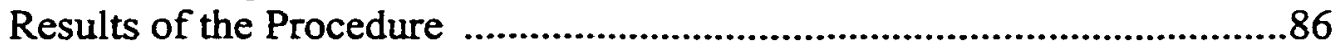

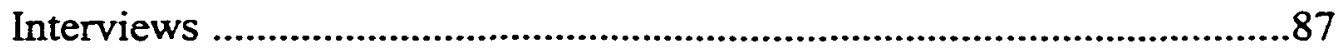

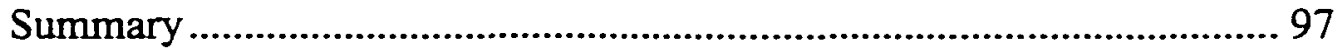

V. CONCLUSIONS AND RECOMMENDATIONS ........................................100

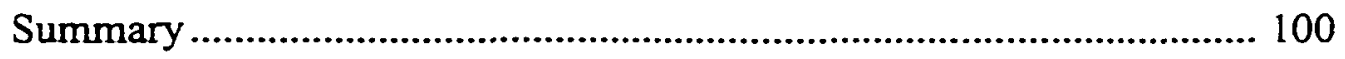

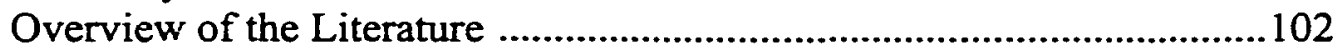

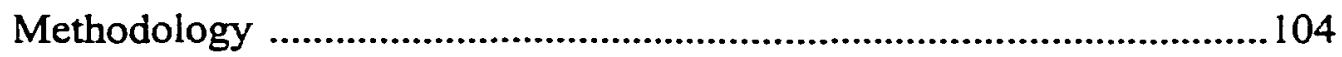

Description of Methodology ..................................................................104

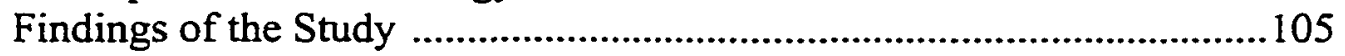

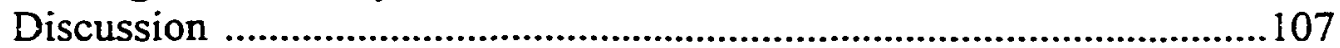

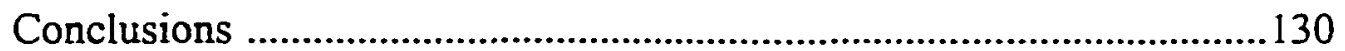

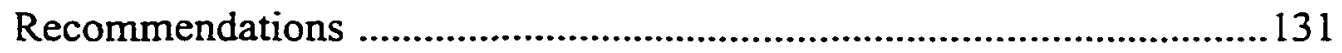

Summary of Recommendations ........................................................ 131

Appendix

A. APPROVAL FORMS/QUESTIONNAIRE ……............................ 136

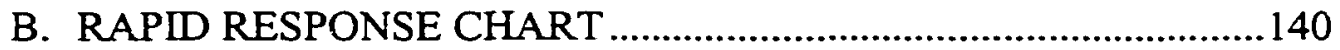

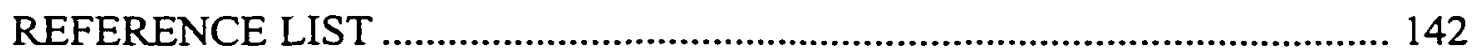

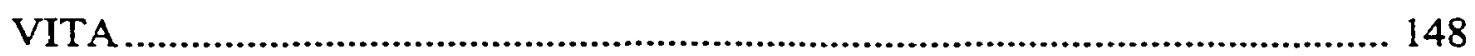




\section{LIST OF TABLES}

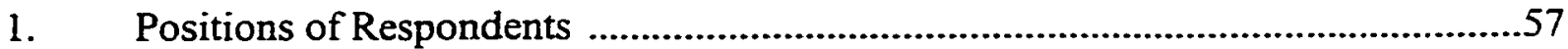

2. Summary of Personal Demographics for Respondents .........................................58

3. Summary of Years in Elected Office …………....................................................59

4. Direct Experience with Intergovernmental Mediation ...........................................59

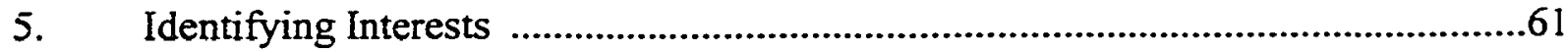

6. Dealing With the Appropriate People .................................................................62

7. Adequate Knowledge and Information .............................................................62

8. Voluntary Mediation Versus Required Mediation ..................................................64

9. Managing the Mediation Process ........................................................................64

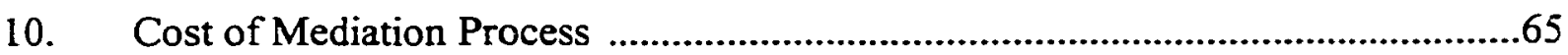

11. Timeliness of Mediation Process ……...........................................................66

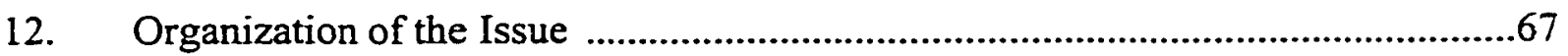

13. Separating the People From the Problem ..........................................................67

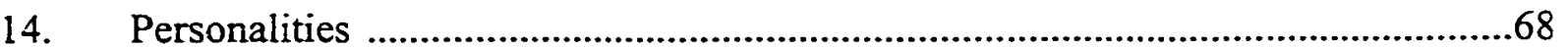

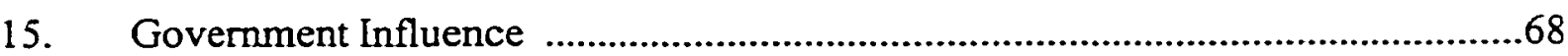

16. Value of Mediation .....................................................................................69

17. Experience Gleaned from Mediation Participation:

Evaluation of the Process for the Future ..................................................70

18. Revising the Mediation Process:

Evaluation of the Process for the Future ..................................................71

19. Defiance County Process Diagram …………….................................................99 


\section{ACKNOWLEDGMENTS}

The process to complete this dissertation truly brought out my frailty as a human being. My deepest appreciation to almighty God for granting me to the strength to fulfill the challenges associated with the task of accomplishing the Doctor of Philosophy degree.

My thanks to the many county commissioners, township trustees, appointed officials, and citizens-at-large, all of whom were so accommodating in the research process.

My appreciation to my dissertation committee, Dr. Elsie Jackson, Chair, and members Dr. Steven O. Ludd and Dr. James A. Tucker, for their encouragement, advice, and counsel. Thank you for your tremendous support, the long hours, and kindness you have displayed to me. A special appreciation to Bonnie Proctor, Dissertation Secretary at Andrews University, and Carol Castillo of the Leadership Program.

My thanks to the Defiance County Board of Commissioners and their fine office staff, especially Alison and Sherry.

Finally, to my family and friends, especially Chad, Natosha and Tayloure Wiseman, Aimee Wiseman, Tim and Ginny Wiseman, Eugene and Mary Walters and Dave Lulfs, all of whom never stopped believing in me: Thank you and may God bless each of you in a very special way. 


\section{CHAPTER 1}

\section{INTRODUCTION}

Few would argue against the idea that intergovernmental conflict reduces the effectiveness of local government. According to the National Association of Counties, "most governments in the United States are at the local level. Currently, there are an estimated 87,000 separate units, including 3,043 counties, 19,296 municipalities, 16,666 townships and 33,131 special districts" (Berman, 1993, p. 167). For the local government officials charged with the day-to-day responsibility of managing these local units of government, the decades of the 1980 s and 1990 s have been periods of ponderous intergovernmental competition. The pledge of President Ronald Reagan in 1980 to reduce the size of the federal government began two decades of increased non-funded mandates coupled with reduction of federal and state monies. According to George Peterson and Carol Lewis, "the President requested a cut of $44 \%$ in budget authority from the pre-Reagan 'baseline' level and achieved a cut of $36.5 \%$ " (Peterson \& Lewis, 1986, p. 68). Consequently, this situation has forced many local units of government to engage in direct and highly competitive activities vying for the limited available revenues.

In 1991 the National Conference of State Legislators convened to discuss the ongoing problem of non-funded mandates being placed on local units of government. The Conference Committee, composed of 14 legislators and staff representing various states, adopted a position that Federal and State Governments need to consider the fiscal 
effects of state mandates on local governments. "These can create a hardship for local governments when they are given service responsibilities without adequate means to finance the delivery" (Mackey, 1997, p. 8). According to Ohio Lieutenant Governor Maureen O'Connor, "This perennial problem impacts counties, municipalities, townships and school districts by saddling them with obligations that carry no corresponding funding to accomplish these requirements" (Rosado, 1999, p. 15). These types of demands, without a method to fund them, create a highly competitive environment for local governments.

State and local officials are faced with a burning question: how to promote growth, development, and community needs in a radically inimical environment. Yet this is not a totally new issue facing local government officials. George F. Break, professor of economics at the University of California, wrote in 1980, "Two prominent features of the current, competitive phase of intergovernmental relations are the vigorous regional rivalries and the continued fiscal shakiness of some of the largest cities." According to Break, "active regional competition for labor, capital, and federal government benefits is one of the basic facts of economic and fiscal life in a big country" (Break, 1981, p. 25).

Non-funded mandates are only one portion of the intergovernmental competition pie being competed for by state and local officials. Competition for new revenues through such mechanisms as economic development projects has long lent itself to the problem. Break in his writings points out that, as early as the $1960 \mathrm{~s}$, public fiscal experts such as Edwin C. Gooding "saw the increasingly active competition by state and local governments for business as serious enough to constitute a "New War Between the States" (Break, 1981, p. 25). 
Why should we even care that there is intergovernmental conflict on the local level? We should care for a variety of reasons. On a practical level, based on current Federal and State philosophy, local government will likely be faced with continued competition and exploitation for available revenues. One such example can be found in the case of Ann Michael, former Director of the Syracuse, New York, Office of Federal and State Aid Coordination. Michael, speaking to MPA students at Syracuse University regarding vying for competitive federal monies, stated, "Our first function is to manipulate the system to get as much money as we can into the City of Syracuse" (Wright, 1978, p. 181).

This type of manipulation promotes competition that can influence intergovernmental cooperation, thus setting up a situation that may create a negative ripple effect on growth and development throughout this entire country. The probability of intergovernmental disputes driving potential developers away from hostile environments is very real. One such case ended in near disaster in Defiance County, Ohio, when a midsize industry attempted to locate in a township contiguous to the city. According to Michael Schultz, former Defiance County Economic Development Director, the developer was caught up in a conflict between the township and the city. The two local governments were competing for the new development in an effort to capitalize upon much needed future tax revenues. As a result, the developer came within hours of totally abandoning the projects with the idea of relocating to another community.

In yet another case, the outcome for two communities caught up in conflict over an economic development project was not so positive. Don Lacey, small, local government specialist and 30-year veteran with the Virginia State Extension program, 
often uses the case of Montgomery County, Virginia, to illustrate what can happen when local governments are in conflict over economic development issues. According to Lacey, the Virginia towns of Blacksburg and Christiansburg had an opportunity to land Mid-Atlantic regional headquarters for Blue Cross Blue Shield. Unable to agree on a joint taxing scheme, unable to get their package together in an efficient way without conflict, they lost the facility to Charleston, West Virginia. The loss was of jobs and potential future revenues that likely would have provided long-term, much-needed income to the local communities' treasury.

Officials can continue to compete and litigate or they can choose to employ intergovernmental mediation tactics. Making the right decision might very well lead to positive economic development outcomes resulting in the sharing of revenues and resources with neighboring units of government.

Considering our recent entry into this new millennium and beyond, customary practices of dispute resolution and conflict management do not appear adequate given the degree of increased complexity and growth of local governments. Berman notes that political scientist Morton Grodzins wrote some 30 years ago: "To put the matter bluntly, government in the United States is chaotic" (Berman, 1993, p. 167). As we consider the degree of increased complexity and sophistication our world has experienced, we can hope to better understand the critical need to be prepared for dealing with even greater degrees of intergovernmental conflict in the future.

\section{Statement of the Problem}

Today, more than ever, local government officials must face the ongoing problem of reductions in the influx of federal and state monies coupled with the burden of ever- 
increasing demands of non-funded mandates. These increased mandates and contention for new dollars have created a somewhat hostile environment among neighboring local units of government. The way in which local officials choose to address these intergovernmental conflicts may very well be of critical importance.

Historically, local government officials, when faced with intergovernmental conflict, have employed litigation as a means of resolution. Litigation was not the preferred action; rather, there were few, if any, other known structured options available. We need now to consider how we can draw from a variety of different techniques that can assist local government decision-making and at the same time encourage citizens to participate in non-adversarial ways, thus avoiding costly litigation.

There exists a vacuum in classical and current research with respect to intergovernmental mediation. The few efforts to evaluate intergovernmental mediation appear to have been approached from a much broader spectrum. Few studies have actually addressed the more narrow focus of intergovernmental mediation as an important technique for successful local government partnerships.

\section{Purpose of the Study}

The purpose of this research is twofold. One is to investigate the relationship between local governmental organizations in terms of intergovernmental mediation and conflict resolution. The second is to examine the Defiance County government's intergovernmental mediation practices. 


\section{Research Questions}

This study attempts to answer the following questions regarding intergovernmental mediation as an important technique for successful local government partnerships.

1. What is the level of experience in the intergovernmental mediation process as perceived by county commissioners, township trustees, appointed administrators, and citizens at large in Ohio?

2. What is the level of understanding of intergovernmental mediation that is perceived by county commissioners, township trustees, appointed administrators, and citizens at large in Ohio?

3. What is the relationship between intergovernmental mediation and successful local government partnerships as perceived by county commissioners, township trustees, appointed administrators, and citizens at large?

4. What are the types of variables that create conflict between and among neighboring units of local government?

5. What types of public sector mechanisms are presently available for local government officials?

6. Do Defiance County local units of government practice intergovernmental mediation? If so, what have been the outcomes in terms of economic development and partnership agreements?

\section{Significance of the Study}

The intent of this study is to provide information regarding the value of intergovernmental mediation in relation to successful local government partnerships. 
America is at a crossroads. There needs to be sophistication for problem solving at the local level that may not be available at this time. We now need to consider, as we look at the decentralization to some degree of government, how we can draw from a variety of different techniques that can assist local government decision-making. In so doing, we hope to encourage citizens to participate in future planning, in non-adversarial ways, thus avoiding costly litigation.

What makes this whole question of intergovernmental mediation interesting to me is the increased degree of sophistication and competition being faced by local government officials charged with doing the day-to-day business of the people. It is my opinion that the demands facing local government officials will continue to heighten with the recent pledge of the Congress to further reduce the size of government. Therefore, it is important that local governments seek out as many tools as possible to solve the inevitable conflicts associated with intergovernmental competition. Increased competition created by federal and state non-funded mandates results in inadequate resources and limited revenues.

It makes sense for local government officials to pay attention to this study because it may offer yet another alternative $w$ uuding with intergovernmental conflict. It also makes sense in that local government officials are under tremendous pressure by the taxpayer to provide a relatively peaceful environment. And, although there has been some development in the area of intergovernmental mediation, the necessity to further develop and refine the process is supported by the writings of Richman, White, and Wilkinson (1986): 
"Mediation in most public policy disputes have been individual one-off demonstrations rather than a developed practice in a particular dispute arena within a structured context of formal public procedures for judicial and public review of negotiated settlements" (p. 1).

\section{Limitations of the Study}

Some of the participants representing the city and township are long-time political associates with the researcher in his tenure as former City Councilman at Large, Mayor, and currently as County Commissioner.

\section{Delimitations of the Study}

1. The study concentrated on township trustees from only Defiance County, as opposed to a cross section of trustees throughout the State of Ohio.

2. This study was limited to intergovernmental mediation programs in the states of Ohio, New Mexico, Oregon, and Washington.

\section{Setting}

Defiance County, Ohio, is located in the northwest corner of the state, bordering Indiana and only a short distance from the Michigan state line. As a result, the county has long competed for a share of economic development projects with these bordering states. The composition of the county consists of one mid-sized city (Defiance), population 18,610 , three villages each under 5,000 population, and 12 townships. The geographical layout is such that the distance between the various units of governments creates a highly competitive environment. One likely reason is that the City of Defiance controls the majority of water and sewer utilities. Over the years, the city has charged an 
"outside rate" of $250 \%$ of the "inside rate" to a number of neighboring units of government. To further complicate relations the city has annexed consicierable land in various townships with the greatest annexations occurring in Noble Township.

Conflict has long been a major player in terms of influencing intergovernmental cooperation in Defiance County. Basically, the trust factor between city officials and officials of neighboring units of government has left a great deal to be desired, particularly in the case of contiguous Noble Township, which continues to experience tremendous growth and development. These somewhat dependent Noble Township officials, as a result of increased annexation and high utility rates, have long viewed the city as a Goliath.

\section{Definition of Terms}

The science of alternate dispute resolution seems to have a language of its own. A variety of these terms is used throughout this dissertation to address the many possibilities associated with intergovernmental mediation. Some of the definitions below are taken from the Ohio Commission on Dispute Resolution and Conflict Management (OCDRCM), which has compiled a list of frequently used terms and their definitions.

Adjudication: A process in which the parties present arguments and evidence to a neutral third party who makes a determination, which is enforceable by the authority of the adjudicator (Consumer Guide, OCDRCM, 1997).

Alternative or Appropriate Dispute Resolution (ADR): Frequently used in the legal community to refer to alternatives to litigation. This includes a range of nonjudicial processes for resolving disputes such as arbitration, mediation, and negotiation (Consumer Guide, OCDRCM, 1997). 
Arbitration: Describes the process used for resolving disputes in which an impartial third party listens to the disputing parties and issues a decision. Arbitration may be court-annexed or private, binding or non-binding (Consumer Guide, OCDRCM, 1997).

Arbitrator: An impartial neutral that hears all sides of a dispute, reviews the evidence, and issues a decision meant to settle the dispute. An arbitrator does have decision-making power and is authorized to provide a judgment about the dispute (Consumer Guide, OCDRCM, 1997).

Assessment: An impartial analysis of a conflict situation conducted with an eye towards determining potential paths by which parties may reach a resolution of their conflict. This usually includes personally interviewing the parties, reaching the history of the conflict, and attempting to find agreements as to the core issues around which the conflict has evolved (Consumer Guide, OCDRCM, 1997).

Binding Agreements: A binding agreement has the force of a contract and, if broken, can be litigated.

Non-binding Agreements: "Good faith" agreements and cannot be litigated (Consumer Guide, OCDRCM, 1997).

Collaborative Problem-Solving: A process whereby parties develop a cooperative approach to defining the problem using a variety of problem-solving processes. Depending on the knowledge and experience of the group this type of process can be conducted with or without the assistance of a facilitator (Consumer Guide, OCDRCM, 1997). 
Caucus: A private meeting between the mediator and one party to gather facts for the mediation, to explore new options, to clarify proposals, or to allow the parties to cool down. If a caucus is used, the mediator talks with each party, one after the other. Information exchanged during a caucus may be confidential and can be communicated by the mediator to the other party only after receiving permission to do so (Consumer Guide, OCDRCM, 1997).

Co-mediation: A mediation process in which two mediators simultaneously or jointly conduct the process. Used in cases where mediators with different areas of expertise would be useful, when there are multiple parties involved, and/or to model cooperation and gender or ethnicity balance. New mediators can benefit from comediating with experienced mediators (Consumer Guide, OCDRCM, 1997).

Conciliation: A process by which a third party works with the disputing parties, individually or together, in an attempt to lower tension, to improve communication, and to explore solutions (Consumer Guide, OCDRCM, 1997).

Confidentiality: Refers to information shared during the course of mediation. This is deemed private and is not to be revealed by the mediator to anyone outside mediation or within the mediation if the information was obtained during a caucus (Consumer Guide, OCDRCM, 1997).

Conflict: A broad term regarding an interaction between people with differing interests, which are perceived as incompatible. Derived from the Latin conflictus, meaning to strike together. Conflict is often inevitable, but constructive outcomes from conflict are frequently possible (Consumer Guide, OCDRCM, 1997). 
Conflict Management: Any collection of actions, responses, and processes and/or systems that help manage, improve, or prevent the deterioration of relationship dynamics and activities (Consumer Guide, OCDRCM, 1997).

Consensus: A method of seeking the resolution of a multiple-party conflict or dispute, relying upon equal participation of all parties. The end goal is to develop an agreement, usually without voting, that all the participants can live with (Consumer Guide, OCDRCM, 1997).

Dispute Resolution: A term describing any array of methods used to resolve conflict. Processes range from negotiation to community empowerment and facilitation (Consumer Guide, OCDRCM, 1997).

Expert Mediation: A process in which the parties to a dispute select a third party neutral based on his or her expert knowledge of the subject matter to be mediated (Consumer Guide, OCDRCM, 1997).

Facilitator: A person competent in the use of dispute resolution who provides neutral services to groups (usually more than two) involved in a dispute or conflict. The facilitator provides procedural assistance to the parties, enhancing information exchange and working with the parties to develop and evaluate possible agreements that could lead to a resolution (Consumer Guide, OCDRCM, 1997).

Facilitation: A method by which an impartial third party works with a group to design and manage a process, which allows for effective participation and communication when addressing a set of related issues or resolving a problem (Consumer Guide, OCDRCM, 1997). 
Fact-finding: Often used in relation to negotiation, mediation, or arbitration of complex disputes. This is a process by which facts relevant to a dispute are determined (Consumer Guide, OCDRCM, 1997).

Indirect Negotiation: A process in which the parties to a dispute use representation such as lawyers or agents to identify issues to be negotiated, to develop options, and to consider alternatives to negotiate an agreement (Consumer Guide, OCDRCM, 1997).

Interest-Based Negotiations: When parties systematically seek to satisfy their own and the other party's interest and needs by developing an agreement (Consumer Guide, OCDRCM, 1997).

Intergovernmental: Used to describe activities involving two or more units of government (Consumer Guide, OCDRCM, 1997).

Litigation: A legal action, court action, or the act or process of carrying on a lawsuit (Consumer Guide, OCDRCM, 1997).

Mediation: A voluntary process in which an impartial third party guides disputing parties in identifying issues and reaching a mutually acceptable resolution of their dispute. A mediator does have the authority to impose a decision on the parties (Consumer Guide, OCDRCM, 1997).

Mediation Model: A model containing a series of reference points that may vary stylistically or adapt the mediation process to meet the individual needs of the parties or the particular situation (Consumer Guide, OCDRCM, 1997). 
Negotiation: The process of disputing parties engaging in discussions to explore their interests and needs in an effort to reach agreement without the assistance of an outside neutral (Consumer Guide, OCDRCM, 1997).

Ombudsman, Ombuds, Ombudsperson: A third party neutral who researches complaints and suggests or implements solutions on behalf of a recognized authority (Consumer Guide, OCDRCM, 1997).

Policy Dialogue: Informal discussion of public policy issues incorporating many different interested parties. This process usually clarifies key issues, and increases understanding between groups that are often publicly opposed to one another (Consumer Guide, OCDRCM, 1997).

Reconciliation: Although not a formalized term in dispute resolution, does describe steps taken to heal or improve relationships that have been damaged by conflict (Consumer Guide, OCDRCM, 1997).

Strategic Planning: A long-term, future-oriented process of assessment, goal setting, and decision-making that maps an explicit path between the present and a vision of the future, that relies on careful consideration of a country's capabilities and environment, and leads to priority-based resource allocation (Personal Communication, February 15, 1999).

Third Party (Neutral): Describes an impartial person, group, or organization that assists disputing parties in reaching a resolution. Mediators, arbitrators, facilitators, and conciliators are all considered third party neutrals (Consumer Guide, OCDRCM, 1997). 
Unit of Local Government in the United States: Usually a specific entity of government found within a larger unit of government. For example, cities or villages are considered units of local government and are usually found within a county (Consumer Guide, OCDRCM, 1997).

\section{Organization of the Study}

Chapter 1 consists of the introduction, the statement of the problem, the purpose of the study, research questions, the significance of the study, the limitations of the study, delimitation's of the study, and the definitions of frequently used terms in the study.

Chapter 2 contains a review of the literature by probing the present knowledge base on dispute resolution, both traditional and non-traditional methods. In addition, this chapter takes a look at what practitioners in the field are actually doing to deal with intergovernmental conflict.

Chapter 3 describes research methodology utilized in this study. The chapter speaks to the population, the method of analysis, and the instruments used.

Chapter 4 presents the findings regarding intergovernmental agreements among various local government subdivisions in Defiance County. It also contains a 6-month case study of the Defiance County experience when faced with intergovernmental conflict.

Chapter 5 consists of a summary of study conclusions and recommendations. The goal of this chapter is to provide the reader with useful information that may assist in dealing with intergovernmental conflict issues. 


\section{CHAPTER II}

\section{LITERATURE REVIEW}

This chapter investigates the need as well as the present availability of publicsector mediation opportunities to local government officials. The process covers a more broad approach by looking at what the theorists have to say on the subject followed by the more narrow approach of looking at what is actually being done in the states of Ohio, Oregon, New Mexico, and Washington. This chapter includes a description of various mediation-related techniques such as mediation style, mediation ground rules, and present evaluative options being utilized by public sector organizations.

Much of the literature in this chapter relates to existing federal and state law with respect to mediation. A section of the literature review is dedicated to what actually is available to the private and public sector by virtue of the law, professional consultant groups, and organizations dedicated to alternate dispute resolution. This chapter is relatively succinct, as literature review chapters found in dissertations generally tend to be one of the longer chapters. The reason for the brevity of this chapter is due to the limited data available on the subject of intergovernmental mediation.

\section{Mediation}

Interest in the area of intergovernmental mediation appears to have increased since the 1980s. The literature reflects the need for local government to consider 
mediation as a means of addressing conflict. To date, much of the research in this area has been directed toward the "need to know." According to Richman, White, and Wilkinson (1986), "Structured negotiations and mediation roles are unfamiliar to public officials, thus, disputing local units of government have no comparable organizational and behavioral models" (p. 4). Hermann (1995) asserts that we are all so well trained to fight or flee, to threaten or coerce, that we find it difficult to use more constructive ways to deal with conflict.

Mediation in the private sector is certainly not a new concept. The Federal Mediation and Conciliation Service (FMCS) established by the United States Congress in 1947 was charged with an exclusive mission of promoting sound and stable management relations through a variety of mediation and conflict resolution services. To this end the private sector was served well in this arena. The public sector, generally, and local government, specifically, have had little direction in the evolvement of intergovernmental mediation. What could make mediation between two units of local government different than, for instance, mediation between a local government and a labor union? In the case of 2 local governments, there generally is no requirement to participate in mediation. Yet, local government is not exempt from conflict. The need to address intergovernmental differences continues to grow at an alarming rate. There appears to be no end to it. If we hope to address this intergovernmental crisis we must be willing to employ intergovernmental mediation tactics. Failure to mediate can result in costly litigation. Not that litigation is wrong; it is sometimes the only resource. But are there other methods that we can utilize to get us to a point where we can live together and respectfully disagree? This study is designed to examine that question. 
The question of the day then becomes, Is there a need to enlighten and educate c

public officials as to the value of constructive intergovernmental mediation? If so, how do we convince them that conflict resolution, unless addressed properly, may very well do more harm than good? One answer may be found in a 1999 survey conducted by The Ohio Commission on Dispute Resolution and Conflict Management. According to Associate Director, Maggie Lewis (1999b), the commission sought to find out if public organizations did in fact employ some form of alternate dispute resolution when faced with conflict. Lewis reports survey results from 32 agencies demonstrate a high level of interest in the use of ADR techniques; however, actual use of the process is mixed.

Over two-thirds of all agencies reported using some form of mediation to resolve workplace disputes, while about the same number indicate an interest in developing a conflict mediation program. Only about a third of the agencies surveyed currently use some form of assisted negotiation or facilitation process in the development of departmental policies and administrative rule making; however, nearly two-thirds of agencies surveyed reported having a high interest in using regulatory negotiation in the future. (Maggie Lewis, Personal Communication, November 5, 1999)

According to Lewis (1999b), state officials report that disputes concerning policy development, administrative rule making, and personnel issues frequently cause extensive delays in program implementation, sidetracking the agency policy agenda. This can have a tremendously negative impact on organizational productivity as well as drain the budget.

Therefore, why does only one-third of those agencies surveyed utilize some sort of assisted process? Why does there seem to be reluctance by people in leadership positions to seek and accept help? One answer for this position is postulated in the writing of Hermann (1995), "Our reluctance to seek help is compounded in political settings, where traditional wisdom equates seeking help with weakness—indecisiveness, 
lack of vision, or lack of political clout" (p. 68). She believes that because we live in a worlc that promotes individualism, we often choose to handle situations alone. To further complicate this issue one need only to consider the fact that public officials are frequently praised by their peers, the media, and the public at large for quick decisive action. According to Lewis (1999b), even though the odds of resolving a conflict issue are probably better with assisted $A D R$, these public officials tend to risk criticism when they choose to go to outside sources such as consultants or mediators.

Nevertheless, public officials who do choose an alternate dispute-resolution approach with outside assistance are not always guaranteed successful outcomes. John Stafford points out in his writing on managing law enforcement agencies (Hermann, 1995): "It is a myth that conflict management techniques can solve all problems" (p. 69). The question then becomes, Does conflict management help? Many believe that although conflict is inevitable, it must be "actively managed." Assuming this is true, then what are the criteria that need be considered to help ensure the best possible outcomes? What types of issues can actually be mediated in public sector settings? What kind of approaches should we consider? What are our options?

\section{What Types of Issues Can Be Mediated?}

The types of issues that are ripe for mediation in the public sector are several. One of the more common areas mediated in the public sector actually involves a combination of private/public sector players. These deal with issues between local businesses versus a consumer-type of disputes. Another frequent area of dispute involves domestic relation's mediation covering divorce and child custody issues. A somewhat closely related area deals with landlord/tenant conciliation issues. Other commonly 
disputed public matters include construction contract disputes, victim offender programs, truancy mediation, small claims issues, criminal misdemeanor mediation, and zoning disputes. The list does not conclude there. Interesting enough, mediation issues may not exclusively concern only the living. Perhaps one of the more unusual and possibly least familiar issues mediated through the public sector process deals with cemetery-related dispute issues.

The Ohio Commission on Cemetery Dispute Resolution, since its creation by Ohio revised Code 4767 in 1993, has processed more than 1,000 cases. The majority of disputes have centered on issues concerning maintenance and care to cemeteries (e.g., failure to cut grass, take care of underbrush, maintain care of roadways, remove dead trees and limbs, etc.). According to Adam Tonti, Office of Investigation Supervisor of the Commissions, Cleveland, Ohio, complaints not resolved through the Department of Commerce, Division of Real Estate Office, are then referred to the Ohio Cemetery Dispute Resolution Commission to mediate the matter.

Clearly, there are a substantial number of public issues subject to the need for conflict resolution. The optimal approach to address these issues is, according to the Ohio Commission on Dispute Resolution and Conflict Management (OCDRCM), the response style that is most likely to enable achieving the desired goal. The following is a synopsis of what the commission believes to be options for addressing public conflict issues. These styles include avoiding, accommodating, compromising, competing, and collaborating.

According to the Commission, avoiding is a response providing for a time of cool-down to reduce feelings of stress, a time to gather information. Accommodating is 
an approach used by individuals placing a high value on personal relationships and are therefore flexible and willing to sidestep conflict. Compromising is usually the choice made by individuals believing that "something for both sides is better than nothing." The competing response, on the other hand, usually occurs when an individual must make a quick decision or commit to a particular belief. According to Lewis (1998) individuals exercising a competitive approach generally tend to be more aggressive and adversarial. Whereas individuals choosing to employ a cooperative style tend to be more open, valuing long-term relationships over short-term gain. She believes that using a combination of competitiveness cooperation is yet another style often chosen.

Each of the aforementioned styles provides for a particular response method to a specific conflict resolution need. However, the granddaddy of conflict response styles appears to be one that "emphasizes objectivity and the use of information and creativity to achieve mutually beneficial agreements" (Lewis, 1998, p. 4)

\section{Collaborative Approaches}

Collaborative problem-solving, also known as consensus building, is often defined as a process to bring people together in an attempt to analyze problems, to generate options in an effort to reach a consensus agreement. Collaborative approaches are not totally new in the arena of private/public sector mediation. Recent publications by Lewis, Roberts, and Silverberg call for applying collaborative approaches in the mediation process. According to Lewis: "The use of the collaborative methods encourages a greater sense of commitment to the process as well as the outcome developed by all stakeholders" (Lewis, 1999b, p. 8). 
Silverberg agrees that choosing a collaborative approach promotes the building and maintaining of relationships toward mutual resolutions, a process she believes that will assist in creating a bond of trust, cooperation, and commitment. However, collaborative approaches may not automatically be appropriate to all conflict situations. Silverberg (Personal Communication, 1998), in a 1998 presentation to State of Ohio agency and department heads in Columbus, Ohio, strongly suggested that to choose a collaborative approach requires conflicting parties to be willing to share control over the process ultimate resolution. A lack of willingness to share control renders the collaborative process ineffective. The OCDRSC agrees, "Because the collaborating response requires time for individuals to meet and share information and ideas, it is inappropriate to use this style when issues are trivial or a quick decisive answer is required" (Lewis, 1998, p. 3).

\section{Collaborative Approach Example}

One excellent model of a collaborative approach can be found in Silverberg's home state of Oregon in the Department of Land Conservation and Development handbook for land-use planners (Silverberg, Tarnow, \& Watt, 1996). The publication Collaborative Approaches to Decision-Making and Conflict Resolution for Natural Resources and Land Use Issues is dedicated to dealing with conflict through the use of the collaborative process. According to Donna Silverberg, consultant and co-author of the publication, "Collaborative processes allow Parties with a stake in an issue to create solutions that are agreeable to all" (Personal Communication, March 3, 2000).

In the case of Oregon, the goal of the State land-use program is to increase the predictability and consistency of land-use decision-making. However, program directors 
agree that by opening these types of volatile issues to a collaborative process actually increases the number of issues arcind which conflicts can develop. Nevertheless, program creators believe a collaborative approach provides perspectives on the full spectrum of conflicts: how they arise, how they can be managed, and how they can be resolved. They believe the program's supporting handbook successfully promotes collaborative processes. Further, that the act of creating mutually satisfying solutions establishes a sense of ownership. Because of this sense of ownership, the stakeholders are more likely to support and implement collaborative solutions, and build connections among diverse interest groups helping to create a better base for future decision-making.

\section{Evaluating Collaborative Approaches}

Do collaborative approaches work? If so, is there a way to evaluate them? To this question David Fairman (1999) stated that "for two decades specialists from a wide range of fields have scrutinized the growing practice of public dispute resolution at the most basic level, trying to find out if it is a good idea. Many are also interested in finding out how we could do it better" (p. 5). According to Fairman, after 20 years, attempts to evaluate consensus-building efforts in the public sector have failed to produce agreement on even the right criteria to use for evaluation

Maggie Lewis, Associate Director of the Ohio Commission on Dispute Resolution and Conflict Management office, does not totally agree with Fairman's perspective on this issue. She suggests that scholars may very well not agree on a "one size fits all criteria." However, for her the criteria in this arena is "pretty elementary." Did it work? Did it produce an agreement? She believes that "when getting into identification of criteria when trying to apply it to large classes of public disputes it is 
very difficult to do." For her, the bottom line is, Did it work? If not, why? Did we incorrectly assess it? Was it not right for resolution? Was it bad "karma?" To the question, Do we even need criteria? she believes we do and states: "There are some out there, but whether or not people agree on them I do not know" (Personal Communication, March 5, 1999).

Yet, Lewis and Fairman are not completely alone in their opinions on the issue of evaluating processes. Dale Blanton of the Oregon Department of Land Conservation and Development agrees there is not a great deal of criteria currently available. However, he acknowledges that there is some work going on in the area of evaluative criteria. Recently he participated in a 21/2-day program in Tucson, Arizona, to discuss a possible pilot program on evaluative criteria methods. The meetings organized by representatives of the U.S. Institute for Environmental Conflict Resolution was composed of a group of researchers and practitioners from the states of Oregon and Massachusetts. According to Blanton their hope "is to come up with some workable evaluative tools in the next year or so" (Personal Communication, June 2, 1999).

Blanton's (1999) personal approach to the evaluative process is from a more pragmatic perspective:

In Oregon the tool we use to evaluate our cases is simply we send out an evaluation which is basically a summary of the case. We ask individuals to evaluate the provider, how they felt the process was conducted, whether their goals were achieved and if they would recommend the process to another person. We generally ask them to rate on a scale from zero to five, with five being the most satisfied, how they felt about the process. It is a tool that gives us quite a bit of feedback from participants in collaborative process providing a range of answers. For the most part responses are very supportive yet we do on occasion find a disgruntled stakeholder who did not like the outcome. (Personal Communication, June 2, 1999) 
According to Blanton, this information is all well and good but he is not sure that it tells us very much about how government is using collaborative approaches. Nor is he certain that it always gives us the information we want about the provider or about how the process was conducted. His sense is that the better evaluation tool is one where you can actually do some debriefing of the case with participants obtaining much more detailed information. Unfortunately this method is very time-consuming, requiring detailed debriefing and written detailed summary, and for that reason cannot be applied in many cases.

Understanding that there are public dispute issues to be addressed and methods to address them is an important step in the public mediation process. However, familiarity with respect to existing law can provide an excellent base for better understanding public mediation issues.

\section{The Law}

The availability of public sector law with respect to intergovernmental mediation is somewhat limited. However, more states seem to be establishing mediation programs of a sort. According to Chris Carlson, Co-Director of Policy Consensus Initiative, Santa $\mathrm{Fe}$, New Mexico, these mediation programs for the most part are not mandated by legislation, but simply available and voluntary in nature. According to Jill Purdy, a 1998 Policy Consensus Initiative identified some 37 organizations that could be considered "statewide" providers of conflict resolution services in this country. Chris Carlson believes the majority of these programs to be judicially based in nature, with few actually dealing with intergovernmental issues (Personal Communication, July 22, 1998). 
One example of a program strongly geared toward intergovernmental mediation is found in the State of Washington. According to Carlson, a state mandate requires that before any state agency can sue another state agency they must first attempt to resolve the issue through a prescribed mediation process. What Carlson is referring to, according to Mary Barrett, a senior assistant attorney general and dispute resolution coordinator for 10 years with the Washington state attorney general's office, is section 43.17 .330 of the Washington State revised code. The section titled "Interagency Disputes-Alternative Dispute Resolution-Methods" reads:

Whenever a dispute arises between state agencies, agencies shall employ every effort to resolve the dispute themselves without resorting to litigation. These efforts shall involve alternate dispute resolution methods. If a dispute cannot be resolved by the agencies involved any one of the disputing agencies may request the governor to assist in the resolution of the dispute. The governor shall employ whatever dispute resolution methods the governor deems appropriate in resolving the dispute. Such methods may include, but are not limited to, the appointment by the governor of a mediator, acceptable to the disputing agencies, to assist in the resolution of the dispute. The govemor may also request assistance from the attorney general to advise the mediator and the disputing parties. (Barrett, Personal Communication, August 3, 1999)

According to Carlson, such programs are a step in the right direction; however, the problem has always been and continues to be "the politics." She believes far too often the Governor or other elected leaders will step in and flex political muscle with particular mandates, effectively reducing the opportunity for a truly mediated consensusbased resolution.

Politics cioes appear to be a rather substantial influencing variable in the equation of intergovernmental mediation. Carpenter (1998) goes yet one more step on the issue in question. Not only does she believe that politics influences cooperation but also that intergovernmental cooperation is most apt to occur among municipalities that share the 
same party affiliation. Is it possible to remove the politics? Former Defiance, Ohio, City Administrator Dr. Mike Abels does not think so. In a 1988 presentation to the Defiance City Council regarding a labor management dispute he stated that he believed "politics to be an inherent part of the public dispute process and could never be removed from the system" (Personal Communication, October 22, 1988). As to the question of whether politics is really all bad in the local government decision process, Ammons (1990) writes, "Personal views and politics play powerful roles in local government decision making as they should" (p. 1).

Advocating for the value of politics in the mediation equation is Dale Blanton, of the Oregon Department of Land Conservation and Development. To the question can politics ever be removed from the intergovernmental mediation process he states: "First the question has an assumption behind it that maybe you would want to do that! My first reaction is why would that be beneficial?" (Personal Communication, June 2, 1999). Blanton (1999) basically believes that in government mediation there exists a somewhat political environment and therefore there is a need to understand politics and political motivations of players. Rather than hide the political considerations, lay them out on the table so that they can be clearly understood. According to Blanton, once a political agenda is on the table, folks with concerns can discuss the issues and the "why" behind those political concerns in a collaborative forum. Further, by understanding the politics at the forefront one can then begin to understand if they are fundamental value-laid politics. The bottom line with Blanton is, if politics are a driving force, do not ignore them; rather, consider the merits and reasons behind them. Sit down in a mediation session; try to understand the needs of the other side and where they are coming from. 
When politicians do flex their political muscle, Blanton (Personal Communication, June 2, 1999) believes it best to sit down, explore their interests, and attempt to educate them as to the difference between the standard right-based political system that exists in government and what the collaborative approach alternative might look like. He believes that by explaining these differences and the potential for benefits, it may very well dispel some of the misconceptions of the mediation process. This is particularly important according to Blanton when there are power-based politics or leadership issues involved. The difficult part is convincing individuals that mediation is not a backroom deal-cutting kind of process, it is not a weak option, nor does it suggest a lack of leadership. Therefore, the likelihood exists that there is not a need for the flexing of their political muscle in a conflict or dispute situation.

\section{Ohio State Law}

Contemporary literature has not adequately addressed the issue of intergovernmental mediation in local government. Consequently, what is intergovernmental mediation in local government? According to the State of Ohio, Chapter $179.01-179.04$ of the Ohio revised code, "Dispute resolution and conflict management includes any process that assists persons with a dispute or a conflict to resolve their differences without further litigation, prosecution, civil unrest, economic disruption or violence." The law in part defines dispute resolution and conflict management programs as programs that encourage mediation or conciliation. The administrative body charged with carrying out the mandates and directives of this section of the law is the Ohio Commission on Dispute Resolution. 


\section{Ohio Commission on Dispute Resolution and Conflict Management}

Section 179.02 of the Ohio revised code establishes that an administrative agency delegated the responsibility to promulgate the rules regarding alternate dispute resolution in Ohio. The agency known as the Commission on Dispute Resolution and Conflict Management is composed of a 12-member board. The agency goal is to provide the necessary funding and to coordinate appropriate programs in the State of Ohio. Four members of the board are appointed by the governor, 4 members appointed by the Chief Justice of the Supreme Court, 2 appointed by the President of the Senate, and 2 by the Speaker of the Ohio House of Representatives. Terms of office are for 3 years with all terms ending on the same day of the same month of the same year. Vacancies are filled in the manner provided for with original appointments. Members serve without compensation but are entitled to reimbursement for actual expenses incurred in the performance of their duty.

Powers and duties of the board are addressed in section 179.03 of the revised code. Duties include maintaining a central office, adopting standards for the evaluation of dispute resolution, and conflict management programs. The goals of the commission are set forth in its mission statement and can be found on its web page. They are:

\section{Mission Statement}

The Ohio commission on dispute resolution and conflict management's purpose is to initiate and establish dispute resolution and conflict management programs and activities in government, educational institutions, communities and the legal system throughout Ohio.

The commission works in partnership with organizations and institutions to build their capacities to manage conflict effectively. To this end the commission serves as catalyst, broker, consultant, collaborator, and facilitator, and it works with others, strives toward inclusion of people from diverse cultures. It seeks to multiply leverage it resources whenever possible. (www.state.oh.us/cdr) 
According to Maggie Lewis (1999a), the commission has indeed focusud its efforts in four fundamental areas across the State of Ohio. These are the schools, courts, community, and government. Between 1991 and 1997, 136 mediation advocates were trained through the Commission on Dispute Resolution. The training program for local elected and appointed officials offers a well-organized highly structured 2-day agenda. Day I provides for a basic overview of the program, the agency expectations of those who complete the training, and accepting the role of mentor. Also on day 1 participants learn about the nature and sources of conflict and subsequent negotiation processes. Day $l$ is capped off with a role-playing exercise followed by an assessment and evaluation phase. Day 2 consists of an overall review of day 1 followed by mediation demonstrations and mediation role-play. The training program concludes with a panel discussion of active trained mentors, followed by the program evaluation process.

As of February 1999 a record 101 mediation advocates were in service. Of the 88 counties in Ohio, 43 have trained mediation advocates of whom 28 are judges, 26 are municipal officers, and 25 are county commissioners. As of April 1988 there were 55 cases referred for mediation efforts, 38 of which were city and county units of government. Because matters are held confidential until resolved, it is not possible to provide an active status report of a case. However, one example of the type of disputes handled might include a conflict between a judge, who would like additional court security, and a board of county commissioners, who oppose funding the project cost. In such an example, a trained mentor would be assigned to work with the opposing parties in an effort to mediate the issue (Maggie Lewis, Personal Communication, March 5, 1999). 
Accordingly, in compliance with the Ohio Revised Code, these programs may serve the legal community, business community, public sector, private sector, or private individual. A second section of the law defines a program as dealing with elimination, prevention, resolution, and management of disputes and conflicts in the domestic and international context. This section is dedicated to education and training in the primary and secondary schools, in colleges, universitues, and other appropriate educational forums in the state of Ohio (Maggie Lewis, Personal Communication, February 13, 2000).

The Commission has taken a pro-active approach on the issues of community mediation and court programs. In each of these cases the commission has attempted to expand public awareness as to the value of alternate dispute resolution processes by providing consultation and technical assistance to courts and communities. One example of a community-based program might be housing mediation project. An example of a court-based program could be the mediation of a civil law suit. Other programs and examples include private sector business mediation and school conflict management services. The primary focus of the school management program has been directed toward public outreach.

\section{Educational/Sarnan' Settings}

Education has indeed been a major focus of the commission since its inception. Currently, one half on the commission's budget comes from the Ohio Department of Education. As a result, representatives from the Ohio Commission on Dispute Resolution and Conflict Management frequently make presentations or respond to school administrator's requests providing information as to the value of mediation programs. Interested school systems can then apply to the Commission for competitive grants to 
establish educational programs. The programs are designed to provide for training opportunities in the area of mediation and conflict resolution. Once trained, school officials frequently return to their school system and establish conflict resolution programs.

Presently, the demand for mediation opportunities and programs in educational settings does appear to be on the upsurge. Nancy Kaplan of the non-profit CRU Institute, Seattle, Washington, agrees:

It just seems obvious that there has been a lot of publicity about violence in schools so obviously people are more aware of it ... and certainly upper class white people are more aware of it then they were before the recent shooting in Colorado. So I think they are putting a lot of pressure on their schools to institute some kind of inner personal communication training. It appears to schools that conflict mediation training is a way to try to ameliorate violent situations. (Personal Communication, October 16, 1999)

The CRU program has more of an emphasis on student training. Kaplan acknowledges the organization has the bias that young people would be taking responsibility for their own conflicts and resolution of their conflicts. She also believes that "if there is no standard or modeling from faculty, and no support from faculty, then student peer mediation programs will probably not be very successful" (Nancy Kaplan, Personal Communication, October 13, 1999).

\section{Mediation Rules}

The Ohio Commission has not actually formulated specific rules or policies with respect to, or for the purposes of, mediation. Stephen Kotev (2000), program assistant with the commission, confirms there are currently no established standards. He does, however, believe the conflict resolution programs for elected officials have a clear direction. That philosophy is to switch the hierarchy of behavior from an adversarial 
style (political in-fighting) to a more consensus-based, collaborative-based process. According to Kotev, the fulcrum used to create a solution is through a facilitator "who seeks out the common interest of what brought the parties to the table" (Stephen Kotev, Personal Communication, June 11, 2000). Nevertheless, Kotev clearly believes that having established mediation ground rules does help to ensure a more effective and clean mediation process.

Roger Schwarz (1999) supports Kotev's position in his writing ground rules for effective groups. He believes that because ground rules serve as a guide to group members, groups who utilize them "are better able to communicate, handle conflict, solve problems and make decisions" (p. 95). Yet, Schwarz acquiesces to the point that ground rules neither replace the struggles of group development, reduce the risk of openness, nor overcome the lack of trust that exists in conflict situations. He does, however, believe that groups who utilize established ground rules would likely be more constructive in addressing conflict. His reason for this position is his belief that ground rules are based on three values: valid information, free and informed choice, and internal commitment. According to Schwarz (1999), valid information means all group members receive the same information. Free and informed choice allows members to define their own objectives and the methods for achieving those objectives, while internal commitment to the decisions extends the right to members to feel personally responsible for the decisions made by the group. Schwarz does caution: "Using these ground rules may require taking risks, to the extent that members of the group may distrust one another" (p. 107). Nevertheless, he believes, with the appropriate degree of reassurance, that the distrust 
factor although not eliminated can be reduced significantly, and furthermore, that such ground rules tend to be the heart of consensus decision-making.

\section{Private Sector}

One important consideration that appears to have been somewhat overlooked in the public sector is the need for creativity in the mediation process. As previously suggested, collaborative approaches in public dispute resolution process are relatively new. The majority of research in this area was done in the mid to late 1990s. The private sector, on the other hand, has long had available, and practiced, creative approaches to alternate dispute resolution. A number of these creative mediation programs serving the private sector are widely available through the Federal Mediation and Conciliation Service (FMCS).

The FMCS was created as an independent agency of the United States government in 1947. With its establishment Congress declared:

It is the policy of the United States that sound, stable industrial peace and the advancement of the general welfare, health and safety of the nation and of the best interest of employers and employees can most satisfactorily be secured by the settlement of issues between employers and employees through the processes of conference and collective bargaining, and further that, the settlement of issues through collective bargaining may be advanced by making available full and adequate government facilities for conciliation, mediation and voluntary arbitration. (Personal Communication, February 15, 1998)

The FMCS national office is located in Washington, D.C. In addition, there are 73 field offices administered in five geographic regions throughout the United States. The primary responsibility of the FMCS is to promote sound, stable labor-management relations through a variety of mediation and conflict resolution services. Among these are: arbitration services (self-governing in the workplace), labor management relations 
for the $21^{\text {st }}$ century, interest-based bargaining (a different way to negotiate), grievance mediation (problem-solving in the workplace), and building labor-management relationships (a winning combination) (FMCS, Personal Communication, February 15, 1998).

\section{Arbitration and Grievance Mediation Services}

Two frequently utilized alternate dispute resolution methods in the private sector, according to the FMCS, are arbitration and grievance services. Yet each has a very different and unique process. The United States Supreme Court on the issue of arbitration has declared in part that arbitration is to be a means of solving the unforeseeable by molding a system of private law. Geared primarily toward collective bargaining agreements, the FMCS has taken the position that arbitration is a system for resolving conflict that keeps bargaining agreements viable, working, and respected by the contracting parties. Arbitrators are generally private individuals, acting in a quasijudicial capacity, which make decisions or awards based on matters submitted to them. Grievance mediation, on the other hand, is a completely voluntary step prior to the arbitration process, usually providing for a third party neutral to assist the parties in reaching "their own" resolution of a dispute (FMCS, Personal Communication, February $15,1998)$.

According to John Wines (1999), Commissioner with the Federal Mediation and Conciliation Service field office in Toledo, Ohio:

Methods governing private sector alternate dispute resolution processes are clearly established. Employers and labor unions dealing with contract negotiations in the private sector are required by the Taft-Hartley Act thirty days prior to the expiration of the contract to notify the Federal Mediation and Conciliation Service in Washington DC if they have not reached an agreement. In 
those cases if there is a substantial impact on commerce, the parties are assigned to the various Federal mediators throughout the country and the negotiations are tracked. If an impasse is declared or if the parties are having difficulty, we go in and assist the parties through mediation to avoid a work stoppage. (Personal Communication, September 3, 1999)

Disputes that occur during the contract term in the private sector go to an arbitrator for final and binding arbitration.

Although the methods of resolving disputes in the private sector do appear to be somewhat more refined, the actual types of disputes in the private sector versus public sector tend to be rather similar. One example, according to Wines, would be proprietary disputes between competing businesses. And although he concedes that just as many disputes in the public sector are litigated, "generally these types of disputes in the private sector are also litigated" (John Wines, Personal Communication, September 3, 1999). Nevertheless, Commissioner Wines believes the private sector offers greater flexibility and, therefore, it is necessary to look at the entire picture in order to determine an appropriate method for resolution.

\section{Choosing a "Best Method"}

Choosing a best method to address conflict in the public sector is as open to debate as politics and religion. The reason for this is that there appears to be no hard and fast rules on the subject. For the most part, "unless there is contractual language requiring specific processes parties are left to choose their options" (John Wines, Personal Communication, September 3, 1999). However, one provision that many in the private and public seem to agree on the value of empowering the disputing parties.

Mediation seems to offer the greatest opportunity in this regard. 


\section{Private Versus Public Sector/Multisector Collaboration}

Is there a difference between private and public sector environments? While it has not been possible to provide a definite answer to this question it would appear that there is somewhat of a difference in the "levelness of the playing field" regarding private versus public sector needs. While private sector situations for the most part are generally limited to confined spaces-malls, industrial factories, office buildings, etc., the public sector generally has a considerably larger physical area of responsibility. For example, units of local government such as townships, villages, cities, and counties are generally charged with the responsibility for maintenance of considerable land mass, infrastructure, and the liability of the health, safety, and welfare of the population. This is not to say that private sector leadership does not face high-level responsibilities! After all, the chairman of General Motors, according to Gene Walters, has the awesome responsibility for some 400,000 plus autoworkers and more than $\$ 275$ billion in assets. But, General Motors does appear to be the exception rather that the rule when comparing public versus private sector with respect to size and degree of infrastructure responsibility. As a result, there does appear to be a difference in the two sectors, with respect to variables influencing the method in which each deals with conflict (Personal Communication, October 9, 2000).

For example, it can be argued that the public sector has availability of unique mechanisms to help deal with dispute resolution processes. Two examples of public sector resources would be unlimited tax dollars and protective tools such as sovereign immunity. Proponents of the private sector, on the other hand, can argue that the imposition of fewer restrictions and more flexibility in the dispute decision process help 
to make it far more palatable to deal with dispute and conflict management issues. What this all appears to suggest is that just as the degree of responsibility in terms of size and numbers differs with public versus private, so do other variables influence how each sector must deal with conflict.

Dr. John B. Stephens of the Institute of Local Government, University of North Carolina at Chapel Hill, speaking at an Ohio Conflict training seminar agrees that there is a difference in how the public sector and the private sector must deal with conflict. According to Stephens, the stakeholders in a private sector mediation setting are typically "clearly defined" while in the public sector this variable is often unclear and not well organized. Likewise, he believes that the representatives of private sector mediation are usually clear: an attorney representing a client. Public sector representatives, on the other hand, are usually not as easily defined due to the various different levels of government and the very nature of bureaucracy. Another area Stephens believes that separates the two sectors involves the "rules of engagement." While the private sector process is set by a court of law, the public sector must negotiate for each individual situation which, according to Stephens, requires alternate ways of resolving conflict issues (Personal Communication, April 11, 2000).

Just as the stakeholders, representatives, and rules of engagement differ between the two sectors, Stephens believes the options and manner in which conflicts are resolved differ. He believes the options for the private sector are "few or none: reach a settlement or continue litigation" (John Stephens, Personal Communication, April 11, 2000). Whereas the public sector, according to Stephens, has a "broad range" of alternative ways 
of resolving conflict. These include political action, media attention, and administrative procedures.

Yet, other areas differing in the public versus private mediation process deal with issues regarding the rules for sharing information and getting parties to the table. On the matter of getting parties to the table, according to Stephens (Personal Communication, April 11, 2000), it is in the private sector, a ruutine process set by law. Conversely, the public sector has no routine process and most often requires advanced contact by the mediator to even be able to begin mediation. On the matter of issues and sharing in the private sector, according to Stephens, relevant evidence regarding the rules of sharing is set by law, namely by process of discovery. While in the public sector, he believes there is a far broader range of issues that can be raised, and there is no requirement to share information between the parties. Therefore, even if public sector officials are able to get parties to the table, there is no guarantee that information will be processed.

One major problem faced in the public sector is the lack of confidentiality regarding the mediation process. This is primarily due to the fact that public sector activities are for the most part subject to open meeting requirements as well as to media reporting. To further complicate the process, even if public sector parties are able to reach agreement, public sector agreements are generally non-binding, according to Stephens (Personal Communication, April 11, 2000), and must be implemented through subsequent policy or administrative action. For example, a legislative body such as a city council, a board of commissioners, or a state legislative body (such as a state house of representatives or state senate) usually requires ratification. 
So is there a difference between private and public sector mediation processes? To answer this question would require a separate dissertation. But it very much does appear that private sector mediation settings are far more structured, having more clearly defined processes. Further, those public sector mediation processes are subject to far greater challenges that can place a mediation issue at risk of failure. All of this discussion leads into yet another question about multi-sector approaches. What happens when private sector and public sector become collaborative partners in problem solving?

Arthur Himmelman (1994) in part answers the question in Communities Working Collaboratively for a Change. He writes that collaborative partners share responsibilities for tasks, large and small, that must be accomplished. He points to the example of credibility with and access to neighborhood residents which ought to be as important as, if not more important than, financial contributions (p. 28). What he is suggesting is that in true collaborative mediation no one single organization can take credit for accomplishments. Even in the best of multi-sector collaborative situations, Himmelman points out that many challenges will be encountered. He, therefore, believes of particular importance in these situations is the way people view and treat each other. Thus, does this imply, given the most optimum of conditions, that there is a propensity for mediation not to be successful? If indeed that is the case, then why should we even try?

\section{Why Mediate?}

There are an abundance of reasons why mediation is a reasonable approach for disputing parties. Among these include the fact that mediation is a confidential, voluntary opportunity to reach an acceptable self-structured agreement. Another good reason for considering mediation is the time and cost factor. According to Ohio 
Commission on Dispute Resolution and Conflict Management data, mediation cases frequently are settled in a single meeting, often in as little as 2 hours. Even more impressive is the statistic that the success rate for mediated cases tends to run at $90 \%$. Perhaps more importantly, mediation provides the opportunity for conflicting parties to rekindle once-healthy relationships.

Jim Prosser, Manager of the City of Richfield (2000), believes there is a strong need for mediation because it is more than a "tool to resolve conflict." Rather, he believes it is a philosophy, which says many people can find solutions to their own problems without government intervention. "It empowers rather than regulates" (Personal Communication, March 8, 2000). The Honorable Victor Pontious, Judge, Fayette County Ohio Court of Common Pleas and trained mediator, agrees with Prosser.

Conflicts continually arise in the course of day to day business in local government environments. We therefore encourage parties to talk and have court appointed mediators. For the most part it has been largely successful when we can get them to talk. Yet we realize that there are cases that cannot be resolved through mediation and therefore must be tried. (Personal Communication, March $8,2000)$

Geauga County Commissioner, Neil Hofstetter, a trained mediator, agrees with Pontious that mediation is a good alternative. According to Hofstetter, mediation can help provide a certain level of maturity to the dispute process, help to identify the issues, and increase knowledge of participants, giving a deeper understanding of the problem (Personal Communication, March 8, 2000).

Perhaps the real key as to why we should mediate is, as participants, we can share a wealth of valuable information while opening the situation and ourselves to looking at other creative resolutions. According to Lewis, when we choose mediation, we are not forfeiting our right, or acquiescing to others our power to determine an outcome. Rather, 
we actually open opportunities, which might very well have a long-term positive influence on our organization or agency. In doing so we can disclose our interests in a way that can generate options that might meet the needs of all of the stakeholders. Most importantly we can make concerted efforts to work out our differences in the hope of avoiding costly litigation and living in an environment of peaceful coexistence (Personal Communication, September 5, 2000).

Richard Altman, a mediation coordinator for a pro-mediation project sponsored by a grant through the Ohio Supreme Court involving the Ohio Counties of Defiance, Henry, and Fulton, agrees with Lewis. Altman, a certified mediator and licensed attorney, has taken 150 hours of mediation training and has mediated some 750 cases between 1997 and 1999. To the question why mediate, Altman points to the following scenario which occurred on December 10,1999, in Defiance County involving a dispute between an architect and a client as the "perfect example":

A couple contracted with an architect and contractor to build a house for them. The construction estimate provided by the architect was $\$ 135,000$. The actual cost of construction came to a whopping $\$ 155,000$. The couple made arrangements to litigate against the contractor. However, rather than go to court, the couple agreed to mediate the issue. Ultimately, it was discovered that the architect made an error in drawing up the plans, while at the same time the contractor did not build exactly to the specifications provided by the architect. As a result, the contractor and architect agreed to absorb the overrun on construction cost.

Altman believes that such a situation in the past would have been litigated with a judge determining the outcome. In this case, the couple was made whole without having to spend $\$ 10,000$ to $\$ 15,000$ for costly litigation because they chose to rediate. (Personal Communication, October ! 8, 2000)

Altman's philosophy on why one should mediate is really quite basic: "It can't

hurt." His reasoning is that "it is a prime opportunity for parties to talk and anytime you get people talking there is a possibility they are going to reach a resolution." He also 
believes mediation empowers people and cites the following: "If you do much domestic mediation at all, you will see the weakest person suddenly be able to say, I need to stand up and make decisions for myself' (Personal Communication, October 18, 2000).

Given the propensity of increased competition and sophistication facing local government managers, intergovernmental mediation strategies may be more important than ever. The review of the literature indicates that the topic of intergovernmental mediation as an effective tool in local government partnerships has been the subject of minimal research. Some researchers say leadership is the key to successful mediation outcomes. Other researchers say education is the key to success. Still others say there are no proven variables, which will help ensure mediation to be a positive influence in intergovernmental relations. While many states have made concerted efforts to establish conflict resolution programs, there appears to be little doubt that many local governments are not aware of these opportunities. Furthermore, as our world becomes more sophisticated and these local governments continue to face increasing competition due to non-funded federal and state mandates, the need for conflict dispute resolution is more important than ever. 


\section{CHAPTER III}

\section{METHODOLOGY}

This study was designed to answer the following questions regarding intergovernmental mediation as a technique for successful local government partnerships:

1. What is the level of experience in the intergovernmental mediation process as perceived by county commissioners, township trustees, appointed administrators, and citizens at large in Ohio?

2. What is the level of understanding of intergovernmental mediation that is perceived by county commissioners, township trustees, and appointed administrators and citizens at large in Ohio?

3. What is the relationship between intergovernmental mediation and successful local government partnerships as perceived by county commissioners, township trustees, appointed administrators, and citizens at large?

4. What are the types of variables that create conflict between and among neighboring units of local government?

5. What types of public sector mechanisms are presently available for local government officials? Do Defiance County local units of government practice intergovernmental mediation? If so, what have been the outcomes in terms of economic development and partnership agreements? 


\section{Research Design}

In an effort to effectively answer these questions, a survey and interviews were conducted with elected and appointed officials and with citizens at large throughout Ohio. In addition, telephone interviews were conducted with selected experts from other states. To answer questions about Defiance County this study utilized a 6-month case study involving Defiance County, Ohio, units of local government. The case study included focus group discussions, document review, and interviews.

A case study appears to be a perfectly legitimate form of research in this instance, as it permits an in-depth study of the Defiance County phenomenon in its natural context from the perspective of the participants. Case studies do have a number of distinct advantages. Among these are their emergent quality and the ability of the researcher to modify the case. Gall, Borg, and Gall (1996) support the value of utilizing a case study in this instance in their writings on approaches to qualitative research. "The case study researcher, through a process of thick description, can bring a case to life in a way that is not possible using the statistical methods of quantitative research" (Gall et al., 1996, pp. 584-585).

Merriam (1998) supports this position in her writings and states, "Case studies afford the reader the vicarious experience of having been there" (p. 238).

Donmoyer (as cited in Merriam, 1998) expands on this notion by saying that "case studies can take us to places where most of us would not have an opportunity to go" (p. 238). Therefore, case studies allow us to experience situations and settings that

we would not normally have access to; all of which can be done without being placed in a threatening environment as opposed to the potential of real life experiences. Donmoyer 
(1998) believes this possibility for sense of security can be a positive factor in promoting the willingness to learn.

There can also be certain disadvantages to using the qualitative case study approach; for example, failure of the writer to adequately provide a vivid narrative to the reader of the situation. As a result, the reader may not adequately be transported into the intended setting. A second disadvantage might be the difficulty of generalizing the findings to other situations. Because circumstances and variables influence outcomes, it may be difficult to align one case study to other similar situations. Nevertheless, the combination of a case study coupled with the use of an interviewing technique will provide a snapshot of the process of a highly qualitative methodological approach. Lincoln and Guba said (as cited in Gall et al., 1996, p. 295) reality is "a multiple set of mental constructions made by humans; their constructions are on their minds, and are in the main, accessible to the humans who make them." And because human beings are the primary instrument of data collection and analysis in qualitative research, interpretations of reality are accessed directly through their observations and interviews. "We are thus closer to reality than if a data collection instrument has been interjected between us and the participants" (p. 295).

\section{Sample Population}

The target population for this study consisted of three basic groups, each of which could possibly be considered in a position to be exposed to intergovernmental issues. These are elected officials and appointed public administrators. The rationale for selecting these sample groups is based on the fact that they are likely to deal with various divisions of neighboring units of government in the performance of their public duties. 
Special care was taken to help ensure that results of the study can be generalized as much as possible from the sample populations that participated. One way in which this was accomplished was by ensuring that all participants share the same understanding of the topic being considered. A second method to help ensure validity in this study was accomplished by keeping the process as highly structured as possible.

\section{The Rationale for Using Interviews}

The rational for using interviews to gather data was, in part, a personal preference. The opportunity to visit with city and township officials to discuss their personal experience offers the prospect for adding yet another perspective to this study. The point of view of local elected and appointed officials being faced with competition and conflict in the process of managing their respective areas of jurisdiction offers "real life experiences" as opposed to only theory. Perhaps of greater importance is the desire to not restrict the study by failing to consider in depth the profound influence of practitioners involved $\mathrm{n}$ the Defiance County joint economic development experience. Jon and Lyn Lofland (1984) remind their readers that "the intensive interview seeks to discover the informant's experience of a particular topic or situation" (p. 12). A second reason for selecting the interview option is that it will provide an opportunity to collect data that are not directly observable. This method fits particularly well in this case as a portion of the study revolves around the attitudes and experiences of the selected populations. Finally, the interview option was selected because it will provide the opportunity for respondents to speak in their own words and express their own thoughts without the influence of potential "suggestive" written questions as might be found in reading a questionnaire. 


\section{Interview Procedure}

According to Patton (1990) there are three basic methods of collecting qualitative data through the interview process. These are:

1. The informal conversational interviews

2. The general interview guide approach

3. The standardized open-ended interview.

The informal conversational interview, according to Gall et al. (1996), is carried out in such a conversational manner that often the respondent does not realize that he or she is being interviewed. The general interview guide approach is far less structured in that the topics explored, the order of questions, and the wordings are not predetermined (p. 309). The standard open-ended interview "involves a predetermined sequence and wording of the same set of questions to be asked each respondent in order to minimize the possibility of bias" (p. 310).

Consideration was given to the idea of employing a group interview involving all of the selected population. This method, also known as a focus group, according to Richard Krueger (1996), provides for "a careful planned discussion designed to obtain perceptions on a defined area of interest in a permissive non-threatening environment" (pp. 307-308). The decision was not to use this type of approach because of the concern for the influence of preexisting relationships between and among the selected respondents.

The method that was utilized in this study is the general interview guide approach. The process involves surveying a set of topics to be examined. The order of questions, the wording, and topics were presented to each participant in a consistent manner. Once 
again, this method was employed to avoid the appearance of bias in the interview process.

The interviews were conducted in a one-on-one, face-to-face meeting. Each participant was contacted in person 1 month in advance of the respective interview. Two weeks prior to each interview, participants were contacted by telephone to confirm the date, location, and time of the upcoming interview. A total of three interviews were conducted with elected and appointed local government officials, all of whom participated in the Defiance County experience. The interviewees included the Defiance City Law Director, the Defiance City Administrator, and a Noble Township Trustee. The rationale for selecting these individuals was twofold: (1) to gather genuine firsthand personal accounts from the individuals actually involved in the Defiance County intergovernmental process, and (2) to evaluate and access the responses of these local government officials in relation to information found in existing literature.

\section{The Interviews}

At the beginning of each interview the participants were given an explanation of the study and advised why they had been selected. Each person was given the option of remaining anonymous if indeed that was his or her desire.

The subject areas that were examined in the interview process included the participants' previous intergovernmental mediation experiences and their perception of the Defiance County intergovernmental process.

\section{Interview Questions}

1. Do you believe Defiance County local units of government are faced with intergovernmental conflict issues? If so, why? 
2. Does conflict affect the ability of local government cooperation in Defiance County? If so, how?

3. Are their incentive programs or mechanisms that you feel might aid in reducing the levels or degree of conflict incidence? If so, what are some examples?

4. Based on your participation do you believe the Defiance County mediation process effectively addressed the issues at hand? If so, why or why not?

5. Who, if anyone, would take the lead in conflict resolution processes among units of local government in Defiance County? Why or why not?

6. Is there anything in your opinion that can be done in the future to influence cooperation between Defiance County units of local government? If so, what?

7. Given your personal philosophy, experience, and participation in the Defiance County intergovernmental process, what if anything would you have done differently? Why?

8. What if anything might you recommend as future considerations to reduce intergovernmental tensions in Defiance County?

A second method of data collection was achieved through the use of a survey. The purpose of this survey was to use a questionnaire or to collect data from a sample of participants about their characteristics, experiences, and opinions in order to make the results more generalized among the intended population.

Careful consideration was also given to the construction of the questionnaire. According to Gall et al. (1996) there are eight major steps in designing a questionnaire. These include: defining research objectives, selecting a sample, designing the format, pre-testing the questionnaire, pre-contacting the sample, writing a cover letter, and 
distributing the questionnaire following up on non-respondents and analyzing the questionnaire. All of the above steps were followed with the exception of the cover letter and mailing out the questionnaire. This is due to the fact that all contacts were prearranged by telephone or by a personal one-on-one visit. However, each participant was presented with an introductory letter explaining the study at the time of the one-onone meeting.

Pre-questionnaire phone interviews were conducted with 25 elected County officials from throughout the state of Ohio. Individuals were asked to state in their own words what they believed to be the meaning of each question. Another method to help ensure optimum effectiveness was achieved by soliciting constructive criticism of the questionnaire from participant respondents.

The purpose of this questionnaire was to seek out the degree of understanding by elected officials, citizens, and government administrators with respect to intergovernmental mediation. The questions were designed to measure individual perception of the effectiveness of employing intergovernmental mediation, the degree of experience, and the outcome of those experiences with respect to the intergovernmental mediation process. Participants were selected randomly without consideration of political affiliation, county size, or population. All eligible participants had an equal and independent chance of being selected.

All respondents were invited to respond to issues based on their perceived intergovernmental mediation experience. A copy of this questionnaire and related demographic information is found in appendix $\mathrm{A}$. 


\section{Document Review}

A third method utilized teward achieving a valid construct involved the study of certain documents. According to Gall et al. (1996), “qualitative researchers often study written communications found in natural settings" (p. 361). Examples of documents could be personal letters, written communications, committee reports, and newspaper articles. One disadvantage to documents is that the text cannot always be interpreted consistently and equally by readers. Rather, the meaning or level of interpretation can change from one historical period to another (Gall et al., 1996). Nevertheless the study of documents can be quite valuable to a qualitative study. In collaboration with the interviews in this study, a rather substantial document review was employed. The documents reviewed included minutes of intergovernmental meeting discussions between the city of Defiance and Noble township covering the period of 1998-1999, minutes of intergovernmental committee meetings, local newspaper articles, City Council meeting minutes, County Commissioner meeting minutes, as well as letters from local elected officials. Other documents that were considered and reviewed included newspaper articles from the Defiance Crescent News, correspondence from the mayor to the Board of Commissioners, from the mayor to the Noble Township trustees, and from the Noble Township trustees to the Board of Commissioners. Information gleaned from the documents was utilized to supplement interview findings. Documents were reviewed and studied for the purpose of examining the chronological sequence of events. The data collected helped to provide descriptive information as well as a better understanding of the development of the intergovernmental process studied. 


\section{Procedure and Disclaimer}

As previously pointed out, data for this study were collected from interviews, questionnaires, and a case study of Defiance County. A considerable number of the individual participants in this study hold membership in the County Commissioners Association of Ohio. Information such as names, addresses, and telephone numbers was obtained through the County Commissioners Association of Ohio files. The actual time associated with collecting the data was a period of 5 months. Finally, having been an elected official for the past 18 years in Defiance County, being responsible for establishing the intergovernmental joint economic development talks, concern for potential bias was always legitimate. It should be noted that every care was taken to collect data and monitor responses with honesty and fairness. As a final note, extra caution was taken in the questionnaire, interview, and case study sections of the study in an effort to ensure that the process met all standards of validity and reliability as other data collection research by other researchers.

\section{Analysis}

In order to compare the responses of elected county, municipal, township officials and public managers the analysis of data collected was done at the individual level. One of the benefits to utilizing this method was being able to analyze data at each level in an effort toward better understanding of viewpoints of selected categories. The goal in employing this approach was to better understand the local government influence or lack thereof, associated with intergovernmental mediation practices. The question of the day then became, Is it possible to determine whether an official's attitude regarding intergovernmental mediation is influenced by virtue of the level of government being 
served? Is there any difference in the level of understanding and experience with intergovernmental mediation between county commissioners and township trustees? Moreover, do these attitudes differ from the attitudes of appointed public managers? 


\title{
CHAPTER IV
}

\begin{abstract}
ANALYSIS OF DATA
The research questions in chapter 1 are intended to investigate the relationship between local governmental organizations in terms of intergovernmental mediation, conflict resolution, and the sharing of revenues and resources. The second reason is to examine the Defiance County government's intergovernmental mediation practices, seek out the level of understanding of intergovernmental conflict, and the methods of addressing it by local elected officials. More specifically, research questions 1 through 5 are intended to determine the level of understanding and experience of elected and appointed officials in the state of Ohio. The intent of the case study is to determine the implication of intergovernmental mediation when practiced by local government elected and appointed officials in Defiance County. This chapter presents the data findings obtained from parts of the survey and case study.
\end{abstract}

\section{General Characteristics of the Sample}

Pre-questionnaire telephone interviews were conducted with selected elected county officials from throughout the state of Ohio. Arrangements were made to personally meet with each individual to be interviewed. The survey instrument entitled "Intergovernmental Mediation" was provided to individuals meeting the following criteria: an individual must (presently) hold the elected position of either county 
commissioner or township trustee in the state of Ohio. County commissioners were selected from a master list made available by the County Commissioners Association of Ohio. Township trustees were selected from a 1998 master list made available by the Defiance County Commissioners Office. The 15 citizens at large had to meet the criteria of living in Defiance County and being a registered voter with the Defiance County Board of Elections. It was necessary for appointed administrators to be active practitioners with a local unit of government at the city, township, or village level.

Individuals were provided with personal data regarding the researcher including telephone numbers and an email address. This information was provided to participants, desiring to contact the researcher, in the event there be the need for follow-up communication, with regard to the survey.

Table 1 provides information about those who participated in the study. One hundred thirty-two surveys were distributed. One hundred and one surveys were returned. Of this number returned, the position with the highest rate was the township trustees $(90 \%)$

The second highest rate of return came from the County Commissioners. This high rate of response by County Commissioners could be due to the fact that many boards of commissioners have one or more clerks to assist with clerical duties such as returning completed questionnaires. The low response rate by citizens might suggest a lack of interest in intergovernmental mediation. It is also possible to interpret the low response rate by citizens to a lack of knowledge and understanding of intergovernmental issues. Nevertheless, a questionnaire return of approximately $77 \%$ is a perfectly 
legitimate response rate, and if considered properly lends creditability to the overall process.

TABLE 1

POSITIONS OF RESPONDENTS

Position

County Commissioners

Township Trustees

Appointed Administrators

Citizens At Large

Total
Surveys Distributed Number Returned_Percentage

42

35

83.33

40

36

90.00

25

15

60.00

25

15

60.00

132

According to the information in Table 2, 94\% of the respondents were White, $3 \%$ were Black, and 3\% were of Hispanic and other origins. The majority of the respondents were male. Sixty-eight percent of respondents were registered Republicans, while the remaining $32 \%$ were registered Democrats and a few Independents.

Table 3 gives a summary of number of years in elected office for commissioners and township trustees. The majority of these elected officials had served anywhere from $1-15$ years (66\%) with over $25 \%$ of them having served more than 10 years. As previously reported, the target population from which the sample was selected was chosen because of the perceived availability of desired information. Although the sample size for each category was intended to be consistent, it was necessary to screen and exclude respondents answering no to question 1. Therefore, statistical data from 
questions 2 through 14 are derived exclusively from those respondents answering yes to question 1 . These consist of 35 county commissioners, 36 township trustees, 15 appointed administrators, and 15 citizens at large.

TABLE 2

SUMMARY OF PERSONAL DEMOGRAPHICS FOR RESPONDENTS

\begin{tabular}{lcc}
\hline Demographic & Number & Percentage \\
\hline & Gender & \\
Male & 84 & 83.16 \\
Female & 17 & 16.84 \\
\hline & Race & \\
Black & 3 & 2.97 \\
White & 95 & 94.06 \\
Other & 3 & 2.97 \\
\hline & & \\
& Political Affiliation & 68.32 \\
Republican & & 27.72 \\
Democrat & 69 & 3.96 \\
Independent & 28 & \\
\hline
\end{tabular}

Research Question 1: What is the level of experience in the intergovernmental mediation process as perceived by county commissioners, township trustees, appointed administrators, and citizens at large in Ohio? The first question of the survey was designed to answer res zarch question 1. The results from the respondents are found in Table 4. 
TABLE 3

SUMMARY OF YEARS IN ELECTED OFFICE

\begin{tabular}{lccccccc}
\hline & \multicolumn{7}{c}{ Years } \\
\cline { 2 - 7 } Office Holder & Less than 1 & $\mathbf{1 - 5}$ & $\mathbf{1 0 - 1 4}$ & $\mathbf{1 1 - 1 5}$ & $\mathbf{1 6 - 2 5}$ & Over 25 \\
\hline County Commissioners & 4 & 21 & 4 & 2 & 4 & 0 \\
Township Trustees & 3 & 4 & 8 & 10 & 5 & 5 \\
\hline
\end{tabular}

TABLE 4

DIRECT EXPERIENCE WITH INTERGOVERNMENTAL MEDIATION

\begin{tabular}{lcccccccc}
\hline & \multicolumn{7}{c}{ Responses to Question 1 } \\
\cline { 2 - 8 } Respondent & Total & Yes & $\%$ & No & $\%$ & No Opinion & \% \\
\hline County Commissioners & 35 & 19 & 54.29 & 16 & 45.75 & 0 & 0.00 \\
Township Trustees & 36 & 2 & 5.56 & 34 & 94.44 & 0 & 0.00 \\
Appointed Administrators & 15 & 10 & 66.67 & 5 & 33.33 & 0 & 0.00 \\
Citizens At Large & 15 & 1 & 6.67 & 14 & 93.33 & 0 & 0.00 \\
Total & $\mathbf{1 0 1}$ & $\mathbf{3 2}$ & $\mathbf{3 1 . 6 8}$ & $\mathbf{6 9}$ & $\mathbf{6 8 . 3 2}$ & $\mathbf{0}$ & $\mathbf{0 . 0 0}$ \\
\hline
\end{tabular}

Of a total of 101 returned questionnaires, 69 respondents $(68.32 \%)$ answered no to the question of having any direct experience as a mediator, observer, or party in intergovernmental mediation. Of the 35 county commissioners returning questionnaires, $45.75 \%$ or 16 answered no. A surprising $94.44 \%$ of the 36 township trustees answered no to the question, while 5 of 15 appointed administrators or $33.33 \%$ responded no. A 
not so surprising $93.3 \%$ of the citizens at large, or 14 out of 15 , responded no to the question. Censequently, the level of participants having intergovernmental experience is quite low. Only $31.68 \%$ of the respondents had any direct experience with actual intergovernmental mediation. Of the $31.68 \%$ who had experience ( 19 commissioners, 2 trustees, 10 appointed administrators, and 1 citizen) answering yes to question 1 responded to the remainder of the questions on the survey.

Research Question 2: What is the level of understanding of intergovernmental mediation that is perceived by county commissioners, township trustees, appointed administrators, and citizens at large in Ohio? Survey questions $2,3,4,5,6,7,8,9,10$, and 11 were designed to answer research question 2 . These questions focus on understanding the mediation process.

Table 5 reflects mediation participant's ability to identify interest of opposing disputing party. Survey question 2 focused on the issue of being able to identify the interest of disputing parties. Participants answering yes to this question believe that interests are clearly indefinable. The results of question 2 are found in Table 5. An overwhelming response rate of $87.50 \%$ of all groups combined responded yes to this question. This could suggest that parties entering into dispute resolution often believe they have a clear understanding of the interest of other stakeholders. One respondent pointed out that the interest of people involved "was somewhat clear, but some investigation had to be done to find the hidden agendas." 
TABLE 5

IDENTIFYING INTERESTS

\begin{tabular}{lcccccccr}
\hline & \multicolumn{7}{c}{ Responses to Question 2 } \\
\cline { 2 - 8 } Respondent & Total & Yes & $\%$ & No & $\%$ & No Opinion & $\%$ \\
\hline County Commissioners & 19 & 17 & 89.47 & 1 & 5.26 & 1 & 5.26 \\
Township Trustees & 2 & 2 & 100.00 & 0 & 0.00 & 0 & 0.00 \\
Appointed Administrators & 10 & 8 & 80.00 & 1 & 10.00 & 1 & 10.00 \\
Citizens At Large & 1 & 1 & 100.00 & 0 & 0.00 & 0 & 0.00 \\
Total & $\mathbf{3 2}$ & $\mathbf{2 8}$ & $\mathbf{8 7 . 5 0}$ & $\mathbf{2}$ & $\mathbf{6 . 2 5}$ & $\mathbf{0}$ & $\mathbf{0 . 0 0}$ \\
\hline
\end{tabular}

Table 6 provides information regarding dealing with people in authority in the mediation process. Survey question 3 focused on the issue of participants having the authority to make decisions to resolve the conflict or dispute. One administrator pointed out that the authority "was in the hands of the county commissioners and therefore, made it difficult to negotiate a resolution at the table. Further, the other side recognized it and appeared somewhat hesitant in the process."

Table 7 addresses the questions of participants possessing adequate knowledge and information to resolve a conflict or issue. 
TABLE 6

DEALING WITH THE APPROPRIATE PEOPLE

\section{Responses to Question 3}

\begin{tabular}{lccccccc}
\cline { 2 - 7 } Respondent & Total & Yes & $\%$ & No & $\%$ & No Opinion & $\%$ \\
\hline County Commissioners & 19 & 12 & 63.16 & 4 & 21.05 & 3 & 15.79 \\
Township Trustees & 2 & 1 & 50.00 & 1 & 50.00 & 0 & 0.00 \\
Appointed Administrators & 10 & 9 & 90.00 & 0 & 0.00 & 1 & 10.00 \\
Citizens At Large & 1 & 0 & 0.00 & 1 & 100.00 & 0 & 0.00 \\
Total & $\mathbf{3 2}$ & $\mathbf{2 2}$ & $\mathbf{6 8 . 7 5}$ & $\mathbf{6}$ & $\mathbf{1 8 . 7 5}$ & $\mathbf{4}$ & $\mathbf{1 2 . 5 0}$ \\
\hline
\end{tabular}

TABLE 7

ADEQUATE KNOWLEDGE AND INFORMATION

\begin{tabular}{lccccccrr}
\hline & \multicolumn{7}{c}{ Responses to Question 4 } \\
\cline { 2 - 8 } Respondent & Total & Yes & $\%$ & No & $\%$ & No Opinion & \% \\
\hline County Commissioners & 19 & 16 & 84.21 & 1 & 5.26 & 2 & 10.53 \\
Township Trustees & 2 & 1 & 50.00 & 1 & 50.00 & 0 & 0.00 \\
Appointed Administrators & 10 & 7 & 70.00 & 2 & 20.00 & 1 & 10.00 \\
Citizens At Large & 1 & 1 & 100.00 & 0 & 0.00 & 0 & 0.00 \\
Total & $\mathbf{3 2}$ & $\mathbf{2 5}$ & $\mathbf{7 8 . 1 3}$ & $\mathbf{4}$ & $\mathbf{1 2 . 5 0}$ & $\mathbf{3}$ & $\mathbf{9 . 3 8}$ \\
\hline
\end{tabular}

Seventy-eight percent of all respondents reported their experience to be that opposing stakeholders possessed the knowledge and/or information to address the issue. 
One dissenting commissioner reported, "The mediator was ill informed and a bit onesided, but it worked out later." Another commissioner reported that the opposing party "had the knowledge, but not the willingness."

Table 8 reflects respondents answers when asked the question, Was their mediation a mandated or voluntary process? An overwhelming $76.05 \%$ reported that the mediation process was voluntary in nature. This lends support to the concept that mediation is generally voluntary in nature. One respondent reported that his mediation experience was court mandated. Further investigation exposed the process as being a court-ordered arbitration process.

Table 9 provides data regarding the concept of mediation allowing parties to maintain control over the outcome of an issue or situation. This question focused on the issue of mediation being an instrument by which parties can cooperatively address dispute resolution. The $94.86 \%$ response rate lends support to widespread belief that mediation empowers parties to create acceptable solutions to conflict.

Table 10 reflects the cost effectiveness of mediation as a tool in addressing conflicts and disputes. 
TABLE 8

VOLUNTARY MEDIATION VERSUS REQUIRED MEDIATION

\begin{tabular}{lcccccccc}
\hline & \multicolumn{7}{c}{ Responses to Question 5 } \\
\cline { 2 - 8 } Respondents & Total & Yes & $\%$ & No & $\%$ & No Opinion & $\%$ \\
\hline & 19 & 16 & 84.21 & 2 & 10.53 & 1 & 5.26 \\
County Commissioners & 19 & 2 & 100.00 & 0 & 0.00 & 0 & 0.00 \\
Township Trustees & 2 & 10 & 90.00 & 0 & 0.00 & 1 & 10.00 \\
Appointed Administrator & 10 & 1 & 0 & 0.00 & 1 & 100.00 & 0 & 0.00 \\
Citizens At Large & 10 & & & & & & & \\
Total & $\mathbf{3 2}$ & $\mathbf{2 7}$ & $\mathbf{7 6 . 0 5}$ & $\mathbf{3}$ & $\mathbf{9 . 3 8}$ & $\mathbf{2}$ & $\mathbf{6 . 2 5}$ \\
\hline
\end{tabular}

TABLE 9

MANAGING THE MEDIATION PROCESS

\begin{tabular}{lcccccccr}
\hline & \multicolumn{7}{c}{ Responses to Question 6 } \\
\cline { 2 - 8 } Respondent & Total & Yes & $\%$ & No & $\%$ & No Opinion & $\%$ \\
\hline County Commissioners & 19 & 13 & 68.42 & 2 & 10.53 & 4 & 21.05 \\
Township Trustees & 2 & 2 & 100.00 & 0 & 0.00 & 0 & 0.00 \\
Appointed Administrators & 10 & 9 & 90.00 & 0 & 0.00 & 1 & 10.00 \\
Citizens At Large & 1 & 1 & 100.00 & 0 & 0.00 & 0 & 0.00 \\
Total & $\mathbf{3 2}$ & $\mathbf{2 5}$ & $\mathbf{9 4 . 8 6}$ & $\mathbf{2}$ & $\mathbf{6 . 2 5}$ & $\mathbf{5}$ & $\mathbf{1 5 . 6 3}$ \\
\hline
\end{tabular}


TABLE 10

\section{COST OF MEDIATION PROCESS}

\section{Responses to Question 7}

\begin{tabular}{lccccccc}
\cline { 2 - 7 } Respondent & Total & Yes & $\%$ & No & $\%$ & No Opinion & $\%$ \\
\hline County Commissioners & 19 & 17 & 89.47 & 1 & 5.26 & 1 & 5.26 \\
Township Trustees & 2 & 2 & 100.00 & 0 & 0.00 & 0 & 0.00 \\
Appointed Administrators & 10 & 9 & 90.00 & 0 & 0.00 & 1 & 10.00 \\
Citizens At Large & 1 & 1 & 100.00 & 0 & 0.00 & 0 & 0.00 \\
Total & $\mathbf{3 2}$ & $\mathbf{2 9}$ & $\mathbf{9 0 . 6 3}$ & $\mathbf{1}$ & $\mathbf{3 . 1 3}$ & $\mathbf{2}$ & $\mathbf{6 . 2 5}$ \\
\hline
\end{tabular}

Unlike some final and binding arbitration processes, which often require the unsuccessful party to pay the entire cost of the process, mediation usually calls for a sharing of cost. Parties utilizing state agencies such as the Ohio Office of Conflict and Dispute Resolution generally have only the cost of travel expenses for the individual doing the mediation. The respondents' reaction to this question supports the theory that mediation can usually be a relatively inexpensive method of addressing conflict issues.

Table 11 deals with the issue of timelines when utilizing mediation to address conflict issues. The focus of this question is to determine whether the mediation experience was conducted in a timely manner. A total of $90.63 \%$ of all respondents reported that their mediation experience was conducted in a timely manner. One administrator reported that the reason for the delay in his mediation was failure to establish a time line or flow chart. This could suggest the value of establishing an agenda and meeting schedule for the intended process. 
TABLE I

TIMELINESS OF MEDIATION PROCESS

\begin{tabular}{lcrrrrrrr}
\hline & \multicolumn{7}{c}{ Responses to Question 8 } \\
\cline { 2 - 8 } Respondent & Total & Yes & $\%$ & No & $\%$ & No Opinion & $\%$ \\
\hline County Commissioners & 19 & 17 & 89.47 & 1 & 5.26 & 1 & 5.26 \\
Township Trustees & 2 & 2 & 100.00 & 0 & 0.00 & 0 & 0.00 \\
Appointed Administrators & 10 & 9 & 90.00 & 0 & 0.00 & 1 & 10.00 \\
Citizens At Large & 1 & 1 & 100.00 & 0 & 0.00 & 0 & 0.00 \\
Total & $\mathbf{3 2}$ & $\mathbf{2 9}$ & $\mathbf{9 0 . 6 3}$ & $\mathbf{1}$ & $\mathbf{3 . 1 3}$ & $\mathbf{2}$ & $\mathbf{6 . 2 5}$ \\
\hline
\end{tabular}

Table 12 addresses question 9 which asked, Was the conflict issue or situation 'ripe' to be addressed in the mediation process? The purpose of question 9 was to extract whether individuals were aware of the need for mediation in their respective situation. An impressive $87.50 \%$ recognized that the need for addressing certain aspects of concern existed.

Tables 13 and 14 deal with the issue of being able to remove personalities from the actual alternate dispute resolution process. As noted in Table $13,53.12 \%$ of the respondents felt they were able to separate the people from the problem while in Table $14,62.50 \%$ of the respondents felt that personalities did not get in the way of achieving a satisfactory result. Th.se findings might very well support the value of utilizing a thirdparty neutral in the mediation process, an "outsider" having no preconceived notion or bias regarding participating individuals. 
TABLE 12

ORGANIZATION OF THE ISSUE

\begin{tabular}{lcccccccc}
\hline & \multicolumn{7}{c}{ Responses to Question 9 } \\
\cline { 2 - 8 } Respondent & Total & Yes & $\%$ & No & $\%$ & No Opinion & $\%$ \\
\hline County Commissioners & 19 & 17 & 89.47 & 1 & 5.26 & 1 & 5.26 \\
Township Trustees & 2 & 2 & 100.00 & 0 & 0.00 & 0 & 0.00 \\
Appointed Administrators & 10 & 8 & 80.00 & 1 & 10.00 & 1 & 10.00 \\
Citizens At Large & 1 & 1 & 100.00 & 0 & 0.00 & 0 & 0.00 \\
Total & $\mathbf{3 2}$ & $\mathbf{2 8}$ & $\mathbf{8 7 . 5 0}$ & $\mathbf{2}$ & $\mathbf{6 . 2 5}$ & $\mathbf{2}$ & $\mathbf{6 . 2 5}$ \\
\hline
\end{tabular}

TABLE 13

SEPARATING THE PEOPLE FROM THE PROBLEM

\begin{tabular}{lcccccccc}
\hline & \multicolumn{7}{c}{ Responses to Question 10 } \\
\cline { 2 - 8 } Respondent & Total & Yes & $\%$ & No & $\%$ & No Opinion & $\%$ \\
\hline County Commissioners & 19 & 12 & 63.16 & 4 & 21.05 & 3 & 15.79 \\
Township Trustees & 2 & 0 & 0.00 & 1 & 50.00 & 1 & 50.00 \\
Appointed Administrators & 10 & 4 & 40.00 & 4 & 40.00 & 2 & 20.00 \\
Citizens At Large & 1 & 1 & 100.00 & 0 & 0.00 & 0 & 0.00 \\
Total & $\mathbf{3 2}$ & $\mathbf{1 7}$ & $\mathbf{5 3 . 1 2}$ & $\mathbf{9}$ & $\mathbf{2 8 . 1 3}$ & $\mathbf{6}$ & $\mathbf{1 8 . 7 5}$ \\
\hline
\end{tabular}


TABLE 14

\section{PERSONALITIES}

\section{Responses to Question 10}

\begin{tabular}{lccccccc} 
Respondent & Total & Yes & $\%$ & No & $\%$ & No Opinion & $\%$ \\
\hline County Commissioners & 19 & 4 & 21.05 & 12 & 63.16 & 3 & 15.79 \\
Township Trustees & 2 & 1 & 50.00 & 0 & 0.00 & 1 & 50.00 \\
Appointed Administrators & 10 & 1 & 10.00 & 8 & 80.00 & 1 & 10.00 \\
Citizens At Large & 1 & 1 & 100.00 & 0 & 0.00 & 0 & 0.00 \\
Total & $\mathbf{3 2}$ & $\mathbf{7}$ & $\mathbf{2 1 . 8 7}$ & $\mathbf{2 0}$ & $\mathbf{6 2 . 5 0}$ & $\mathbf{5}$ & $\mathbf{1 5 . 6 3}$ \\
\hline
\end{tabular}

Table 15 addresses the issue of mediation in relation to dealing with units of local government.

TABLE 15

GOVERNMENT INFLUENCE

\begin{tabular}{lcccccccc}
\hline & \multicolumn{7}{c}{ Responses to Question 11 } \\
\cline { 2 - 8 } Respondent & Total & Yes & $\%$ & No & $\%$ & No Opinion & $\%$ \\
\hline County Commissioners & 19 & 7 & 36.64 & 5 & 26.32 & 7 & 36.84 \\
Township Trustees & 2 & 2 & 100.00 & 2 & 0.00 & 0 & 0.00 \\
Appointed Administrators & 10 & 4 & 40.00 & 4 & 40.00 & 2 & 20.00 \\
Citizens At Large & 1 & 1 & 100.00 & 0 & 0.00 & 0 & 0.00 \\
Total & $\mathbf{3 2}$ & $\mathbf{1 4}$ & $\mathbf{4 3 . 7 5}$ & $\mathbf{9}$ & $\mathbf{2 8 . 1 3}$ & $\mathbf{9}$ & $\mathbf{0 . 0 0}$ \\
\hline
\end{tabular}


Participants viere actually being asked for an evaluation of the process of mediation when dealing with units of local government. Respondents were somewhat mixed in their answers to this question. Although $43.75 \%$ felt that being a local government entity had influence, a nearly equal number disagreed or questioned the issue. One commissioner responded that "being in local government always makes processes more difficult." Nevertheless, the divided response rate seems to suggest that local government officials and citizens do not fully understand the variables facing units of local government with respect to conflict resolution.

Table 16 provides information of respondents to determine if mediation was a better option as opposed to litigation through the court system.

TABLE 16

VALUE OF MEDIATION

Responses to Question 12

\begin{tabular}{lccccccc}
\cline { 2 - 7 } Respondent & Total & Yes & $\%$ & No & $\%$ & No Opinion & $\%$ \\
\hline County Commissioners & 17 & 17 & 100.00 & 0 & 0.00 & 0 & 0.00 \\
Township Trustees & 2 & 1 & 50.00 & 1 & 50.00 & 0 & 0.00 \\
Appointed Administrators & 10 & 8 & 80.00 & 1 & 10.00 & 1 & 10.00 \\
Citizens At Large & 1 & 1 & 100.00 & 0 & 0.00 & 0 & 0.00 \\
Total & $\mathbf{3 0}$ & $\mathbf{2 7}$ & $\mathbf{9 0 . 0 0}$ & $\mathbf{2}$ & $\mathbf{6 . 6 7}$ & $\mathbf{1}$ & $\mathbf{3 . 3 3}$ \\
\hline
\end{tabular}


The goal of the question regarding comparing mediation to litigation was to seek out the respondents' feelings as to the value of mediation. An incredible $90.00 \%$ of all respondents believe mediation to be a better alternative than litigation. One reason for this high response number may be the cost of litigation as opposed to mediation. This response strongly supports the value of promoting mediation in cases of local government conflict.

Table 17 provides information regarding experience gleaned by respondents as a result of participating in the mediation process.

TABLE 17

EXPERIENCE GLEANED FROM MEDIATION PARTICIPATION: EVALUATION OF THE PROCESS FOR THE FUTURE

\begin{tabular}{lrrrrrrrr}
\hline & \multicolumn{7}{c}{ Responses to Question 13 } \\
\cline { 2 - 8 } Respondent & Total & Yes & \% & No & \% & No Opinion & \% \\
\hline County Commissioners & 19 & 16 & 84.21 & 1 & 5.26 & 2 & 10.53 \\
Township Trustees & 2 & 1 & 50.00 & 0 & 0.00 & 1 & 50.00 \\
Appointed Administrators & 10 & 8 & 80.00 & 1 & 10.00 & 1 & 10.00 \\
Citizens At Large & 1 & 1 & 100.00 & 0 & 0.00 & 0 & 0.00 \\
Total & $\mathbf{3 2}$ & $\mathbf{2 6}$ & $\mathbf{8 1 . 2 5}$ & $\mathbf{2}$ & $\mathbf{6 . 2 5}$ & $\mathbf{4}$ & $\mathbf{1 2 . 5 0}$ \\
\hline
\end{tabular}

Table 17 provides information to determine if individuals, having experienced some type of mediation, garnered valuable insight to support future use of the process. One commissioner reported that the experience helped to prepare him for active 
involvement for future conflict resolution efforts. The $81.25 \%$ response lends support to the need to educate local officials through conflict resolution training such as that provided by the Ohio Office of Dispute Resolution.

Table 18 reflects respondents' answers to question 14 which asked what, if anything, might they do differently in future mediation situations.

TABLE 18

REVISING THE MEDIATION PROCESS:

EVALUATION OF THE PROCESS FOR THE FUTURE

\begin{tabular}{lccccccc} 
& \multicolumn{7}{c}{ Responses to Question 14 } \\
\cline { 2 - 8 } Respondent & Total & Yes & $\%$ & No & $\%$ & No Opinion & $\%$ \\
\hline County Commissioners & 19 & 12 & 63.16 & 6 & 31.58 & 1 & 5.26 \\
Township Trustees & 2 & 2 & 100.00 & 0 & 0.00 & 0 & 0.00 \\
Appointed Administrators & 10 & 9 & 90.00 & 0 & 0.00 & 1 & 10.00 \\
Citizens At Large & 1 & 1 & 100.00 & 0 & 0.00 & 0 & 0.00 \\
Total & $\mathbf{3 2}$ & $\mathbf{2 4}$ & $\mathbf{7 5 . 0 0}$ & $\mathbf{6}$ & $\mathbf{1 8 . 7 5}$ & $\mathbf{2}$ & $\mathbf{6 . 2 5}$ \\
\hline
\end{tabular}

An incredible $75.00 \%$ of respondents answered yes to question 14 and said they would do something differently. Among some of the more common themes or responses were included comments such as better communication, work on building relationships, promote cooperation, and suggest using the mediation process right up front.

As previously mentioned in this chapter, the intent of the survey was in part to seek out just what local government officials and citizens alike believe about mediation. 
The results of the survey strongly suggest that these individuals recognize there is something out there and that it is probably an alternative. What they do not seem to agree on is that government is different from the private or non-profit sector, because of the rules. Local government officials are faced with intense measures of inherent conflict by virtue of the system. This position can be substantiated in the results of the information gleaned from the interviews of those individuals participating in the Defiance County experience.

Research Question 3: What is the relationship between intergovernmental mediation and successful local government partnership as perceived by county commissioners, township trustees, appointed administrators, and citizens at large? This question was answered through the interview process.

\section{Defiance County Case Study}

According to the executive director of the Maumee Valley Planning Organization, Defiance County was organized by an act of the Ohio General Assembly on March 4, 1845. Geographically located in the Northwest corner of the state and covering 411.2 square miles, its western border bounds the state of Indiana. Once a part of the "great black swamp," Defiance County was one of the last counties to be settled in the area. Rich in history, the area composing Defiance County was an important center for Native American trading and council sites. In 1794 Fort Defiance was constructed at the confluence of the Auglaize and Maumee Rivers under the direction of General "Mad Anthony" Wayne. In 1845 a system of canals was completed connecting Defiance with Toledo and Cincinnati in Ohio and with Fort Wayne in Indiana. This transportation system significantly contributed to Defiance becoming a major center of trade in 
Northwest Ohio. The city continues to enjoy the success with having five major state routes passing through the central business district.

The county is composed of the city of Defiance and the villages of Hicksville, Sherwood, and Ney. In addition to the city and villages, there are 12 townships, most of which are in a rural setting. In 1990 the population of Defiance County was estimated to be at 39,350 with $51.9 \%$ living in an urban setting and $48.1 \%$ in a rural setting. The 1990 census population breakdown placed Defiance City at 16,787 , Hicksville Village at 3,664 , Sherwood Village at 828 , and the village of Ney at 331 . Statistical data provided by the State of Ohio Department of Development in 1994 gives the ethnic breakdown as 98.0\% White, 1.4\% African American, with the remainder being Hispanic, Asian, American Indian, or Eskimo. In 1990 the total number of households was estimated to be at 14,070 with an average of 2.74 persons per household. The median household income is estimated to be $\$ 36,680.00$ annually. The high school graduation rate is $76.8 \%$, with the number of individuals obtaining a 4-year degree at $9.0 \%$.

Agriculture is a major industry with 213,000 acres of land dedicated to 930 farms. Other major job markets, in order of ranking, are: manufacturing; wholesale, retail trade; services; government; and construction. Construction statistics have been abnormally high since the mid-1980s primarily as a result of a trenicudously productive period of economic development. Economic development issues have been at the heart of conflict between Noble Township and the city of Defiance (Personal Communication, September $19,2000)$. 


\section{The City}

The city of Defiance covers 7 square miles and is governed by a strong mayor/council form of government. The city is the largest community, nearly double the size of any other in a five-county radius. Since the construction of a 250,000 -square-foot shopping mall in 1986, Defiance has become the regional service center of rural Northwest Ohio. The major employer is a General Motors plant employing nearly 2,700 individuals. Since 1980 the city has invested in excess of $\$ 35$ million in the wastewater and water treatment plants. Citizens and the business sector have paid for most of these EPA-mandated improvements through user fees.

\section{The Township}

Noble Township is in a semi-rural setting covering some 38 miles of land and is governed by a non-partisan, elected, three-member board of trustees. It is contiguous to the commercial/industrial, economically booming, north side of the city of Defiance. Since the late 1970 s, the city has systematically annexed highly desirable sections of Noble Township land in the name of economic development. City Hall's justification was simply being the provider of sanitary sewer and water services as leverage to developers. The city established a policy in the early 1980 s requiring annexation, when beneficial to the city, before sanitary sewer services could be obtained. As an incentive for the city to promote annexation, it established an cutside rate for water at two and onehalf times the inside rate.

Townships are the oldest forms of government in the state of Ohio. As part of the Ohio revised code section 503.08 , townships are required to maintain a size of not less than 22 square miles unless included in the boundaries of a municipal corporation. When 
a township falls below the magic number, there are two options available. Option one is to be absorbed by another township. Option two is to create a new township by annexing land from an existing contiguous township (Personal Communication, September 23, 2000).

The problem issues facing the two local governments were that of the city of Defiance and Noble Township's need for new revenues which are primarily obtained through income tax, i.e., new development and the Township's need for sewer and water services while resisting annexation attempts and fighting for its political existence. By October of 1997, the situation between Noble Township and the city of Defiance was at a crisis stage. Political infighting, negative press coverage, and several annexations had stretched the relations of the two units of local government. Although the series of intergovernmental meetings established by me as a county commissioner continued to be held, there was little gain toward agreement between the two units of government.

In retrospect, the year-long series of intergovernmental meetings involving the city, Noble Township, and Defiance County, although not overly productive, proved to be somewhat of a wise move. During these meetings an established communication was put in place. Although parties were at least meeting and talking, the meetings had little struciuie, were unorganized, and accomplished little. Individuals, as well as participating units of government, had hidden agendas with no mechanism for addressing the burning issues.

Nevertheless, at my request, intergovernmental meetings continued to be scheduled. Each passing month resulted in further erosion of the relations between the two units of government. Not knowing when to back out of the way was a near-fatal 
mistake. Not realizing the need to bring in a neutral third party nearly caused a breakdown in the intergovernmental dialogue. Had it not been for the suggestion of the then Defiance County Economic Developer, a third party mediator would probably not have been considered. Nevertheless, with this suggestion and with the approval of the Defiance County Board of Commissioners, the process to select a professional consultant was begun.

The first formal step in the process was to create a committee to review proposals for selection of a professional consultant. The committee was composed of one representative of Defiance City, one county commissioner, and the County Economic Development Officer. Unfortunately, no thought was given to including a Noble Township representative on the selection committee. Once again the process was in jeopardy of collapsing. Immediately a representative from Noble Township was added to the committee. This one move might have been the most important in the entire process. Being made a part of the selection efforts most certainly influenced Noble officials to accept the committee's decision.

The selection process in itself was very informal and somewhat unorthodox. The committee reviewed candidate resumes and within a 30-minute period made a selection. In part, the choice to select the professional consulting firm of Brae Birch was because of the familiarity of two of the selection team members with the firm's director. Given the unscientific method of selection, the group was very lucky as the chcice proved to be an excellent one. The first valuable benefit from the consultant was the advice and direction to modify the process that the committee had already put in place. For example, up until that time, meetings between the local units of government were held in the meeting 
chambers of the Board of County Commissioners. Upon the recommendation of the consultant, a neutral site was selected and a room secured at the local hospital.

The next action, at the advice of the consultant, was to modify the existing committee of participants by adding somewhat disinterested or quasi-neutral people. The two new members included the Defiance County Economic Development Director and the Director of the Maumee Valley Planning Organization, a non-profit multi-county planning agency. With these additions, the process had advanced to the point of scheduling the first meeting with the new committee. Meeting times were difficult to coordinate because of the busy schedules of the participating members.

The first formal meeting of the group was held on October 1, 1997, at the Defiance Hospital. In attendance were the director of the Brae Birch consulting firm and his assistant. Representing the city of Defiance were the Mayor, City Administrator, and City Law Director. Representing Noble Township were the three trustees. As previously mentioned, neutral parties attending were the Defiance County Economic Developer and the Director of the Maumee Valley Planning Organization. Representing Defiance County was a county commissioner.

As a first order of business the group agreed to establish a basic set of ground rules. The key word is "basic." The ground rules were arbitrarily established on the spot by those participating in the intergovernment process. The newly established rules were as follows:

Rule 1: allow the consultant to conduct and facilitate the process.

Rule 2: keep general rather than "nit-pick."

Rule 3: put all agreements in writing. 
Rule 4: agreement by the parties to meet for a total of 3 meetings, to be held on October 1,15 , and 29.

Rule 5: all news releases shall be done jointly and require the approval of each participating entity.

Being an inexperienced group in the mediation process, there was little understanding of the value of ground rules; otherwise, it is likely the rules would have been developed much more extensively. Nevertheless, these limited rules served to function as a guide to all participants throughout the entire intergovernmental process.

At the recommendation of the consultant, the second decision by the group was to respectfully request the cooperation of the press not to cover the meetings. The consultant felt it best to work off the record, as a small group, but emphasized the need to ultimately share the outcome with the non-participating units of local government and with the public at large. Although, technically, such public meetings are open to the press and the public, the group was fortunate that neither chose to attend during the course of the process. This allowed participants to speak freely without concern for negative feedback from the press or from local citizenry. The decision likely expedited the process because people felt comfortable about expressing even their deepest hidden concerns. As a result of not having to deal with the press and citizens' issues, the group was immediately able to establish a new course of action.

The new approach, once again at the direction of the consultant, was to divide the discussion process into three key topic areas. These included: first and foremost, talking theory; second, talking needs; and last, talking concerns. The theory was the concept of local governments working together in the name of regionalization. The needs issue 
instituted discussion on availability of particular resources by individual units of government as wel! as their specific needs. An example was the ability of the city to provide water and sewer services and the township's need to obtain the services. The township's ability to provide much needed land and the city's need for the additional land were noted. The needs process also brought out the same supreme issue facing each unit of government, namely the need for increasing much desired tax revenues. Lastly, the discussion centered on the issue of individual concerns. This discussion offered officials an opportunity to talk about such significant issues as preserving and enhancing their respective political areas of jurisdiction.

Having added this new approach of dividing the discussion process into three primary areas, the mediator then assisted the group in identifying and prioritizing the issues, which each party desired to have addressed. These include regionalization of services, revenue, sharing, annexation of land, home rule issues, controlled growth, public perception, and serving the public interest. The consultant, realizing this to be a tremendously ambitious agenda, facilitated the process by categorizing the issues into three areas, all of which were done in the name of serving the public interest through a regional partnership. The categories and breakdown are as follows:

1. Payment for services

a. Fairness in cost sharing

b. Revenue share

c. Long-term strategy plan for fire, police, water, sewer, and EMS services

d. When possible, eliminate reduction of services

e. Establish a clear picture of revenues and costs

2. Home rule/annexation/planned growth

a. Economic development 
b. Township autonomy in conjunction with and respect for city responsibilities/priority

3. Composition of a partnership team

a. Ability to impact public perception

b. For planned growth

c. Forum for open communication.

As a last order of business at the first meeting, three separate committees were formed to address those issues which had been categorized. Participants were given committee assignments based on their position or area of specialty and were asked to report to the group at the October 15,1997 , meeting. Ultimately, it proved to be a wise decision to strategically appoint individuals to committee assignments according to their interest in the process. The reason for this action being taken was really quite simple. Having a personal need to achieve a specific goal ultimately proved to motivate and to propel the committees to seek quick results. Participants later reported that they felt the effects of their "influence" in the process because they were involved with issues that had meaning to them.

The actual makeup of the groups and their specific committee assignments were as follows: group one was composed of the city administrator, the regional planning agency director, and a Nobel Township trustee. They were assigned to the "payment for services" committee. This committee considered such issues as water/sewer services, storm drainage issues, and road and other infrastructure considerations. They also considered police and fire services, snow removal services, overall infrastructure issues affiliated with designated joint areas of economic development, who would provide for such services, and who would pay the cost of providing these services. 
Group two consisted of a Noble Township trustee, the city law director, the county economic developer, and a local attorney who was running for a position as a Noble Township trustee. This group took on the issues of home rule, annexation, and planned growth. The ultimate goal of this group was to establish policy to address future potential joint economic development projects affecting the various units of local government. The third group was the partnership team consisting of the Defiance City mayor, the county commissioner, and the previously mentioned attorney running for Noble Township trustee. The task of this group was to deal with the political issues affecting the participating units of government associated with expansion and development.

As pointed out the committees began their assignments almost immediately with noteworthy enthusiasm. As a result of their hard work and commitment, the second meeting proved to be very productive. The groups' reports at the October 15, 1997, meeting provided what proved to be an excellent base for future partnership success between the units of government. The recommendations of the groups, to everyone's surprise, were very similar, and for the first time there appeared to be recognition that groups wanted a cooperative economic development plan. The groups reported the following recommendations:

Group One:

1. Need for shared economic development districts

2. City should provide water/sewer to township

3. Recommend needs and benefits study for EMS/Fire service Group Two:

1. Need for shared economic development districts

2. Planning and zoning coordination for contiguous areas 
3. Method to determine sharing of revenues and services

Group Three:

1. Need to improve public perception

2. Need for shared contractual economic development zone

3. Planning and zoning coordination for contiguous areas

4. Establish a partnership team and empowerment plan

5. Encourage regionalization.

Much of the activity by the groups was done through informal processes. Groups met, discussed broad ideas, and reached general, rather than specific, plans. Yet, out of the informal processes came some highly valuable formal agreement, most of which likely occurred as a result of the facilitation process and intervention by the consultant. As previously stated, the more than 1 year of talks set up by the county commissioner had done little more than cause the parties to meet. For more than 1 year, the county commissioner promoted the idea of a Joint Economic Development District (JEDD). The process was finally taking shape, and it appeared for the first time that a JEDD might actually come about. Then, a major bombshell was dropped when the Mayor of Defiance made a very ice-cold anti-JEDD statement, expressing herself in this way:

I am not convinced a Joint Economic Development District is in the best interest of the city. WE cannot give up our right to obtain land as needed for expansion, growth and development of the city. I do not believe that the city has the desire at this time to engage in such an agreement nor is it likely they will in the near future. We want cooperation ... but not at the expense of the city's ability to expand its borders. (Personal Communication, February 15, 1999)

To further complicate the issue, the then highly respected and popular sitting President of the County Board of Commissioners stated at a board of commissioners meeting his belief that a JEDD agreement "would probably never be reached." 
As previously suggested, the initial process seemed to go from one of hope for an intergovernmental agreement to a feeling of despair after 1 year of floundering without direction. Once more the outlook to those participating appeared to be bleak at best. The participants later reported having a general feeling that the process had all been in vain. Fortunately, the consultant was able to save the day by keeping the parties talking in spite of the mayor's comments. This was accomplished by bringing the discussion back to the findings of the three subcommittees. The committees seemed more determined than ever to find a resolution. At the recommendation of the city administrator, a pattern agreement was established with Noble Township. A semi-formal process was established to include appropriate individuals in addressing specific future issues. In the past, top-level officials would meet to try to reach an accord without including the very individuals who could be impacted the most by a decision. For example, if a joint fire district were under consideration, past practice would have been to leave jurisdictional fire chiefs "out of the loop." The new plan created a process of inclusion as well as a shared commitment within and among local units of government. The flow chart found in appendix B is a product of the mediation process and serves as an example in addressing future intergovernmental issues.

With a mechanism in place to help guide the decision-making process between units of local government, the major task left undone was the creation of a Joint Economic Development District. Since there still appeared to be a lack of support for a JEDD on the part of the city, it was surprising to many when the contractual team, in accordance with the regional partnership agreement, presented at the third meeting a signed agreement calling for a Joint Economic Development District. It is likely the 
committee process, with the direction of the consultant, played a significant role in this positive outcome. The actual agreement, as prepared by Defiance City Law Director David Williams, read in part:

The parties agree to form a joint economic development district on land located near the airport owned by the Defiance County Commissioners. The city to provide potable water, sewage treatment service, engineering review, building inspection services, income tax collection and political cooperation. Noble Township agrees to provide fire/rescue response, industrial zoning of the JEDD area and political cooperation. (Personal Communication, December 17, 1998)

The agreement further detailed the sharing of income tax and personal property tax revenues between the cooperating units. Yet, perhaps the most notable outcome of the 40-year agreement is the language regarding the annexation issue.

As pointed out early in this chapter, annexation was the driving force of conflict between the city and Noble Township. Through the intergovernmental talks, it seems the parties came to the realization that annexation could never be totally eliminated and, as a result, agree to language providing possibly the next best option on the issue, namely that:

Part A: When a request for annexation is made, the city agrees to provide a forum to be attended by the township trustees, the county commissioners, and all affected parties to air all concerns associated with the request.

Part B: In the event of annexation, the city of Defiance agrees to return to Noble Township an amount of money equal to the amount of real property taxes levied on the annexed land just prior to annexation. This compensation shall be paid annually and shall continue for a period of 10 years after the annexation occurs.

This portion of the agreement gives strong support to the positions of Maggie Lewis, David Roberts, and Donna Silverberg, as pointed out in chapter 1 calling for 
applying collaborative approaches in the mediation process. This was indeed a collaborative problem-solving effort. It also fits quite well into the definition by Maggie Lewis as found in chapter 1: "The use of the collaborative process encourages a greater sense of commitment to the process as well as the outcome developed by all stakeholders" (Personal Communication, March 9, 1999). After decades of conflict, a decision of this magnitude, agreeing to the annexation language, clearly required a great sense of commitment to the intergovernmental mediation process.

In less than 2 months, with the aid of a professional mediator, an agreement had been reached. This is the first time in memory an agreement between the city and a contiguous township had been reached-something that could not be accomplished after 1 full year of unassisted intergovernmental discussion meetings. Moreover, the agreement tailored to Noble Township could be used as a template for future agreements between other townships and the city.

When two contractual team members were interviewed and asked the question, "Why do you think so much progress was made in a few short weeks when effectively nothing could be accomplished in a year of negotiation efforts?" their responses were:

City Administrator: "Clearly it was the opening of communication."

Noble Township Trustee: I believe the difference was having a third neutral party, an individual who really opened up communication, one who looked for common ground, one who looked at each of the party's needs while separating out the politics. There is so much politics involved, especially when you are charged with the responsibility of serving those who have elected you to office. When we tried to do it ourselves, we were just plain too close. We could see only our side of an issue. I think we learned a lot from the process, which we will possibly be able to use in the future. I don't know ... maybe ... we could do it ourselves the next time without any help. But just the same, it is good to know that we can always call on someone from the outside if we need help. 


\section{Results of the Procedure}

Defiance County intergovernmental relations still have along way to go. The city and Noble Township still struggle with economic development issues, annexation concerns, and land use issues. Nevertheless, a number of good things have resulted from the intergovernmental mediation experience. One prime example is the development of a countywide comprehensive plan. This instrument serves as a tool for directing and encouraging desirable patterns of growth and development, particularly in unincorporated areas of the county. Consideration is given to the study of population trends, demographics, economic analysis of business, and residential and agricultural data in relation to areas being studied. Other significant areas evaluated include quality of life issues such as historical preservation, environmental issues, educational institutions, and infrastructure. The primary purpose of a comprehensive plan is to serve as a planning tool for local officials and as a guide for directing future growth and development while preserving specific areas of interests such as quality farmland and historically significant areas. Although the comprehensive plan has no legal binding worth, it can serve as a guide to local planning commissions and zoning boards in helping to regulate future growth and development patterns.

The process in Defiance County involved a series of five town meetings held in the five school districts throughout the county. The eighteen-member hand-selected advisory board was composed of individuals representing agriculture, banking, education, environment, industry, real estate, and local government planning interest. Advertisements were placed in local newspapers inviting citizens to participate in a "county wide" comprehensive planning process. At the meetings, citizens were asked to 
express their fears and the strengths they associated with a comprehensive plan. After five public meetings over a 3-month period, the concerns and the strengths expressed were very consistent:

1. Fears:
a. Lack of control of land
b. Missing something important in master plan
c. Costly litigation
d. Inadequate monies to implement plan
e. Putting farms out of business

2. Strengths:
a. Empowers people
b. Community consensus on issues
c. Awareness of future trends
d. Saving tax payers money
e. Reduce duplication of services
f. Reduce conflict
g. Speak with a unified voice.

For Defiance County, the comprehensive plan produced five major findings.

These are:

1. Targeted controlled growth

2. Foster cooperation among political groups

3. Preserve quality of life sub-divisions

4. Recommend strategies for development

5. Recommend standards for preserving prime farmland.

\section{Interviews}

As pointed out in chapter 3, participants in the Defiance County experience included the City Law Director, City Administrator, and a Noble Township official. Each 
was asked a series of questions in an effort to gather first-hand personal accounts from

his involvement in the Defiance County intergovernmental experience and to provide answers for research questions 4,5 , and 6 .

Research Question 4: What are the types of variables that create conflict between and among neighboring units of local government? The first and second interview questions were designed to answer research question 4 . The results are as follows:

Question 1. Do you believe Defiance County local units of government are faced with intergovernmental conflict issues? If so, why?

Trustee H: Yes, I do believe they are and the reason is, they won't go "out of the box" and look at regionalization, instead of earned true protection of their turf, and not looking at the good for the taxpayers and the people as a whole. (Vol. 3, p. 1)

Trustee W: Yes, I would agree with that statement, Tom, and I think in particular the local governments in the eastern end of the county (those closest to the city boundaries) have issues as far as providing services and as far as tax base and issues which include economic development, industrial development, residential and, of course, annexation. (Vol. 4, p. 1)

City Administrator F: Well, I think that Defiance County area governments do have some conflict; however, I think that the conflict is generally a result of a natural conflict between governments that have different constituent groups that are trying to compete, really, for services. I think that conflict in Defiance County can become heightened on certain issues more than in another community simply because of Defiance County's political past's being a little more conservative. (Vol. 2, p. 1)

City Law Director W: Gee, I would say that we are from time to time ... some of them are really legitimate. I think we can see some instances where the City's interest and the county commissioners' interest have not always been in perfect alliance. There are times when ... why, in the most fundamental sense, is that government, like other things in the world, have to deal with finite resources; and when people are competing for those limited resources their interests are sometimes going to be, by the nature of it, antagonistic. I mean, if there is $\$ 100,000$ of grant money for Defiance County for example from ODNR in a year ... if the city of Defiance says we are half of the population and we want half of 
the money, and county commissioners say we speak for all of those townships and they, as $90 \%$ of the land mass, should get $90 \%$ of the money. . then there is going to be some friction for what is the fair apportionment of those limited resources.

(Vol. 1, p.1)

Citizen SJ: Yes, because I think one of the problems is teamwork. The issue is one of jurisdictions. Also, people are elected into positions that they know nothing about. (Vol. 5, p. 1)

It is of particular interest to note that Law Director Williams went on in his response to question one, stating: "I never quite understood why they [township officials] feel as threatened as they do by the ongoing process of annexation."

This statement seems to support the data in chapter 2, as pointed by Carlson: "The problem has always been and continues to be the politics" (Personal Communication, September 24, 2000). Based on the law director's statement, it would appear that his thinking is "city exclusive." This type of thinking would appear to hold true in the case of many local government officials. Perhaps it is, as the city administrator suggested, that the conflict is often a result of the constituents being represented (Personal Communication, February 5, 1999).

Question 2. Does conflict affect the ability of local government cooperation in Defiance County? If so, how?

Trustee H: Absolutely! (Vol. 3, p. 2)

Trustee W: I think it probably does have some effect. There are probably opportunities for cooperation and some type of mutual agreement whether that be in development or in providing of services and the sharing of revenues . . . that are possibly not brought to the forefront because of history of conflict between the jurisdictions .... and that is not limited to just the area around the city of Defiance. I think there are conflicts throughout the county ... where maybe . . . for instance, and townships and villages could work together beneficially . . but for whatever reason, and that might include personal reasons or whatever ... it does not happen maybe as often as it should. (Vol. 4, p. 2) 
City Administrator F: Well, you know, ultimately I have to say that is a tough question, because ultimately it makes the process more difficult. Reason is because often conflict becomes so high profile in a smal! community. In Defiance it raises itself up to the front-page story. (Vol. 2, p. 2)

City Law Director W: I think it affects the way we work with one another. I think that the key to getting along is that we have to understand what interests are important to other governmental units and try as best we can to work out arrangements that accommodate everyone's essential core interest. I think that is really the heart of JEDD deal. (Vol. 1, p. 2)

Citizen SJ: Yes, I think we have conflict of personalities and conflict of interest in terms of power plays. When one official believes his or her own area of interest is more important than say another political jurisdiction. (Vol. 5, p. 2)

It is interesting to note the types of variables that create conflict among local government units. The city administrator points out the influence of the media, particularly in small rural settings. The city law director speaks to the need for governmental units to learn to work as a team and to address turf issues and annexation differences.

Research Question 5: What types of public sector mechanisms are presently available for local government officials? The third and fourth interview questions were designed to answer research question 5 . The results are as follows:

3. Are there incentive programs or mechanisms that you feel might aid in reducing the levels or degree of conflict incidence? If so, what are some examples?

Trustee H: I don't know any out there right now other than if there would be some type of course or something that local governments could take to utilize the regionalization of the area. (Vol. 3, p. 3)

Trustee W: Well, not being involved in government for a long time Tom ... I am not sure that I am aware of everything that is available. Obviously, the township, Noble Township, and Defiance City have worked on water agreements, have been involved in sewer discussion ... have worked, and are working on a JEDD agreement. Those are some examples of some things currently in progress. I am not certain that there are probably not a lot more that could be looked at. I am just not aware of them. (Vol. 4, p. 3) 
City Administrator F: Well, I think that what we have done in Defiance is really on the cutting edge of some of that stuff. You know that we have introduced the Joint Economic Development District and there is actually an economic development zone we have taken advantage of. (Vol. 2, p. 4)

City Law Director: One of the things that I think that we [the city] have indicated ... a city has to, if it annexes more than a certain percentage of the townships tax base for a period of time, make donations back to the township trustees to replace those revenues. (Vol. 1, p. 4)

Citizen SJ: Perhaps education of public officials as to mandates regarding Ohio Aid Federal law would be one option. (Vol. 5, p. 3)

The responses to question 3 seem to reveal that local government officials are not totally aware of available incentive programs. Even those individuals directly involved in the Defiance intergovernmental experience at best were uncertain as to available incentive programs geared toward reducing the levels or degree of intergovernmental conflict.

4. Based on your participation, do you believe the Defiance County mediation process effectively addressed the issues at hand? If so, why or why not?

Trustee H: I think it effectively addressed it to $90 \%$. I still think that there are issues out there that are touchy. (Vol. 3, p. 4)

Trustee W: I think it helped in the short term, Tom. There are still a lot of questions that are not resolved and you know, let's look at it from the standpoint, did it solve the conflicts? ... and I would have to answer that, no! I am not sure hat decision making and the level of cooperation on both sides of the fence, both township and city ... I am sure they have been smoothed out. I am not sure that everyone would say today that we have a beautiful arrangement. I don't think that is the case. I think it is a start and that is probably about it. (Vol. 4, p. 4)

City Administrator F: Yes, I think we did. You know that I think the greatest thing in the process was that we sat down with each other and we got the issues right out on the table. We tried to understand each other's needs, each other's concerns, and each other's political obstacle. (Vol. 2, p. 5) 
City Law Director W: Well, I guess I would have to say yes, because we tried it without a corsultant very early on. With a consultant, we experienced businesslike negotiaticns over every aspect of the process. (Vol. 1, p. 5)

Citizen SJ: I did not participate in the actual process. All of the information that I acquired was from talking with public officials and from what I learned from the news reports. (Vol. 5, p. 3)

The responses to question 4 seem to suggest that local government officials are aware of the issues, which affect their area of jurisdiction and likely need to be addressed.

Question 5 was designed to answer research question 1. What is the level of experience in the intergovernmental mediation process as perceived by county commissioners, township trustees, appointed administrators, and citizens at large in Ohio?

5. Who, if anyone, should take the lead in conflict resolution processes among units of local government in Defiance County? Why or why not?

Trustee H: Boy, that is a tough one. I would have to say the best would be the county commissioners. The only reason is they are elected by the whole general public of the county, not just the city. (Vol. 3, p. 5)

Trustee W: That is a good question. I am not sure who should take the lead, Tom. You know, that lead could come from any number of places. It could come from the office of economic development. That leadership obviously could come from county offices. I guess it could come from any of the parties involved. I guess what has to happen has to be in that leadership position. Someone more or less has to take the bull by the horns and then there has to be a willingness . . . whether it is two townships working together or the city and a township together. You know there has to be a true willingness ... come to an agreement that both sides see as favorable. (Vol. 4, p. 5)

City Administrator F: I think it is the county commissioners. Ultimately, you are hopeful that the county commissioners will take a broad perspective on who their constituent base is. You hope that the county commissioners understand that their electorate is made of both incorporated and unincorporated areas. (Vol. 2, p. 6)

City Law Director W: Oh, yeah, there's sort of kind of a knee-jerk reaction initially that the commissioners are ideally placed to do it, but my experience has 
been that doesn't just serve as maybe to the participants and more importantly, to the entire county. (Vol. 1, p. 7)

Citizen SJ: Actually, I would think it should be the county commissioners. The reason is the county is made up of all the townships and citizens within its boarders. (Vol. 5, p. 4)

The general feeling seems to be the highest level of elected officials should take the lead in terms of promoting a conflict or dispute management. In the case of this study, county commissioners were overwhelmingly selected as the appropriate leadership officials to promote intergovernmental relations in their jurisdictional boundaries.

Research Question 3: What is the relationship between intergovernmental mediation and successful local government partnerships as perceived by county commissioners, township trustees, appointed administrators, and citizens at large?

6. Is there anything in your opinion that can be done in the future to influence cooperation between Defiance County units of local government? If so, what?

Trustee H: You got a good start on city/county meetings maybe. Maybe townships and villages should meet quarterly and sit down to discuss some of the issues. (Vol. 3, p. 8)

Trustee W: I am sure there is one thing that comes to mind, I guess Tom, is the idea of writing a plan to cover when certain projects, certain proposals, whether it be services like water or sewer or road maintenance or whatever, as changes come up, or as mandates are enacted by the State or Federal government, or when new programs come into being as it is now sometimes the local governments have to react to those programs under, say, the county umbrella. And we wouldn't want to see a lot of those programs fostered or pushed onto the township. Let's say to the townships, as an example, unwillingly. And the other thing is from time to time one government entity, and this is just common sense, I guess, may be in a position to assist another, whether that is one township or work with another township or the county work with township. And I think a lot of good will could be realized when both opportunities come up that people are free to share and assist another entity and maybe, not necessarily, maybe not get a whole lot back from it in return. A few instances like that would go a long way down the road when a problem comes up and has to be addressed. (Vol. 4, p. 3) 
City Administrator F: Yes, continued dialogue, you know we did a good job of that with our quarterly meetings. You know this is true, Tom, you know this more than anybody else ... because you were the guy fighting for it. (Vol. 2, p. 3)

City Law Director W: In Defiance County I really think that the biggest hurdle has been costs. Now that we have gotten the dialogue to the point where people understand that we are economically interdependent, and if we develop these resources in a cooperative manner, we can provide a better quality of life for a lower cost. (Vol. 1, p. 7)

Once again a number of variables found in the literature review seem to surface.

Law Director W speaks of the money influence, Administrator F and Trustee $H$ promote communication, while Trustee $\mathrm{W}$ promotes the necessity of planning for the future.

Research Question 2: What is the level of understanding of intergovernmental mediation that is perceived by county commissioners, township trustees, appointed administrators, and citizens at large? Interview question 2 was designed in part to answer research question 3.

7. Given your personal philosophy, experience, and participation in the Defiance County intergovernmental process what, if anything, would you have done differently? Why?

Trustee $\mathrm{H}$ : We are going to do a newsletter at the end of the month explaining what annexation is, where the trustees stand on it, where the commissioners stand on it, and what the options are with the JEDD (Vol. 3, p. 6) Trustee W: Gosh, I don't know, Tom. It's easy to second-guess sometimes. I got a second guess. Perhaps given the situation again, or a like situation, I would probably go into that process hoping to have more specific and defined goals or list of items. Maybe even draw a line at some point, and say this is the interest of my entity. Either meet these minimum criteria, or there is no point in proceeding too much farther. (Vol. 4, p. 7)

City Administrator F: I probably would have preferred each side to have a rough draft on paper. Ultimately, the mediator is going to be the one to bring the two sides together. I think that the types of negotiations ought to take place with a group of administrators first, and then elected officials should be brought into the process. (Vol. 1, p. 8) 
City Law Director W: Frankly, I would have tried to keep a more direct hand early on in the process. There was a point when the city's negotiations team was myself. (Vol. 2, p. 8)

Citizen SJ: Once again, my observation was only from the news reports and talking with public officials. One thing that might have been done a bit sooner would be to bring in experts earlier in the process. (Vol. 5, p. 6)

8. What, if anything, might you recommend as future considerations to reduce intergovernmental tensions in Defiance County?

Trustee H: I think the best suggestion is that the townships, the city, the county government ... and there is nothing wrong with wanting to get a chamber person on the committee. I think that you need to open the lines of communications ... actually take specific topics, talk about them, and bring in experts in those fields. (Vol. 3, p. 8)

Trustee W: Oh boy ... Well, I wonder about that, Tom. I don't know, I think the government leaders need an opportunity to sit down and talk unofficially. Not so much off the record or conducting business, but just getting together to share some ideas, just being a little more personal or knowledgeable with the people you might end up sitting across the table from. And I guess if we look at it, some of these conflicts result from economic growth, expansion of whatever type. Maybe we need to rely a little more on comprehensive planning to where the parties are involved and looking at future planning, so that when future developments, expansion, enlargements, whatever happens, we have a map, we can look back and say, we presented that five or ten years ago and everybody was aware this is what could happen and this is where we are today and we shouldn't be upset by the way things are going. (Vol. 4, p. 8)

City Administrator F: I think maintaining those lines of communication, looking for any opportunities and especially at the county level ... the county, I think more than anybody else, needs to look at opportunities to maintain contact with the sub-division, the government sub-divisions. Somebody has to take the lead, and again the county commissioners are elected to be county care-takers in both incorporated and unincorporated, and I think when the county board recognizes that obligation, it carries with it a responsibility for exercising leadership for trying to bring those units together. (Vol. 2, p. 9)

City Law Director W: This is going to sound kind of stupid, but I think what we need to do is maintain little more of a personal connection with one another. I mean, we deal with each other in a business setting, but maybe we need a midJuly hog roast. I think that if we can deal with one another on a social level once in a while, that would be helpful. (Vol. 1, p. 9) 
The responses to question 8 by the interviewees are quite clear. Their recommendation appears to be very consistent. They are, simply, to communicate, communicate, and communicate.

In the grand scheme of things, communication and building relationships with those individuals with whom we must work and who live near are most important. We must look at the entire picture rather than our own little comer of the world. As to the question, Was the Defiance County experience a success? Perhaps the question can best be answered by what has transpired since the passage of the Joint Economic Development District. The city, county, and township (Brunnersburg water sewer district) agreed to and subsequently installed a new 12-inch water line, thus increasing the quantity of water available to the JEDD area. This additional water will not only provide an excellent base for future economic development in the Joint Economic Development District, but it now provides water to nearby citizens living in a low-income trailer park. Prior to the installation these citizens were able to obtain their water supply only by having it brought in by tanker trucks, as most of their wells had either gone dry or were determined unsafe for human consumption. One of the research questions to be answered by this study was, Do Defiance County units of local government practice intergovernmental mediation? If so, what have been the outcomes in terms of economic development and partnership agreements? Clearly, the signing of a Joint Economic Development District agreement, and the sign-off of a multi-jurisdictional agreement for a several million dollar express sewer very much seem to answer the question with a resounding yes. Most important is the fact that the agreement has created a win/win situation not only for the local public officials, who must do the day-to-day business of 
the people, but also, for the citizens. Yes, even the trailer park families, by reason of local government intergovernmental cooperation, can feel secure in knowing their children will have safe, clean water to drink.

\section{Summary}

The population of this study (County Commissioners, Township Trustees, Appointed Officials, and Citizens-at-Large) came from within the state of Ohio. The research sought to examine the relationship between local governmental organizations in terms of intergovernmental mediation, conflict resolution, and the sharing of revenues and resources. Second, it sought to examine Defiance County government's intergovernmental mediation practices.

A significantly high percentage of county commissioners and appointed officials had moderate to strong intergovernmental mediation experience as opposed to township trustees and citizens-at-large.

The results indicated that almost $95.00 \%(94.86)$ of individuals having intergovernmental experience believe that mediation allows parties to maintain control over the outcome of an issue. The results also indicated that mediation serves as an instrument by which parties can cooperatively address dispute resolution. This high percentage implies that practicing intergovernmental mediation helps to reduce the potential of intergovernmental conflict. The results indicate that there is a relationship between intergovernmental mediation and timely resolutions, all at relatively low cost.

Figure 1 provides information regarding the major steps involved in the Defiance County intergovernmental process. Step 1 involved contacting the parties to be involved in intergovernmental discussions. Step 2 was the scheduling and coordination of 
intergovernmental meetings with the three local units of government. Step 3 involved establishing a committee made up of representatives of the various governmental entities. Step 4 was the selection of an outside neutral third party to mediate the discussion process. Step 5 was the actual discussion process with parties talking theory, needs, and concerns. Step 6 was reaching an agreement, followed by step 7 , the sharing of revenues and the sharing of resources.

In chapter 5 consideration is given to a summary of the study, conclusions, and recommendations gleaned from the Defiance County intergovernmental experience along with the information garnered from the literature review. The goal of this chapter is to provide the reader with useful information that may assist in dealing with intergovernmental issues in an effort to reduce the potential for intergovernmental conflicts. 
(Step 1)

Defiance County

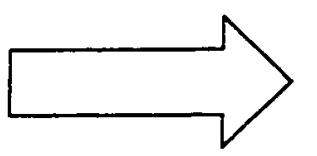

Defiance City

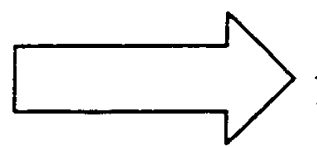

Noble Township

(Step 5)

Share Revenues

Share Resources

Talk Theory

Talk Needs

Talk Concerns
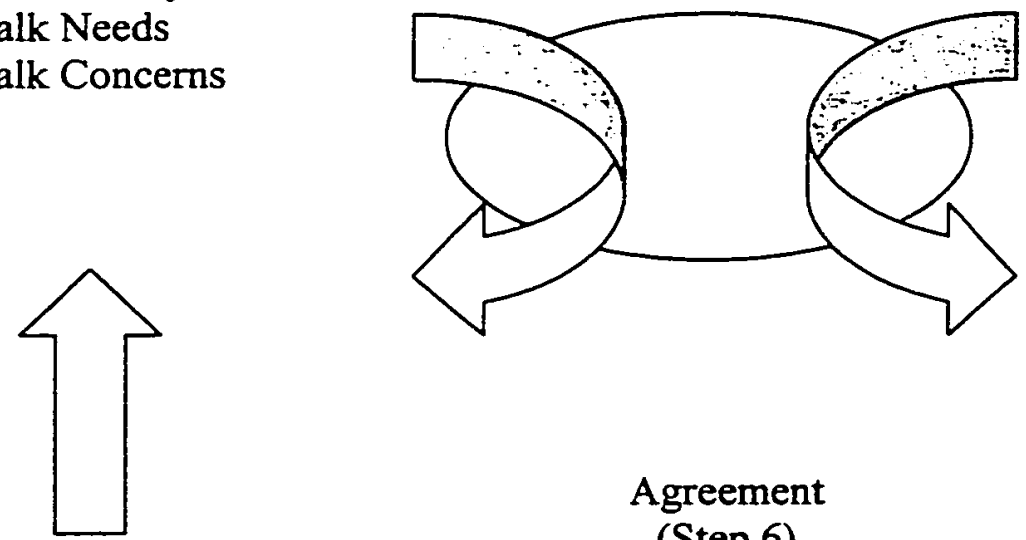

(Step 2)

Agreement

Intergovernmental

(Step 6)

Meetings

Step 4

Step 3

Select Consultant

Committee Selection

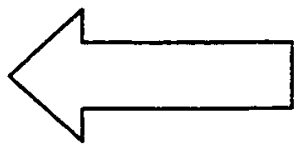

Figure 1. The Defiance County process. 


\section{CHAPTER V}

\section{CONCLUSIONS AND RECOMMENDATIONS}

In the final chapter can be found a summary of the study, discussion of the findings, conclusions, and recommendations suggested as a result of the study. The summary also includes an overview of the problem, the literature review, and the methodology, that was utilized in the study.

\section{Summary}

Since the creation of mankind there have existed opposing viewpoints, conflicts, and disputes between opposing parties. In many such cases the resolution of disputes came about by the intervention of a third party neutral. Many of these neutrals appear to have commonly utilized tactical approaches and deductive reasoning as methods of resolving disputes. One early example can be found in I Kgs 3:16-3:27.

Then came there two women, that were harlots, unto the King and stood before him. And the one woman said, O my lord, I and this woman dwell in one house; and I was delivered of a child with her in the house. And it came to pass the third day after that I was delivered, that this woman was delivered also: and we were together; there was no stranger with us in the house, save we two in the house. And this woman's child died in the night; because she overluid it. And she arose at midnight, and took my son from beside me, while thine handmaid slept and laid it in her bosom, and laid her dead child in by bosom. And when I arose in the moming to give my child suck, behold, it was dead. But when I had considered it in the morning, behold, it was not my son, which I did bear. And the other woman said, Nay; but the living is my son, and the dead is thy son. And this said, No; but the dead is thy son, and the living is my son. Thus they spake before the king. Then said the king, the one saith, this is my son that liveth, and thy son is the living. And the king said, bring me a sword. And they brought a sword 
before the king. And the king said, Divide the living child in two, and give half to the one, and half to the other. Then spake the woman whose the living child was unto the king, for her bowels yearned upon her son, and she said, $\mathrm{O}$ my lord, give her the living child, and in no wise slay it. But the other said, Let it be neither mine nor thine, but divide it. The king answered and said, Give her the living child, and in no wise slay it; she is the mother thereof.

This is a crude but obviously effective means of resolving a burning dispute between opposing parties. In theory, it was a reasonable and somewhat acceptable approach as an effective method of dispute resolution in a kind servant relationship. Yet, it is not very plausible in a $2 \mathrm{I}^{\text {st }}$ century, small, local, government setting in the United States of America. Over the centuries methods of alternate dispute resolution processes have been refined and improved upon. Today, more than ever the need to utilize alternate dispute resolution in local government appears to be more important than ever. Data gathered from interviews with local government officials strongly suggest awareness that there is a need to address conflict between units of local government. The dilemma is that many of these officials are hindered by a lack of understanding of how to deal with conflict through effective means.

The real problem, as pointed out in chapter 1 , is getting the message out to local government officials. Historically, local government officials, when faced with intergovernmental conflict, have employed litigation as a means of resolution. Not that litigation was necessarily the preferred action; rather, there were few, if any, other known structured options available.

This study sought to determine the effectiveness and value to local units of government utilizing intergovernmental mediation as a successful technique in local government partnerships. 


\section{Overview of the Literature}

The literature review addressed several areas related to the present study. It began with the development of mediation in the private sector through the Federal mediation and conciliation service established by the United States Congress in 1947.

Interest in the area of intergovernmental mediation appears to have increased since the late 1980s. The review of the literature discussed what actually is being done in the states of Ohio, Oregon, New Mexico, and Washington with regard to intergovernmental mediation. For the most part, recent research has been directed toward a need to know.

One consideration for local units of government, when faced with intergovernmental conflict, according to the literature, is employing a collaborative problem-solving approach. This is defined as processes to bring people together in an attempt to analyze problems and generate options in order to reach a consensus agreement. Collaborative efforts have not been typically used in the public sector as they have in the private sector. What makes the public sector different from the private sector is the variable of politics. Carpenter believes that politics influences cooperation, and that intergovernmental cooperation is most apt to occur among municipalities that share the same party affiliation. To the question, "Can politics ever be removed?" Dale Blanton believes that there will always be a political environment. When politicians flex their political muscle, he believes, it is best to sit down and explore their interests in an attempt to educate them (Personal Communication, May 24, 2000).

In Ohio, educating local public officials to the value of alternate dispute resolution processes seems to be a sincere motivation of state officials. For example, 
Section 179.02 of the Ohio Revised Code establishes an administrative agency which delegates the responsibility to promulgate the rules regarding alternate dispute resolution in Ohio. The agency, named the Ohio Commission on Resolution and Conflict Management, has as a primary mission to educate public officials and establish dispute resolution and conflict management programs. Between 1991 and 1997, 136 mediation advocates were trained through the Commission on dispute resolution. The training programs have been primarily directed toward schools, courts, community, and local government officials. As of February 1999, a record 101 mediation advocates, trained through the commission, were in service in the state of Ohio. Nonetheless, alternate dispute resolution processes in the public sector remain relatively new, unlike that of the private sector.

Alternate dispute processes in the private sector are more clearly established according to John Wines, Commissioner with the Federal Mediation and Conciliation Office in Toledo, Ohio. Dr. John B. Stephens (Personal Communication, September 14, 1999) believes there is a difference in how private and public sectors must deal with conflict. He believes that private sector mediation processes are generally more clearly defined; whereas the public sector is often unclear and much less organized. This is in part due to the many governmental rules and hoops faced by public sector organizations.

There are an abundance of reasons why mediation is a reasonable approach for disputing public sector parties. Among these include the fact that mediation is confidential, voluntary, and allows participants to structure their own resolution. The review of the literature indicates that intergovernmental mediation, as a technique for successful local government partnerships, has been the subject of minimal research. 
Furthermore, as our world becomes more sophisticated and these local governments continue to face increasing competition due to non-funded federal and state mandates, the need for conflict dispute resolution is more important than ever.

\section{Methodology}

For this research a comprehensive purposeful population was used. Therefore, the population consisted of county commissioners, township trustees, appointed officials, and citizens at large ail from within the state of Ohio.

\section{Description of Methodology}

To meet the research criteria, pre-questionnaire telephone interviews were conducted with selected elected county officials from throughout the state of Ohio. Arrangements were made to personally meet with each individual to be interviewed. The survey instrument entitled "Intergovernmental Mediation" was provided to individuals meeting the following criteria: an individual must (presently) hold the elected position of either county commissioner or township trustee in the state of Ohio. County commissioners were selected from a master list made available by the County Commissioners Association of Ohio. Township trustees were selected from a 1998 master list made available by the Defiance County Commissioners office.

The 15 citizens at large had to meet the criteria of living in Defiance County and being a registered voter with the Defiance County Board of Elections. It was necessary for appointed administrators to be active practitioners with a local unit of government at the city, township, or village level. 
Individuals were provided with personal data regarding the researcher including telephone numbers and an email address. This information was provided to participants desiring to contact the researcher, in the event there was a need for follow-up communication with regard to the survey.

\section{Findings of the Study}

Research question 1: What is the level of experience in the intergovernmental mediation process as perceived by county commissioners, township trustees, appointed administrators, and citizens at large?

County commissioners and appointed officials have a significantly better understanding and considerable more experience with interguvernmental mediation as opposed to township trustees and citizens at large. The number of years in office by county commissioners did not impact the level of understanding.

Research question 2: What is the level of understanding of intergovernmental mediation that is perceived by county commissioners, township trustees, appointed administrators, and citizens at large in Ohio?

Township trustees and citizens at large had very minimal understanding of the intergovernmental mediation process. County commissioners and appointed administrators had a significantly higher understanding of the need for and the value of the process.

Research question 3: What is the relationship between intergovernmental mediation and successful local government partnerships as perceived by county commissioners, township trustees, appointed administrators, and citizens at large? 
County commissioners and appointed administrators strongly support the relationship of intergovernmental mediation to successful local government partnerships. Township trustees and citizens at large did not significantly relate intergovernmental mediation to successful local government partnerships.

Research Question 4: What are the types of variables that create conflict between and among neighboring units of local government?

The results displayed a significant relationship between lack of revenues, unfounded mandates, and contention for new dollars by competing units of government.

Research question 5: What types of public sector mechanisms are presently available for local government officials?

A significant number of county commissioners, township trustees, appointed administrators, and citizens at large knew there was something out there to help address intergovernmental conflict in the public sector. Few could identify the actual mechanisms available for local government officials.

Research question 6: Do Defiance County units of local government practice intergovernmental mediation? If so, what have been the outcomes in terms of economic development and partnership agreements?

The units of government in question very much practice intergovernmental mediation. The outcomes have been the successful signing of a Joint Economic Development District agreement between the city of Defiance, Noble Township, and Defiance County. A second favorable outcome is the recent construction of a \$2.1 million express sewer serving the residents of Defiance City, Defiance County, and Noble Township. 


\section{Discussion}

The results of the data collected suggest there is a need for public officials to recognize that there is a problem within the system. Many historians of the American Civil War seem to agree that one of the major outcomes was establishing the dominance of the federal govemment over states. Taking into consideration the trickle-down theory, states have clearly, over the years, established dominance over units of local government. Subsequently, units of local government are required to function by a set of rules divergent from the private sector. Therefore, local government officials are faced with a variety of unique considerations as they do the day-to-day business of the people. These officials need to be cognizant that there are built-in variables that place them in a highly competitive environment subject to public scrutiny.

What makes the public process of dealing with public issues different from the private sector is that almost all formal, and many informal, actions are open to public consumption. In Ohio, the "sunshine law" requires public bodies to advertise meeting dates, meeting places, and agenda items in major newspapers of circulation. With the exception of executive sessions dealing with personnel issues, pending litigation, or land acquisition, these meetings must be open to the public. Therefore, sensitive or litigious isst_; for the most part must be placed in the "front store window." Quite often, the only time citizens attend public forums is to vent their dissatisfaction about an issue. Private sector officials, on the other hand, are free to conduct business and make decisions removed from the customers. Public officials conversely are frequently faced with the task of making unpopular decisions in the face of citizen scrutiny. Often these unpopular decisions can be very damaging to a public official. For example, a Defiance City 
councilman in the 1960s ultimately lost his dry-cleaning business because many of his customers, who were also his constituents, were angry about his vote on a zoning issue. Support for this position is found in the writings of John F. Kennedy (1956).

Where else, in a non-totalitarian country, but in the political profession is the individual expected to sacrifice all-including his own career for the national good. In private life, as in industry, we expect the individual to advance his own enlightened self interest within the limitations of the law in order to achieve overall progress. (pp. 27-28)

Another variable that can make the public process quite cumbersome is its being open to media interpretation. The reporting of public policy actions can often result in mixed response by citizens at large. As a result, public officials are frequently placed in a situation whereby they are unable to totally express their position or disclose pertinent information on an issue. In yet other cases, public pressure can have an impact on a public official's decision-making process and outcome. That is to say, an official might be tempted to alter a decision to gain media and/or public support. Indeed, media influence is an important variable in the public sector. It is important for elected officials to recognize that the media influence does place them in a competitive environment, with the media, with citizens, as well as with other units of local government.

Finally, as a part of recognizing the problem, it is important to understand the influence of unfunded mandates and competition for available revenues. As stated in chapter 1 , the continued downsizing of federal and state government has resulted in increased non-funded mandates to local governments. Officials are faced with competing with area units of local government for lucrative, revenue-pıoducing economic development projects. These competing units of local government, in an effort to woo developers, commonly create incentive packages to the dismay of other competing units 
of local government. This type of competition creates an atmosphere ripe for dispute and conflict.

Lack of revenues, competition for economic development projects, coupled with citizen scrutiny and media exposure create a highly competitive environment for local government officials. These local officials need to recognize the magnitude of adversity to which they are exposed. One way of bringing about this recognition is through the education process. Educating upper echelon local officials to the need for recognizing their competitive environment will bring them one step closer to considering the employment of intergovernmental mediation as a method of dealing with intergovernmental conflict.

The data suggest that educating local officials and citizen groups as to what is out there is a very big piece of the puzzle. One step in this education process is to better understand the law and the mechanisms that are made available through it. For example, as discussed in chapter 2, the Ohio Commission on Dispute Resolution and Conflict Management has as one of its primary goals to initiate and establish dispute resolution and conflict management programs and activities in government, educational institutions, communities, and the legal system throughout Ohio. In meeting this goal, the commission has established a 2-day conflict resolution service for government officials' training, as described in chapter two. Among these are: attempting to understand conflict; viewing conflict as an opportunity; considering the value of "outside assistance;" selecting mediator; and utilizing collaborative approaches.

One of the best ways of educating people to the value of intergovernmental mediation is by establishing an organizational education program. One way in which this 
might be accomplished is by establishing in-service educational opportunities. For example, individuals from the street department might meet with employees from the water department to share and exchange information about their job responsibilities. This process can then be extended between and among neighboring units of local governments. Another suggestion is to establish monthly or quarterly meetings with neighboring units of government.

At these meetings, experts from various fields of mutual interest to the parties could be brought in. One example might be to bring in a representative from the State Department of Transportation to discuss department policies affecting local government issues. Educating people is a key to successfully understanding intergovernmental conflict. Currently, nearly every state in the union has a web site dealing with intergovernmental issues and strategies for addressing intergovernmental conflict. Employees could be given time to search out these valuable web sites. Middle and upper level managers could be encouraged and rewarded for investigating, learning, and utilizing intergovernmental strategies in the workplace. Employees and managers could be sent to seminars such as those periodically presented by the Ohio Office of Dispute Resolution and Conflict Management. These seminars are usually generally low to moderate in cost, with the participant normally paying only transportation, food, and lodging costs. Yet, even if educating employees, managers, and elected officials stretches the budget, the potential savings to the alternative of costly and long-term litigation should be considered. Finally, it is recommended that public sector and local government organizations appoint, train, and educate officers with the objective of promoting intergovernmental dispute and conflict education management. 
Education is a very important piece of the intergovernmental process. Yet, perhaps even equally closely allied to the intergovernmental issue is understanding the influence of politics in the mediation process. Nonetheless, understanding conflict should be one of the primary steps in the process of understanding intergovernmental mediation.

The study demonstrated a real need for public officials to better understand conflict. Maggie Lewis believes conflict to be a natural, inevitable phenomenon resulting from a variety of reasons. The most common causes are misunderstandings, personal agendas, and lack of communication, often resulting in a dispute of the facts. Yet, conflict is not just dealing with facts but with emotions as well. Conflict can involve anger, ego, fear, selfishness, self-esteem, uncertainty, and distrust. The most frequent sources of conflicts include money, politics, power control, value differences, overlapping authority, lack of information, and understanding of roles. These factors all have one thing in common. All contain a human element subject to discretion in dealing with human relationships. As copious as conflict is, it remains of vital importance to consider the potential good that can result from conflict when viewed in a positive manner.

The results imply that how we view conflict is critically important. It is generally believed that the manner in which we view things can have a tremendous impact on outcomes. In the case of conflict, Herrman believes that "we do have the power to choose how we view conflict" (1995, p. xiv). The first and perhaps most basic choice concerns how one views conflict: Is it an ally or an enemy? Just as we associate conflict with loss, we also associate it with negative feelings such as anxiety, tension, fear, and 
anger. These enculturated responses may shift over time, but most of us still prefer that things run smoothly, without fuss or bother (Hermann, 1995, p. xiv). It is understandable that we might choose to view conflict as a negative. After all, it can be very painful, but then so can vigorous exercise. What we need to consider is the good that can result. In the case of exercise, it is a healthy body, and in the case of conflict, an opportunity to seek out a mutually acceptable resolution. It is of utmost importance to recognize when choosing to view conflict in a positive manner that it affords the opportunity to select an effective method to deal with issues at hand.

It is important to remember that tension is not all bad. It offers an opportunity for disputing parties to sit down and talk, which might very well result in the repairing of relationships. When people are talking there is hope! One good way to help keep the process healthy is by trying to "lighten up the environment" where the discussions will be taking place. Including a positive environment can be just as important as having a positive attitude. One way that might be helpful is to find a neutral spot for meetings. Most people enjoy a clean, pleasant environment. If the meeting room temperature is too warm or too cold, this may make it difficult for people to concentrate. There should be adequate lighting, comfortable seating, and all participants should have equal seating arrangements. The process might begin with some light humor, remembering that it is best to make oneself the butt of the joke rather than one of the other participants. As much as possible, the activity should begin with pleasant and light-hearted conversation. Why not consider providing some soft drinks or cookies and milk? After all, nearly everyone enjoys cookies and milk, as it is something we learned from our kindergarten years. 
The study examined the need for considering outside assistance. The results suggest that disputing parties should consider utilizing a third party mediator in conflict resolution for a variety of reasons. As pointed out in an earlier chapter, employing mediation is an informal way for people to work through problems and deal with conflict disputes. Since mediation is usually a voluntary process, it offers the opportunity and empowers people to design their own solution. This is important because disputing parties tend to focus on their interests rather than their positions. The benefit of utilizing a third part neutral is that conflicting parties are often encouraged to reach a mutually acceptable solution.

As previously pointed out, another reason to use a mediator is that it is voluntary in nature; therefore, rules can be structured to permit flexibility in the mediation process. For instance, when preparing for dispute resolution, parties can feel comfortable in knowing they are not being forced into the process. Moreover, any time that conflicting parties feel discomfort or become disenchanted, they have the power to adjust and/or to terminate the procedure. Clearly, a major value of using a mediator is to have assistance in setting up the process and helping the conflicting parties through it without compelling them to major obligation. Finally, using a mediator can provide a safe and comfortable environment because a mediator can bring structu _ 2. .. balance to the dispute resolution process. Having structure and balance is of particular importance in the initial stage of the mediation process. This is especially true when establishing a set of ground rules to guide the mediation process.

In this study the need for establishing ground rules surfaced time and again. One of the first steps disputing parties are often asked to take by a third party neutral is to 
agree to some basic ground rules. For the most part, ground rules are a matter of common courtesy and a method to maintain some semblance of order in the process. Dispute resolution without some rules can be expected to be a chaotic experience. Ground rules, according to Maggie Lewis (1999b), help to ensure "a more even playing field" for the disputing parties. Some very basic but generally universally accepted ground rules according to Lewis are:

1. Only one person to speak at a time

2. Each party is given opportunity to be heard

3. Mediator summarizes the information shared by each party

4. Mediator assists parties in generating agreement options

5. Mediator assists in drafting an agreement.

Another important consideration when establishing ground rules is to keep in mind that dealing with conflict means dealing with people. People are human, and most humans have certain basic psychological needs. Most of us from a very early age were required to follow some rules, if not at home then probably in school. Therefore, we are likely to feel more comfortable when there are at least some guidelines to help us along the way. Nonetheless, it is important to understand that as humans we do not see things as black and white. Ground rules are no exception! We should try not to become too frustrated if there is an interpretation issue associated with the ground rules. Rather, in that situation it is best to defer interpretation to the third party neutral.

There are many possibilities or options to select when establishing a set of ground rules. A set of rules can be structured as firm or as flexible as the parties desire to fit the need, and, although it is best to reduce ground rules to a written form, it is not necessary to require the signing off by disputing parties. Ground rules do help to address the issue of psychological needs, which significantly promotes the effectiveness of the mediation 
process. The following suggestions are not cast in stone; however, they do offer some guidelines and do merit consideration. Some of the ways to help address those needs and ought to be considered are:

1. When seeking a solution ask others their ideas.

2. Allow people to make choices.

3. Show people they are being listened to by paraphrasing what they have said.

4. When making points refer back to the other side's points.

5. Make points firmly without being aggressive.

6. Remain friendly.

7. Use terms like "We can understand how you can feel the way you feel."

8. People like to hear their first names; use them often.

9. When disagreeing, do it respectfully.

The best ground rule of all is the Golden Rule: Treat others as you would like to be treated. Utilizing ground rules is just one example of how disputing parties can add stability to the dispute resolution process. Still, the real key to increasing the chance of successful intergovernmental dispute resolution lies in choosing a mediator. Selecting a ne::.:al empowers the parties to create their own solutions rather than inilibiting the resolution process by being required to live with an arbitrator's decision.

Finally, there is a genuine concern by local government officials as to the issue of time and money. As previously noted, mediation can save a great deal of time and money by avoiding costly, lengthy litigation. Yet, perhaps the utmost reason for using a 
mediator in intergovernmental issues may be difficult to assign a value to because of the abstractness of the issue. Maggie Lewis captures it best in her statement,

The cost of a community divided by an issue is impossible to quantify, likewise the cost of political ill will can't be quantified. Local government officials, specifically, those elected, are very aware of the impact of a divided community, particularly when a tax issue or their name appears on the ballot. Harmony and minimal fragmentation are of vital importance to the success of a community, two factors that can very likely be positively influenced by employing a mediator in the intergovernmental dispute resolution process. (Personal Communication, June 16, 2000)

This study suggests that once parties have made the decision to utilize a mediator, it is of utmost importance to consider the selection process that will be followed. Making an informed choice is the best choice. Choosing a quality-experienced mediator is a plus. Choosing an individual who specializes in the specific subject area requiring mediation is not always necessary. What is significant to a healthy selection process is evaluating certain criteria of potential candidates. If time is not a factor, the process can be done through a request for proposal (RFP). In this method, a unit of local government would obtain quotes from agencies and organizations based on certain information requested by the unit. The benefit of this method is that it permits managers to review candidates' specific qualifications, proposals and fee structure. Since this process is time consuming, it is not recommended in situations where time is of the essence. Fortunately, organizations such as the Ohio Commission on Dispute Resolution and Conflict Management maintain lists of qualified active mediators and, therefore, can minimize search time significantly.

The process to select a mediator should not be a great deal different from that used to select other professional service providers. Many states have laws requiring local units of government to go through a competitive bidding process when seeking outside 
services above a specific dollar figure. Generally, an exception is granted in cases dealing with professional services such as architectural, engineering, and legal consulting services. Employing the services of a mediator is considered in many states to fall within the definition of "professional consulting services." Therefore, in these cases the process of selecting a mediator is not subject to the "lowest and/or best bid" as required in the competitive bidding process. Examples where the competitive bidding process for services is generally required would be issues such as construction contracts or vehicle purchases.

Selecting a mediator on "price only" may very well lead to the selection of the least qualified rather that the most qualified. The problem is the difficulty of defining the scope of work for professional services at the time of selection, unlike selecting a product such as a vehicle or a structure, which can usually be defined to nearly exact detail at the time of seeking bids. For example, at the time of bidding, one has usually decided about a vehicle's desired specifications such as power steering and anti-lock brakes or a 40-by60 -foot Butler Building with concrete floors. It is not easy to specify a mediator's qualifications. This also holds true when selecting engineers, legal counsel, and other professional consultants.

So what is the optimum selection method for procuring a mediator? The answer seems to be requiring some degree of accountability by employing some formal procedure in the selection process. One highly recommended procedure involves the use of a qualification-based selection process. Using this technique, local government officials are afforded the opportunity to interview and evaluate professional firms based on certain criteria. Typically, a selection committee of two or more persons representing 
a disputing party would interview prospective firms. Based on responses received and other statistical data, points would be assigned based on individual evaluation. An example of a qualification-based questionnaire that might be used to select a professional firm is shown in Figure 2.

Other criteria that should to be considered are the number of years the firms have been in business, the firms' capacity to meet schedules, and the satisfaction level of former clients. An effective method of evaluating satisfaction levels of former clients is through a reference check. Some questions that might provide helpful answers and ought to be considered include:

1. When was your project completed?

2. What did your issues involve?

3. Name of firm's representative you worked with most closely.

4. Overall, how would you evaluate the quality of service performance? Meeting schedules and deadlines?

5. How would you rate the firm's overall attitude and ability to communicate and work cooperatively? 


\section{Name of Project or Issue}

Names of Firms:

- Firm \#1

- Firm \#2

- Firm \#3

- Firm \#4

Name of Evaluator

Possible Points

Points Awarded

$\# 1$ \#2 \#3 \#4

1. Qualifications and experience of firm's key personnel

15

2. Understanding of public policy and local government constraints

25

3. Firm's analysis, interview preparation, and level of interest

25

4. Firm's history, previous experience on similar projects

15

Page 2 of Evaluation

Possible Points

Points Awarded \#1 \#2 \#3 \#4

5. Ability to perform scheduled activities and respond to non-scheduled activities as needed.

6. Interview Score

15

7. Comprehensive/Fees

Total

Figure 2. Qualification-based questionnaire. 
Selecting the best-suited individual or firm to meet your organization's needs is imperative. Taking time to interview, review, and talk with others might very well be the most important step in the entire mediation process. Failure to select the best available professional might result in total disaster. Mediation is difficult enough! Intergovernmental mediation, with all the obstacles and restrictions, is at best extremely difficult. Selecting and accepting a neutral third party is indeed a challenging task. The reason is that it requires conflicting parties to accept a position of vulnerability. To allow an unknown, unfamiliar participant to engage in very personal and confidential concerns makes the parties vulnerable. Yet, even if the decision to accept a third party neutral is made, the real challenge is letting go!

Elected local government officials, for the most part, have a tremendous degree of responsibility. Likewise, by virtue of their office they have a considerable level of discretion and local control. Therefore, it is sometimes difficult for these local officials to acquiesce their authority, real or perceived, to an unknown. As pointed out in the literature review, accepting the assistance of a third neutral party does not require giving up control. It simply means allowing someone to assist by facilitating the process for disputing parties. Keeping in mind that the two primary objectives of a mediator are to set the process and to get the parties through the process might ease the trepidation of letting go. Yet, it is perfectly reasonable for local officials to be cautious in selecting and accepting a mediator. Even an innocent mistake by a well-intentioned mediator could place the elected official at risk in the next public election.

Take, for example, the account of two sisters arguing over an orange. In an effort to help settle the dispute, the babysitter cut the orange in half, giving each young lady her 
share. Yet, the dispute continued! One of the girls wanted just the pulp to make orange juice. The other wanted just the peel to make orange marmalade. The babysitter thought she was doing what was best to resolve the dispute. Unfortunately, each of the girls obtained only one half of what she could have.

One good approach to selecting a mediator is to utilize the three P's: prior proper planning. In other words, the parties should not nush into a mediator selection simply to fill the void. Caution must be used, taking time, and talking with others who may have experience and a history of working with a particular individual or firm. Selecting a mediator often requires mutual consent by each of the disputing parties. Preparing, developing a selection process by using a rating system similar to the one previously shown, and establishing a working list of potential individuals or firms will ensure that when it becomes time to select a mediator, a resource list will be available from which to choose.

In this study the importance of selecting the right firm or individual is critical toward achieving the best possible conflict resolution. Alternate dispute resolution, if managed improperly, can result in a highly undesirable domino effect. This can, in turn, create a negative environment that could be even worse than that of the original dispute. This is particularly true when the equation involves $2 . .$. .ssue between citizens and local government.

Because so many of the decisions of public officials have a direct impact on citizens at large, it is wise, when practical, to involve them in dispute resolution processes. It should be noted that it is not appropriate to involve citizens' participation in all dispute resolution issues. There are simply some issues that should be handled 
exclusively by local government leadership. These types of issues tend to be internal issues requiring understanding of organizational needs, statutes, mandates, and codes. An example would be internal organization issues such as staffing additions.

Conflict resolution issues that probably should include citizens' involvement would be high-profile issues needing public support. For example, citizens should help to decide where to locate a regional jail or multi-county landfill east of the village, otherwise, it will likely be perceived as an unreasonable forced action. On the other hand, if two local industrial leaders say, "We need to place a landfill east of the village in order to keep business operations competitive," it is more likely to be accepted. After all, industry means jobs, and jobs are what it takes for people to survive.

The real key to effective citizen involvement is to include local individuals who have the trust and confidence of the general public. Supportive words by a well-thought of citizen can go a long way in selling an idea to the general public. Finally, citizen/local government partnerships tend to promote media involvement. Getting the media to understand and support the issue of conflict can often be half of the battle.

Likewise it can be good to involve the general public, when practical, in addressing litigious issues. Public officials are more often considered part of the problem rather than part of the solution. The reason for this is because public officials are often considered by the general public to be "self-serving." Caution must be used in selecting a citizen to champion a cause. For example, it would not be good to select an individual to head the committee for a second fire station who had been convicted of arson. Such negative exposure can quickly be picked up and reported by the media. 
The importance of maintaining good relations with the media was quite evident throughout this study. There is an old amusing story that circulates in many of the council chambers and meeting rooms of local governments throughout this nation. It talks about the conflict between a local elected official and the editor of the town newspaper. Rather than being able to mutually work out the burning issue, the two continually butted heads. The politician at every opportunity publicly professed the news editor's ignorance on the fiery issue. The editor regularly blasted the politician in the front-page stories and with negative editorials. The more the conflict grew, the greater number of negative stories concerning the politician's position was published. As a result, at the next general election the local official was defeated while the editor and newspaper went on to prosper. The moral of the story is, "Local elected officials should not try to take on anyone who buys ink by the barrel."

Whether or not the story is true is open to debate. The fact is that, as previously pointed out, public sector officials are often the subject of high profile coverage by the media. Basically, all records and meetings are open to public consumption and, therefore, the lot is "fair game." That is not to say that the mission of the news media is essentially one of "getting politicians." However, there does appear to be a different atti ' de being reflected by the media these days regarding public officials. One example is found in a July 22, 1995 presentation to the American Political Science Association in San Antonio, Texas, by author Thomas E. Patterson (1995). He reported:

The rules have changed with Vietnam and Watergate, when the deceptions perpetuated by the Johnson and Nixon administrators convinced reporters that they had let down the nation by taking political leaders at their word. Two presidents had lied; therefore, no politician was to be trusted. The poisonous effect of Vietnam and Watergate on the relationship between journalist and 
politicians has not dissipated. The anti-politics bias of the press that came out of the closet two decades ago has stayed out.

The wise public official is one who realizes the public sector is subject to a divergent set of rules and that media support is vitally important when dealing with intergovernmental conflict issues. One problem is that public agencies have limited budgets and generally cannot pay for advertisement like a private sector J.C. Penny or Elder-Beerman Company would do. Therefore, it is necessary to work with the media in an effort to achieve the highest level of support attainable.

This does not suggest that local elected officials must compromise personal beliefs to establish positive media relations. It does, however, support the wisdom of local government officials utilizing a win/win strategy in dealing with the media. To realize a win/win outcome in media relations, it is essential to understand the environment in which they must compete.

In the past 20 years the number of newspapers and radio and television stations in just the tiny area of Defiance, Ohio, has grown significantly. For example, in 1980 there was one radio station serving the area. Today there are four. Likewise, in 1980 the city did not have a television station serving the area. Today there are two public television stations located within the city boundaries. Multiply this growth on a statewide or even nationwide basis and it is clear there has been a substantial increase in media competition. Newspapers and networks are engaged in a boundless race to be the first to report a breaking news story. Consequently, there are circumstances when accuracy is exchanged for timing. This is not a totally new phenomenon when considering the erroneous 1948 Chicago Newspaper headlines "Dewey Defeats Truman." In an effort to be first with the "breaking story," newspaper leadership decided to print the headline 
since Dewey was favored in the polls. By the time votes were counted and it was discovered Truman had actually won, the paper was on the streets. With this fast-paced media, the problem becomes an issue of accuracy. Further complicating the issue is the reality that the media today are all about ratings. What this should mean to the public official is "look out." It seems today, more than ever, that the media choose to sensationalize all in the name of ratings.

In faimess to those in the profession, it is not secret that being in local media is not the greatest paying profession in the world. Compound the problem with the realization that almost everyone, for one reason or another, dislikes the media at some point. Perhaps it is for what was reported or for what had not been reported. To this end, local media personnel and local politicians share something in common. Understanding this commonality can help structure a mind-set that should help create an amicable relationship with the media. The result can be an even playing field, which is a real plus in intergovernmental dispute issues that go public.

Perhaps the best way to create a harmonious relationship with the media is through mutual respect. Understanding that media reporting will not always satisfy personal needs for agendas, accepting that news media personnel are people too and have needs as well as feelings, one should treat them fairly and not try to use them for personal gain. Permissible information should be shared equally across the board, and one medium or personality must not be favored over another. Honesty is vital. If an answer is not available, the media should be told or, better yet, the correct answer should be sought and the media advised. Most importantly, the media should be treated with kindness and compassion. If something does not go the way it was hoped for, one should 
shake it off, and above all, one must never hold a grudge. Having a reasonably good relationship with the media will very much help set the stage for the actual mediation process.

This study suggests that all of the positive press possible would not assure an effective process without following some sort of mediation model or structured process. As discussed in chapter 1 , the degree of increased complexity and competition facing local government has created the need for some type of intergovernmental mediation process. There are a variety of mediation models which serve as reference points that adapt specific mediation processes to individual case needs. One mediation technique that particularly deserves review and consideration involves the use of a collaborative approach. As previously noted, when parties who have a stake in an issue engage in collaborative problem solving, solutions acceptable to all are frequently promoted. Also, as previously noted, there is an increased call among dispute resolution agencies for applying collaborative approaches in the mediation process. The reason, according to Maggie Lewis (1999b) is that the use of the collaborative process encourages a greater sense of commitment to the process as well as to the outcome developed by all stakeholders.

Yet, collaborative approaches are not appropriate in every situation. In some cases this approach should be reserved only as a last-ditch effort. The reason is collaborative approaches take time and some issues do not allow that luxury. True collaboration requires disputing parties to create a solution by focusing on everyone's interests. This is primarily because participants mutually define the problem by engaging 
in a concerted effort to identify the issues. Having an unreasonable deadline would greatly diminish the effectiveness of the process.

Other pitfalls of intergovernmental mediation at the local level are personal issues and petty jealousies. In local situations there tends to be "relationship history." Thus, it can be difficult to focus on the problem rather than on personalities. It is also important to recognize that this method requires equality of authority. If there is a substantial imbalance of power, it is difficult to achieve the openness required to make the process effective. Nevertheless, a true collaborative effort is most effective in long-term relationships. Examples of matters that are likely to recur or to be ongoing are annexations, water, and sewer. The reason is that solutions can be designed to address continuing change and development while leaving room for future modification issues.

Since collaborative dispute resolution involves developing creative solutions, it is best suited for issues involving value judgments. For those issues predicated on legal statutes, collaboration is not always as effective. The reason for this is that parties must stay within the spirit of the law; thus, the degree of flexibility to design a creative solution is minimized. It is not impossible to use collaborative methods in these types of situations. It is just that there are other more effective methods that should be considered. For example, there are times when issues are so emotional or public sentiment so strong that it is not possible to sit down and go through a collaborative process. In either case, the options are similar, only the process is different.

Whether using a collaborative or non-collaborative style, the choices are generally unassisted negotiation, facilitated negotiation, or out-and-out mediation. These types of processes tend to be more structured and less time consuming. Yet they all provide a 
mechanism for bringing people together to communicate. Finally, it is important to recognize that no matter what method is utilized, intergovernmental mediation takes time. Although as pointed out by Maggie Lewis, some methods take more time than others, the fact is, the success that comes out of intergovernmental mediation will likely be determined by what is put into it (Personal Communication, March 23, 2000).

As pointed out in the literature review, there is not "one size fits all" in terms of mediation models. The individual circumstance and the nature of the situation should determine the approach we choose to utilize. Nevertheless, when possible it is good to use a collaborative approach because it not only allows parties to feel a part of the process but also to be a part of creating the solution. Some issues can be resolved one on one, but for the really tough issues, the recommendation is to get a third neutral party to assist in the process.

There has not been a great deal of work on establishing methods for assessing dispute resolution practices. One reason is that in mediation processes are like snowflakes, having many different shapes and variations. As previously pointed out, David Fairman (1999, p. 2) believes, after 20 years, that attempts to evaluate consensusbuilding efforts in the public sector have failed to produce agreement on even the right criteria to use for evaluation. Yet, if there is any hope to improve on the intergovernmental mediation process, we need to be able to evaluate the process and subsequent outcomes. There are a number of considerations that should be pondered in the evaluation process. Was the process a comfortable process for all stakeholder participants? Which approaches seemed to work best in the process? Which methods seemed to be the least effective? What were the main obstacles encountered? If faced 
with a similar situation or issues, what might be done differently? Finally, what could have been done to improve on the overall process? Of course, there is room for many other possible evaluative questions. The point is to be able to assess the process with the hope of establishing a more effective procedure to improve similar, future activities.

Some other techniques include keeping a journal and ending each session with a review of the bullet points of that session. Other methods include providing a written summary of the previous session at the beginning of each meeting. Yet perhaps the best method is to review the process immediately after the session. The advantage to doing it right away is that participants are more likely to be able to recall the events of the day. Waiting or delaying the process can result in loss of vital information. Nonetheless, later is better than not doing any evaluation whatsoever. The important point in doing an evaluation is being as objective as possible.

The most important reason for doing an effective evaluation and assessment is that there will be made available a valuable mechanism to address future conflict opportunities: A resource providing information about past issues and players with whom one may have dealt. Having an understanding of where people are coming from can very much promote an effective mediation process. This is particularly true in the case of local elected officials.

Understanding the players is a key element to successful intergovernmental mediation efforts. More often than not the mediation process will find local elected officials in the "driver's seat" to manage the course of action. The problem is that local elected officials are often selected by voters more on the basis of popularity than for their understanding of public administration. This can create what I call the "Wizard of $\mathrm{Oz}$ 
Syndrome." In the 1938 classic Hollywood movie, "The Wizard of Oz," the Scarecrow, Tin Man, and Lion each sought a special endowment from the wizard. The Tin Man sought a heart, the Scarecrow a brain, and the lion, courage. The wizard granted the requests and immediately each became something they were not. In the case of the Scarecrow, there was instantaneous receipt of perceived knowledge. In the 18 years of being a local elected official it has been my observation that many newly elected local officials frequently feel endowed with incredible knowledge of public administration. Just at the Scarecrow became an immediate expert, so does the official with the new endowment by the voters. This can provide a recipe that can be very destructive in the mediation process.

It can be good to consider the degree of understanding or lack there of, particularly when dealing with newly elected local government officials. If one can recognize and accept the "Wizard of $\mathrm{Oz}$ " syndrome, one can then adjust and fine-tune the mediation process to help ensure a better prospect for success.

\section{Conclusions}

The following conclusions were made based on the findings of the study:

1. Local government officials are faced with increased demands as a result of federal and state non-funded mandates.

2. Local officials must compete for reduced available revenues, thus creating an environment ripe for conflict and dispute.

3. Citizens' expectations and demands on local government officials appear to be greater than ever.

4. Available public-sector dispute resolution programs are few at best. 
5. Some local officials recognize there are mechanisms to address intergovernmental dispute and conflict, but do not know exactly what they are.

6. The need exists for competing units of government to communicate and build relationships that are vital to harmonious intergovernmental relations.

\section{Recommendations}

The following recommendations are proposed:

Recommendation: The need for more educational programs for local government officials as to the value and benefit of intergovernmental dispute resolution programs.

Solution: Local units of government establish an in-house alternate dispute resolution education program for managers and employees.

Recommendation: Public officials need to recognize and understand that conflict is an inherit part of local government management.

Solution: Learn to view conflict as an ally and not as an enemy. Public officials must recognize that it affords an opportunity for informal dialogue.

Recommendation: Agencies and organizations need to be prepared to meet conflict head on with a plan.

Solution: Establish a dispute resolution management plan to address future conflict issues.

\section{Summary of Recommendations}

Opposing viewpoints, conflicts and disputes are not new among human beings, local government officials included. Personal data collected suggest there is very much a need to address intergovernmental dispute issues. Recognition by local government 
officials who are placed in a highly competitive environment is the first step in taking a pragmatic approach to intergovernmental mediation. One effective method is through an education process such as that offered by the Ohio Commission on Dispute Resolution and other similar agencies throughout the states. Through education, local officials can better understand some of the more common causes of conflict, which, in turn, can open an entirely new perspective to managing local intergovernmental relations. In doing so, conflict can be viewed as an opportunity for potential good and effective change in dealing with intergovernmental conflict and intergovernmental relations.

This attitude can open up an entirely new world of intergovernmental mediation to local government officials. By following a few simple guidelines, it is possible to select the best possible mediator for the issue at hand. By involving citizens' participation when applicable, establishing a few ground rules, and establishing a good working relationship with the media, intergovernmental disputes can be properly managed. Moreover, what is obtained through an intergovernmental mediation process will likely be based on what effort is put into it. Finally, doing an objective evaluation of the intergovernmental mediation processes will provide useful information that can be gleaned for future conflict-resolution opportunities.

The key for local government officials is to recognize that tension is not entirely bad and to understand that they are in a highly competitive environment. Intergovernmental mediation allows an opportunity for reducing politics while saving and repairing intergovernmental relationships. It also substantially reduces the formality of the process by keeping away from the judicial system. Many judges are saying, "Keep it out of court!" Besides, the court dockets are usually very full, resulting in long and 
costly delays. By avoiding the courts and creating a mutually acceptable solution, the "pay me now or pay me later" syndrome can be avoided.

Alternate dispute resolution is good because it creates an informal dialogue. Yet even the best of intentions may need some help. Therefore, the recommendations are: to promote communication between area units of local government; to establish quarterly meetings of area public officials to sit down and discuss issues of mutual interest; to create a county council of governments even if it is in an advisory capacity only. The council could be made up of mayors, township trustees, county commissioners, and appointed administrators representing the political subdivision; to create and foster personal relationships with other elected officials; to set aside at least one meeting a year to have a picnic, including not only the elected officials, but their families as well. In doing so it will be possible to see the other side of the individuals with whom the only previous contact was work or dispute related.

Each organization should establish a conflict dispute resolution plan. Nearly every public agency has on file a disaster plan offering a response in the event of a tornado or fire. Likewise, a plan to address conflict and dispute resolutions is an effective means of dealing with crisis situations. As suggested by Law Director William, an individual should be appointed to serve as head of the agencies, conflict dispute program. The agencies prepare a resolution management plan to address future conflict issues. The city or village council, the township trustees, or the county commissioners should pass a resolution or ordinance mandating all public agencies within their jurisdiction to be required to sit down and talk on an issue before there can be any action 
toward litigation. Better yet, the mandate should state that disputing parties unable to resolve a conflict must go through a mediation process prior to going to the next step.

At the state or national level, legislators should be encouraged to establish a law establishing mediator certification. As it is today, an individual can hand out a "shingle" and purport to be an expert mediator. Today even most insurance salesmen are required to be licensed by the state in which they sell. When considering the tremendous stakes at risk in an intergovernmental mediation situation, it makes a lot of sense to require some educational requirements and accountability.

Intergovernmental conflict issues are not going to go away anytime soon. As local government officials, we can do one of two things. We can become bitter or we can become better. Doing nothing to address the increased complexity of local intergovernmental issues will likely result in a feeling of frustration and bitterness. However, by looking at intergovernmental conflict as an opportunity, and by addressing it in a responsible manner, we can become better. We can establish a positive attitude and meet conflict head on with a plan. 
APPENDIX 
APPENDIX A

COVER LETTER AND QUESTIONNAIRE 
October 12, 1999

To Ohio Residence and Government Officials:

I am a doctoral student in the Leadership program at Andrews University in Berrien Springs, Michigan. The attached survey is a very important part of my study on intergovernmental mediation. The actual title of the study is "Intergovernmental Mediation: A Technique for Successful Local Government Partnerships." The outcome of this study is intended to provide helpful information to the local officials faced with conflict issues involving neighboring units of local government.

Your participation in this intergovernmental study is totally voluntary. However, your considerable experience and knowledge of local government is a vital part of the success of this study. The information collected from you will help to build on existing data involving dispute resolution at the local governmental level.

Realizing that you are a very busy person, every effort has been made to minimize the time required to complete the attached questionnaire. The average time for completion by individuals pre-testing was less than 10 minutes. If, for any reason, after starting the questionnaire you do not feel comfortable in continuing the process, please feel free to decline completion. If you do choose to complete the survey, you can be assured that your responses will remain completely and totally confidential. Please do not include your name on the survey. As with much graduate student research, there is no payment associated with participating in this study.

Any comments that you might share will be very much appreciated. The attached consent form provides valuable information concerning the procedures associated with this study. If you have any questions about the research or should you desire a summary of the research results, please feel free to contact me or my dissertation Chairperson:

Dr. Elsie Jackson

Andrews University

School of Education

Bell Hall 160

Berrien Springs, MI 49104

Phone: $616-471-3200$

Sincerely,

W. Tom Wiseman, Doctoral Student

Andrews University 


\section{INTERGOVERNMENTAL MEDIATION}

Questions for Elected Officials

Administrators and the General Public

\section{Title}

Organization Name

\section{Elected or Appointed}

Years in Position

(Would you piease be so kind as to take a few minutes and answer the following questions?)

1. Have you had any direct experience with inter-governmental mediation as a mediator, observer, or party? If so, briefly describe the conflict or situation that prompted the mediation?

I want to ask you now about your mediation experience in a more detailed way. My goal is to determine whether you were satisfied with the process and the outcome of the ıediation.

2. Were you able to clearly identify the interests of the people involved?

3. Did the people involved have the authority to resolve the situation or conflict?

4. Did the people involved have the knowledge and information needed to resolve the conflict or situation? 
5. Was the mediation a voluntary process? Did the parties involved come to the table on their own or were they forced there? If so, by whom?

6. Do you believe that mediation allowed the parties to maintain control over the outcome instead of placing control in the hands of an outside person who was less familiar with the situation at hand?

7. Was the mediation conducted in a cost-effective manner?

8. Was the mediation conducted in a timely manner?

9. Was the situation "ripe" for mediation? That is, were the parties with stakes in the outcome properly identified and were the issues capable of being framed in a manner that was cohesive and clear enough to bring results?

10. Were you able to "separate the people from the problem?" Or did personalities get in the way of achieving a satisfactory result?

11. Were there any aspects of the mediation that proved easier or more difficult to deal with because you were dealing with units of local government?

12. Do you feel that the mediation process was a better alternative than litigation through the court system?

13. Did you learn enough from this experience to be able to handle a similar situation more effectively in the future?

14. If you had the chance to start the mediation process over again from the beginning, would you do anything differently? 
APPENDIX B

RAPID RESPONSE CHART 


\section{Rapid Response Chart}

\begin{tabular}{|c|c|c|}
\hline & & \\
\hline Issue & D) & Joint Fire District \\
\hline$\nabla$ & & \\
\hline $\begin{array}{c}\text { Professional } \\
\text { Sub-Committee }\end{array}$ & D) & $\begin{array}{l}\text { Fire Chiefs From } \\
\text { Respective }\end{array}$ \\
\hline$\nabla$ & & Government Subdivision \\
\hline $\begin{array}{c}\text { Appropriate } \\
\text { Subdivision or } \\
\text { Units of Government } \\
\end{array}$ & $\Rightarrow$ & $\begin{array}{l}\text { Maybe Township, City, } \\
\text { Village, County, or Quazi } \\
\text { Public Entity }\end{array}$ \\
\hline $\begin{array}{l}\text { Regional Partnership } \\
\text { Review Team }\end{array}$ & $\Rightarrow$ & $\begin{array}{l}\text { Representatives of } \\
\text { Regional Partnership }\end{array}$ \\
\hline$\nabla$ & & Committee \\
\hline $\begin{array}{l}\text { Joint Meeting of } \\
\text { Affected Units of } \\
\text { Government }\end{array}$ & $\Rightarrow$ & $\begin{array}{l}\text { Appropriate Officials i.e. } \\
\text { Mayor, Township Trustee }\end{array}$ \\
\hline$\overline{7}$ & & Public Hearings \\
\hline Public Response & b) & $\begin{array}{l}\text { *Township Meetings } \\
\text { *City Council Meetings }\end{array}$ \\
\hline $\bar{\nabla}$ & & \\
\hline $\begin{array}{l}\text { Contractual } \\
\text { Agreement }\end{array}$ & $\Rightarrow$ & Signed Documents \\
\hline
\end{tabular}




\section{REFERENCE LIST}

Reproduced with permission of the copyright owner. Further reproduction prohibited without permission. 


\section{REFERENCE LIST}

Abels, M. (1985). The effect of leadership style on the motivation of professional employees working in agencies experiencing external threat. Ft. Lauderdale: Nova University.

Adams, G., \& Balfour, D. (1998). Unmasking administrative evil. Thousand Oaks: Sage.

Ammons, D. (1990). Administrative analysis for local government: practical application of selected techniques. Athens, GA: Carl Vinson Institute of Government, University of Georgia.

Benton, J., \& Morgan, D. (1986). Intergovernmental relations and public policy. New York: Greenwood Press.

Berman, D. (1993). Relating to other governments. Washington, DC: International City Management Association.

Break, G. (1981). Financing government in a federal system. Washington, DC: Brookings Institution.

Burns, N. (1998). Creatures of the states. Urban Affairs Review, 34(1), 150-164.

Carpenter, D. (1998). Devolution of local government: Responses to the changing legal, political and fiscal environment. Binghamton: State University of New York.

Caywood, C. (1997). The handbook of strategic public relations and integrated communications. New York: McGraw-Hill.

Coch, L., \& Frech, J. (1948). Overcoming resistance to change. Human Relations, I, 512-532.

Cohen, A. (1997, August 8). City boosters. Time, 15, 20-24.

Coke, J., \& Gargam, J. (1972). Political behavior and public issues in Ohio. Kent, OH: Kent State University Press.

Cole, R., Stenberg, C., \& Weissert, C. (1983). Two decades of change: A ranking of key issues affecting intergovernmental relations. Publius, $13,4$. 
Dolive, C., \& Fox, E. (1998, January/February). Clout group gets closer to introducing new limited home-rule legislation. Ohio Township, 45-46.

Dommel, P. (1974). The politics of revenue sharing. Bloomington, IN: University Press.

Dunlop, M. (1984). Dispute resolution. Dover, MA: Auburn House.

Ehrenhalt, A. (1999, June). Powerless pip-squeaks and the myth of local control. Governing, 12, 7-9.

Eldersveld, S. (1995). Party conflict and community development: Postwar politics in Ann Arbor. Ann Arbor: University of Michigan Press.

Engdal, L. (1999). Training down iron fences. The New Public Innovator, 95, 26-29.

Fairman, D. (1999, January). Evaluating consensus building efforts. Consensus, 5.

Fosler, D. (1998, October). Think globally, act regionally. Public Objective, 4(3), 1.

Fulton, W. (1998). Learning from New Jersey. Governing, 12, 46.

Fulton, W. (1999). The endless subsidy cycle. Governing, 12, 101.

Fulton, W., \& Shigley, P. (1999). Operation desert sprawl. Governing, 12, 16-22.

Gall, M., Borg, W., \& Gall, J. (1996). Educational research: An introduction. White Plains, NY: Longman.

Garland, S.B. (1994, May 30). Getting stuck with the check. Business Week, 337, 46-48.

Goetz, E.G. (1994). Expanding possibilities in local development policy: An examination of U.S. cities. Political Research Quarterly, 47(1), 15.

Gonzalez, R. (1995). Why is it townships do not want to incorporate? Ohio Township, 58, 25.

Grunkemeyer, B. (1992, Summer). Building a sustainable future. The Gazebo, 2(2), 1, 2.

Hale, G., \& Palley, M. (1981). The politics of federal grants. Washington, DC: Johns Hopkins University Congressional Quarterly Press.

Hanson, R. (1998). Governing partners: State-local relations in the United States. Boulder, CO: West View Press.

Herrman, M. (1995). Resolving conflict: Strategies for local government. Washington, DC: International City Management Association. 
Himmelman, A. (1994). Communities working collaboratively for a change.

Washington, DC: International City lisanagement Association.

Honeyman, C. (1999 January). Setting criteria for mediator performance. Consensus, 2-4.

Hubbell, L. (1979). Fiscal crisis in American cities: The federal response. Cambridge, MA: Ballinger Publishing Company.

Huelsburg, N., \& Lincoln, W. (Eds.). (1985). Successful negotiating in local government. Washington, DC: International City Management Association.

Kennedy, J. F. (1956). Profiles in courage. New York: Harper and Brothers.

Kerbel, R. (1995). Remote controlled: Media politics in a cynical age. Boulder, CO: Westview Press.

Lewis, M. (1998). Conflict resolution services for local government officials. County News Quarterly, 4(9), 27-28.

Lewis, M. (1999a). Survey results: Do state agencies in Chio use ADR? Resolution, 99, 2.

Lewis, M. (1999b). Using collaborative processes to address public policy issues. Resolution, 99, 2.

Liberman, C. (1995). Government, politics, and public policy in Ohio. Akron, OH: Midwest Press.

Lituan, L.M. (1993, December). Cities and states blast mandates. Nation's Business, 81, 12.

Locarn, D. (1963). The politics of state and local government. New York: Macmillan Company.

Lofland, J., \& Lofland, L. (1984). Analyzing social settings. Belmont, CA: Wadsworth.

Mackey, S., (1997, July). Critical issues in state ." 'fiscal policy: Sorting out state and local responsibilities. Denver, CO: Foundation for State Legislators and National Conference of State Legislatures.

McDonough, K. (1998). Public finance. City and County, 113, 6, 18-27.

Merriam, S. (1998). Qualitative research and case study applications in education (6th ed.). San Francisco: Jossey-Bass.

Miller, M., \& Miller, T. (1992). Assessing excellence poorly: The bottom line in local government. Journal of Policy Analysis and Management, 11, 612-624. 
Ohio Commission on Dispute Resolution and Conflict Management. (1997).

Orr, J. (1994). 14 case studies in local government ( $2^{\text {nd }}$ ed.). Bangor, ME: J.H. Orr.

Patterson, T. (1995). News decisions: The impact of journalists ' partisanship. Annual meeting of the American Political Science Association, San Antonio, Texas.

Patton, M.Q. (1990). Qualitative evaluation and research methods ( $2^{\text {nd }}$ ed.). Newbury Park, CA: SAGE.

Peterson, G., \& Lewis, L. (1986). Reagan and the cities. Washington, DC: Urban Industries Press.

Poindexter, G.O. (1996). Legal empowerment of the neighborhood. Urban Studies, $33,1821-1830$.

Radin, B.A. (1995). Intergovernmental partnerships and rural development: An overview assessment of the National Rural Development Partnership. Washington, DC: Department of Agricultural Research Services.

Reed, B. (1984). Managing small cities and communities: A practical guide. Washington, DC: n.p.

Richman, R., White, D., \& Wilkinson, M. (1986). Intergovernmental mediation negotiations in local government disputes. Boulder, $\mathrm{CO}$ : Westview Press.

Roberts, D. (1989). Carving out their niche: State advisory commission on intergovernmental relations. Public Administration Review, 49, 576.

Rosado, E. (1999). Federalism takes center stage. County News, 31, 14, 2.

Savas, E., Privatizing the public sector: How to shrink government. Chatham, NJ: Chatham House.

Schwarz, R. (1994, Spring). A consumer's guide to hiring and working with a group facilitator. Popular Government, 12-18.

Schwarz, R. (1999). Ground rules for effective groups. Washington, DC: International City Management Association.

Silverberg, D., Tarnow, K., \& Watt, P. (1996). Collaborative approaches to decisionmaking and conflict resolution for natural resources and land use issues. Portland, OR: n.p.

Thornburg, D. (1999, February). Constructive compromise. Public Objective, 5, 1. 
Weidner, E. (1960) Intergovernmental relations as seen by public officials. Minneapolis: University Press.

Wright, D. (1978). Understanding intergovernmental relations: Public policy and participants ' perspectives in local, state and national governments. New York: Duxbury Press. 


\section{VITA}

Name: $\quad$ W. Thomas Wiseman

EDUCATION:

2001

Ph.D. Candidate in Leadership

Andrews University, Berrien Springs, MI 49104

1990

Master of Public Administration

Bowling Green State University, Bowling Green, Ohio

1976

Bachelor of Science Major: History

Defiance College, Defiance, Ohio 43512

\section{EMPLOYMENT HISTORY:}

$1 / 92$ to $12 / 01$

County Commissioner

Defiance County Commissioner

Courthouse

Defiance, Ohio 43512

$1 / 84$ to $12 / 91$

Mayor

City of Defiance

324 Perry Street

Defiance, Ohio 43512

$1 / 82$ to $12 / 83$

City Councilman at Large

City of Defiance

324 Perry Street

Defiance, Ohio 43512

PROFESSIONAL PRESENTATIONS:

Penner, T., Schultz, M., Wiseman, W. T. (1999). Intergovernmental Mediation. Columbus, Ohio: County Commissioners Association of Chio $199^{\text {th }}$ Annual Conference.

Wiseman, W. Thomas (2000). Joint Economic Development Districts. Delaware, Ohio: Delaware County and Township Elected Officials Group.

Wiseman, W. Thomas (2000). Intergovernmental Partnership Agreements. Bryan, Ohio: Williams County Elected Officials Group. 